\title{
Seismic Performance of Unreinforced Masonry Walls Retrofitted with Post-Tensioning Tendons
}

\author{
A Thesis \\ Presented to \\ The Faculty of California Polytechnic State University \\ San Luis Obispo, California
}

In partial fulfillment

of the Requirements for the Degree

Master of Science in Architecture with a Specialization in Architectural Engineering

by

Daniel Louis Lazzarini

June 2009 
(C) 2009

Daniel Louis Lazzarini

ALL RIGHTS RESERVED 


\section{COMMITTEE MEMBERSHIP}

TITLE: $\quad$ Seismic Performance of Unreinforced Masonry Walls Retrofitted with Post-Tensioning Tendons

AUTHOR: Daniel Lazzarini

DATE SUBMITTED: June 2009

COMMITTE CHAIR: $\quad$ Peter Laursen Ph.D., P.E.

COMMITTEE MEMBER: Cole McDaniel, Ph.D., P.E.

COMMITEE MEMBER: Kevin Dong, S.E. 


\begin{abstract}
Seismic Performance of Unreinforced Masonry Walls Retrofitted with Post-Tensioning Tendons

Daniel Louis Lazzarini
\end{abstract}

Unreinforced masonry (URM) structures have historically been regarded as structurally unsound in response to seismic events. The tendency for URM walls to collapse out-of-plane in a brittle manner is continually cause for concern. Retrofit of these walls is necessary in order to prevent severe damage and injury to occupants.

This paper concerns with the retrofit of unreinforced masonry (URM) walls in response to out-of-plane loading. A retrofit design was developed and verified through structural testing. The selected retrofit technique incorporates vertical coring of a URM wall allowing for the insertion of a single post-tensioning (PT) tendon. Tendons are spaced at a regular interval and anchored at the top of the wall parapet and at the lower diaphragm level. Tensioning of the tendons imparts a compressive stress to the wall that effectively increases the wall cracking moment strength, ultimate moment strength and displacement capacity. Additionally, the insertion of PT tendons allows the wall to behave in a ductile manner in response to out-of-plane ground motion. Research was conducted in order to accurately portray the material properties and construction methods of unreinforced masonry walls in San Luis Obispo, California. Various mortar mix designs were generated and tested so that a mix design could be selected to best reflect the target URM structures. Seismic parameters were generated to reflect a URM structure in San Luis Obispo. 
An unreinforced masonry wall was constructed by a professional mason using the established mortar mix proportions and salvaged bricks from the 1920 era. Having a pinpin unsupported height of 11 feet, the wall constructed for testing was reflective of the configuration of URM walls in many downtown San Luis Obispo structures. The wall was loaded in the out-of-plane direction by 4 equal point loads mimicking a uniformly distributed load. The testing program consisted of cycling the wall through target internal moments and target displacements.

It was verified through testing that post-tensioning tendons can be successfully introduced in URM walls to resist out-of-plane bending. Testing showed that the addition of PT tendons significantly increased the wall's cracking moment capacity, giving it the elastic strength to resist twice the forces imposed by the design-level ground motion. PT tendons also increased the nominal strength of the wall, allowing the wall to achieve large displacements without collapse. It was also found that PT tendons provided a restoring force to the wall returning it to almost no residual displacement after each displacement cycle. Thus, the URM wall retrofitted with PT tendons demonstrated significant integrity as a structural system, providing for improved strength and ductility with no residual displacement. Section 7.0 discusses the results of structural testing in detail. 


\section{ACKNOWLEDGEMENTS}

Bricks for testing were graciously donated by Garden City Construction in San Jose, CA. Brick shipment was provided by Mission Valley Truck Company to transport the bricks from San Jose to San Luis Obispo. The post-tensioning tendon and anchorages were donated by Dywidag-Systems International and General Technologies Incorporated. The contributions of each company are gratefully acknowledged. The author also wishes to thank the Architectural Engineering Department for donating the structural steel used for the testing setup, and for allowing the use of their testing laboratory and equipment.

The author also wishes to acknowledge the helpful input of Robert Vessely of Robert Vessely Civil and Structural Engineering, and Mark Cardosa of Biggs Cardosa Associates, Inc. Special thanks are also given to Robert Hogue of Mission Masonry for generously donating his time and equipment to construct the wall for testing.

Special thanks are given to those who took time to help in the development of this thesis. This includes thesis committee chair and Assistant Professor Dr. Peter Laursen, Assistant Professor Dr. Cole McDaniel and Associate Professor Kevin Dong. Thank you as well to Professor Mary Forte for taking the time to review this thesis.

Finally, very special thanks to my parents, Mark and Jeanne who took the time to travel to San Luis Obispo to help in wall construction and to document testing. Thank you to my brother Robert for his support and for traveling to see testing. Your enthusiasm for my work is much appreciated. Thank you to Jennifer for her love and unyielding support through this process. 


\section{TABLE OF CONTENTS}

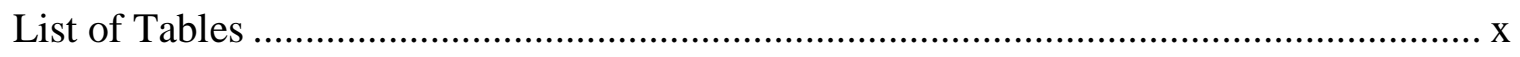

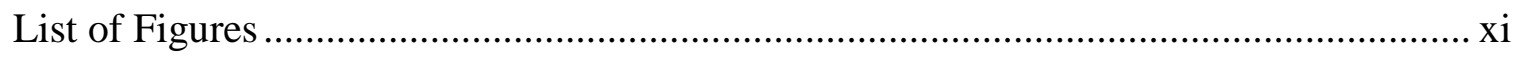

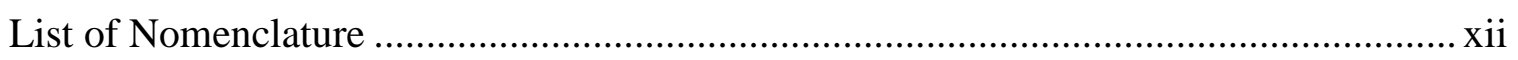

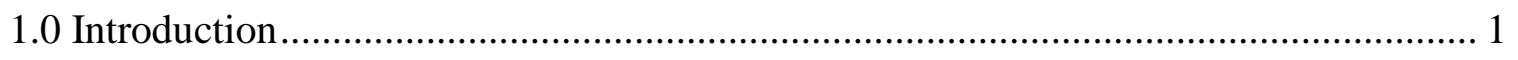

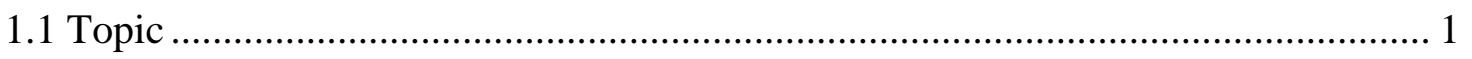

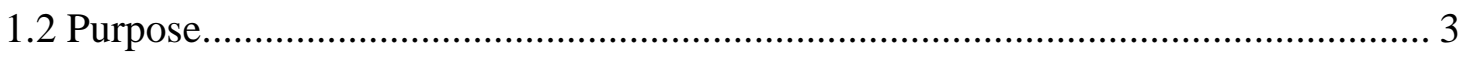

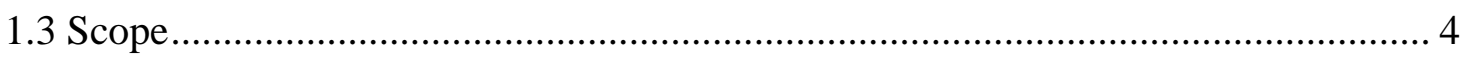

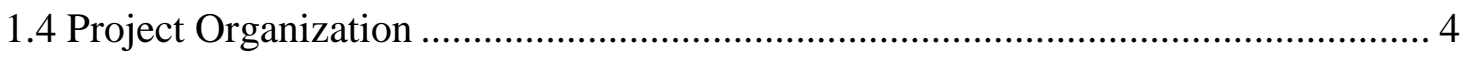

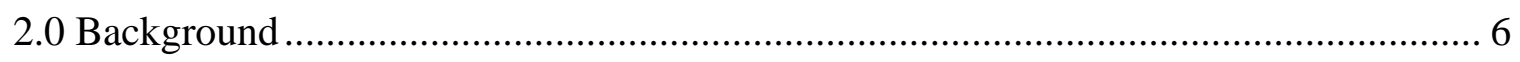

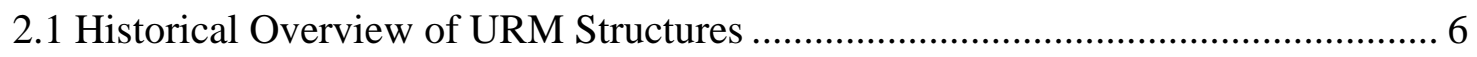

2.2 Typical Weak Points of URM Structures ......................................................... 8

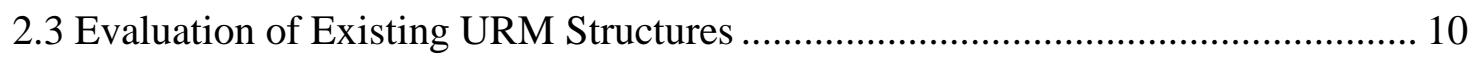

2.4 Codification of Prestressed Masonry ................................................................ 11

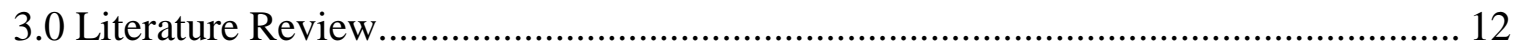

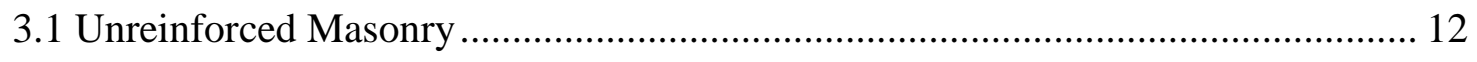

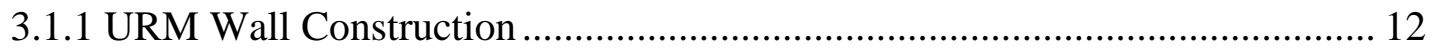

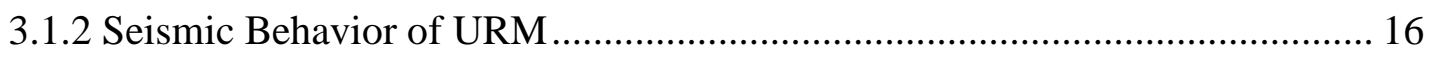

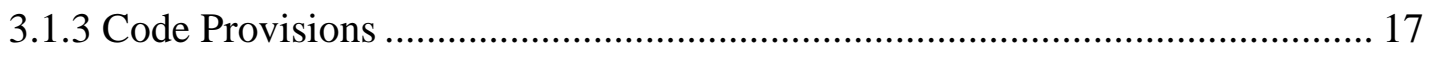

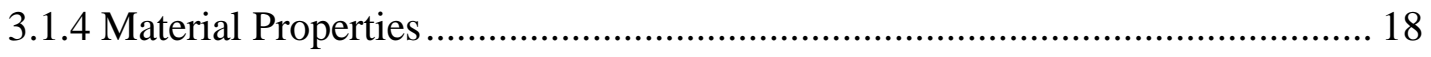

3.2 Current Retrofit Options for Out-of-plane Bending ....................................... 20

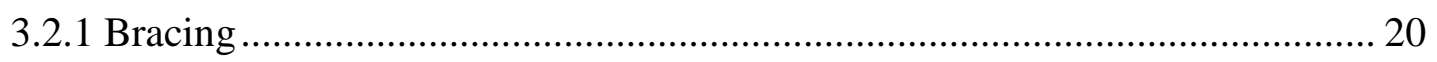

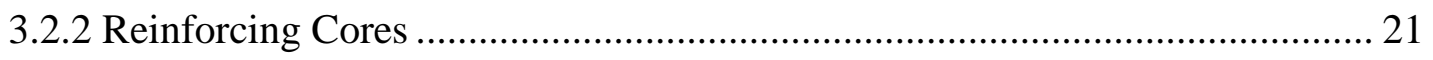

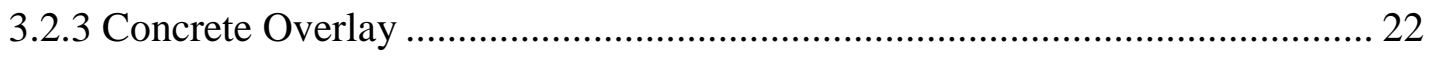

3.2.4 Fiber-Reinforced Polymer Overlay............................................................ 23

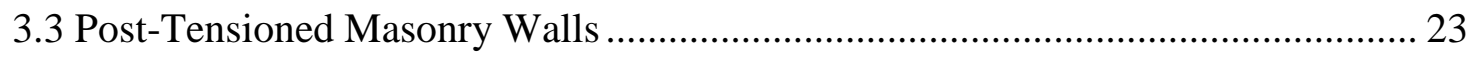

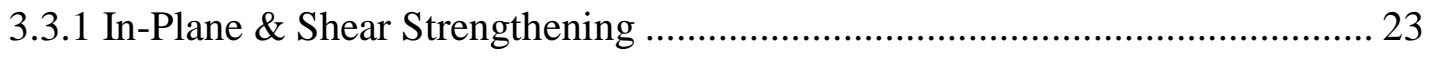

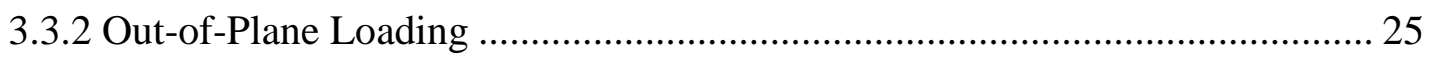

3.4 Post Tensioning Losses and Masonry Creep .................................................. 33

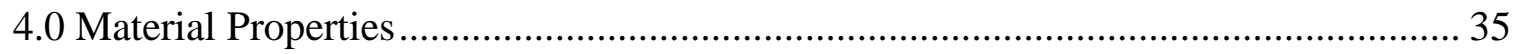

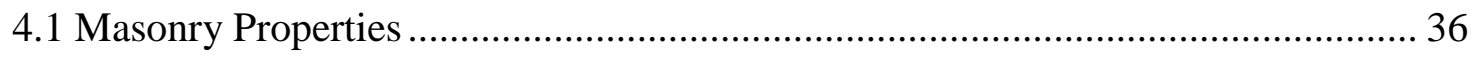

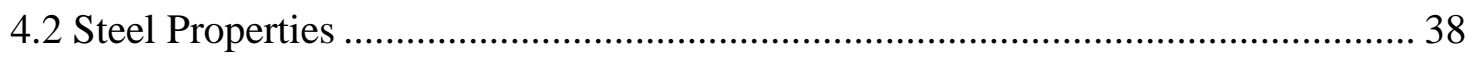




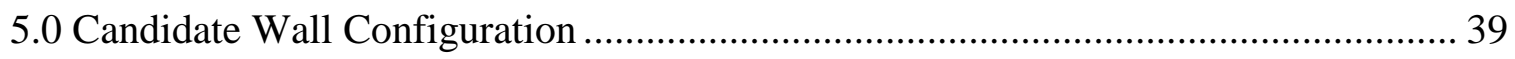

5.1 Wall Configuration in a Typical URM Building .................................................. 39

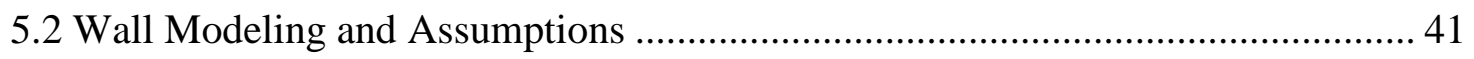

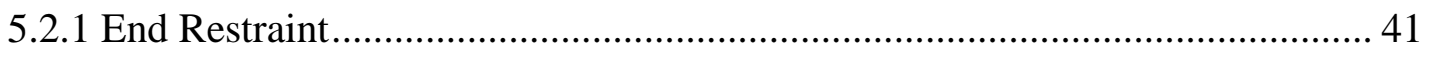

5.2.2 Location of Tendons, Propagation of Forces and Tendon Restraint................. 43

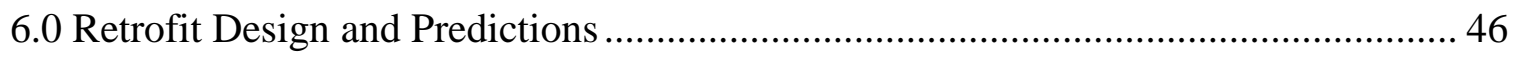

6.1 Development of Equivalent Lateral Force........................................................... 47

6.2 Unreinforced Wall Subject to the Design-Level Ground Motion........................... 48

6.3 Out-of-Plane Analysis and Retrofit Design ..................................................... 49

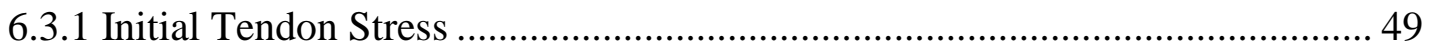

6.3.2 Transfer of Prestress Force to Wall and Initial Masonry Axial Stress............. 50

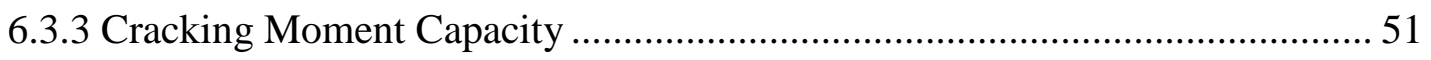

6.3.4 Hinging and Nominal Moment Capacity Predictions ...................................... 52

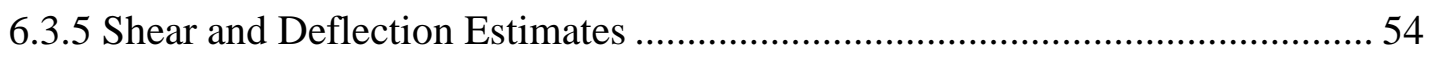

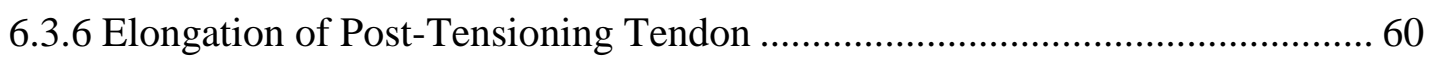

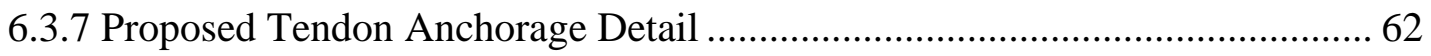

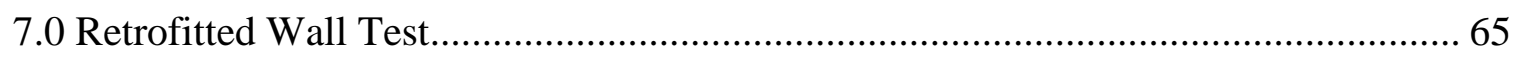

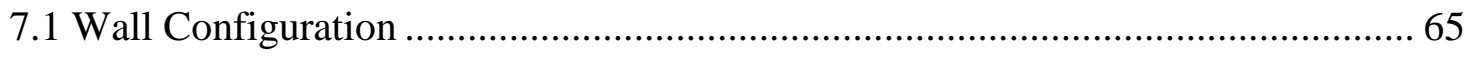

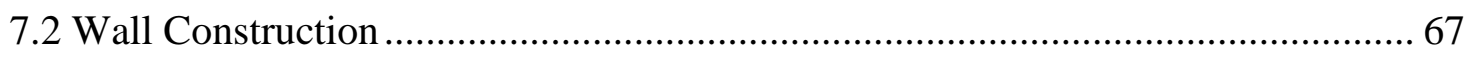

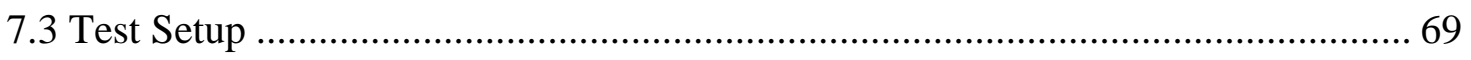

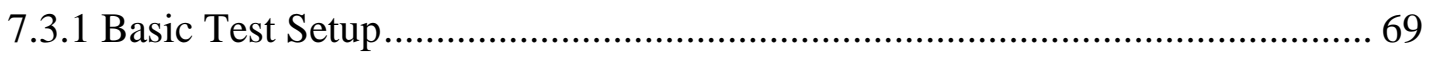

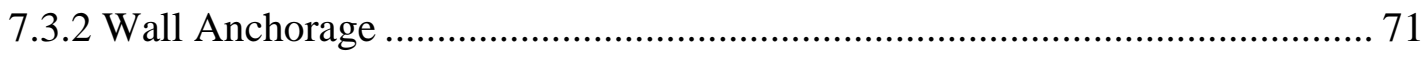

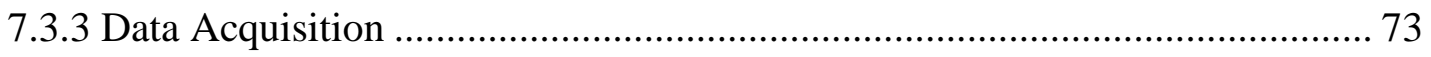

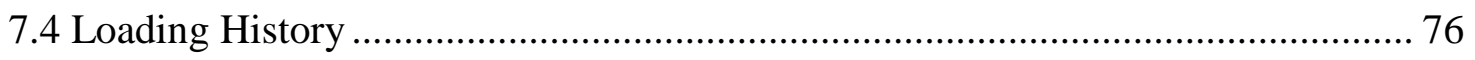

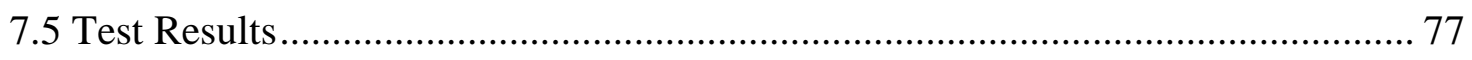

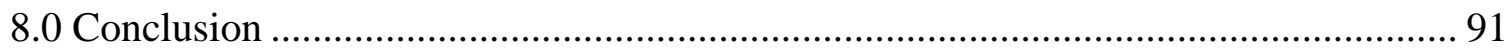

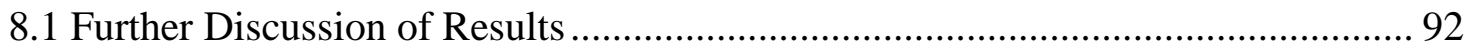

8.1.1 Improved Flexural Strength ....................................................................... 92

8.1.2 Ultimate Displacement \& System Ductility ................................................... 94

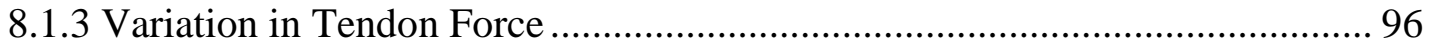

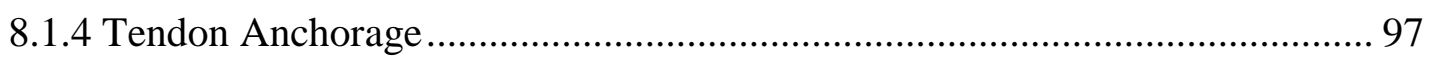

8.1.5 Effects of the Out-of-Plane Retrofit on the Overall Structure ......................... 98

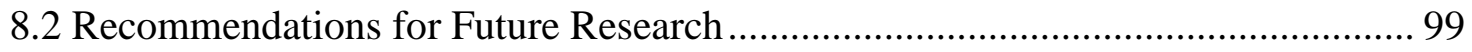

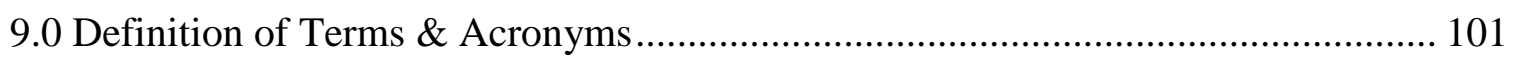




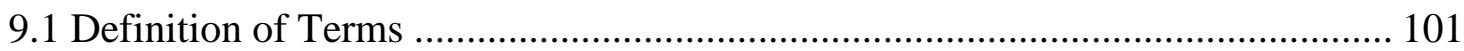

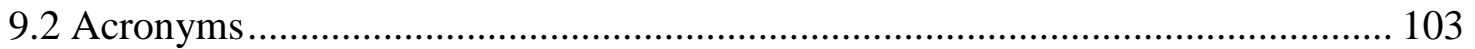

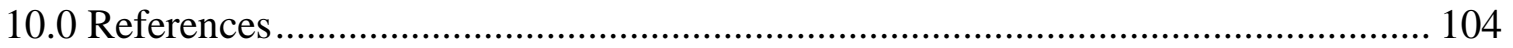




\section{LIST OF TABLES}

Table A: Average Brick Dimensions and Collar Fill Percentage for a Survey of URM

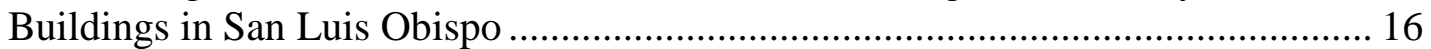

Table B: Material Strengths for a Survey of URM Buildings in San Luis Obispo .......... 19

Table C: Material Properties of URM Used in Design and Testing ................................. 36

Table D: Material Properties Used in Design and Testing ............................................. 38

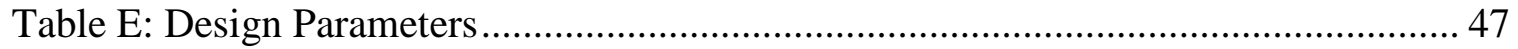

Table F: Seismic Parameters....................................................................................... 47 


\section{LIST OF FIGURES}

Figure A: Retrofitted URM Wall ..................................................................... 2

Figure B: Common Failure Modes of URM Buildings ............................................. 9

Figure C: Brick Bond Pattern- 778 Marsh Street, San Luis Obispo ............................... 13

Figure D: Bond Courses- 1130 Garden Street, San Luis Obispo ................................... 14

Figure E: Brick Irregularities- 962 Monterey Street, San Luis Obispo .......................... 15

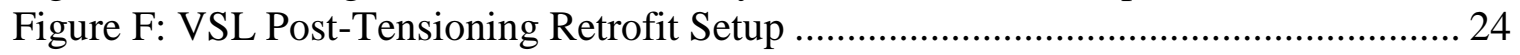

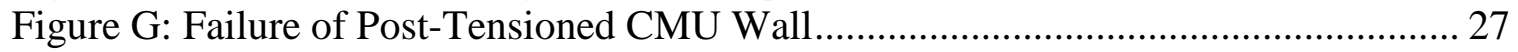

Figure H: Prestressed Test Specimen Detail............................................................ 28

Figure I: Wall Specimen Setup ............................................................................... 29

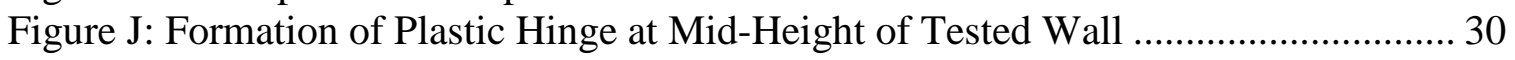

Figure K: Stress Distributions at Benchmark Events ................................................ 33

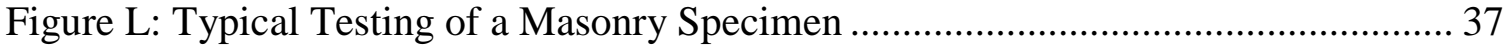

Figure M: Wall Configuration in a Typical URM Structure ....................................... 40

Figure N: Moment Diagrams Depicting Varying Levels of End Restraint in Wall

Modeling ................................................................................................ 42

Figure O: Propagation of Post-Tensioning Stresses in a Retrofitted URM Wall ............ 44

Figure P: Stress-Strain Diagram for URM Test Samples ........................................... 56

Figure Q: Strain (a) and Stress (b) Profile at Ultimate Capacity ................................... 58

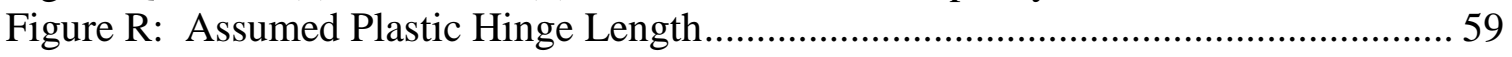

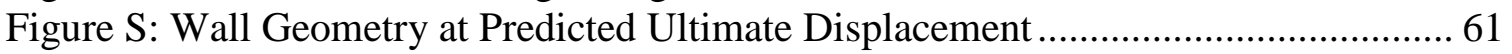

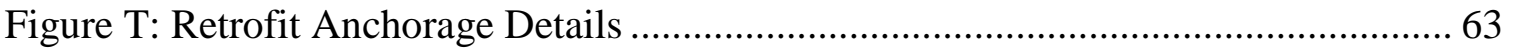

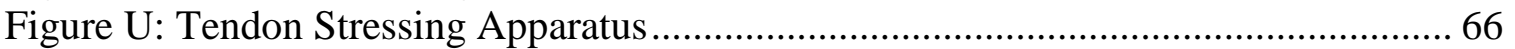

Figure V: Wall Setup and Construction: (a) First Stage, (b) Second Stage..................... 69

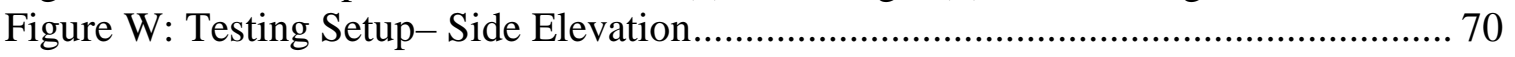

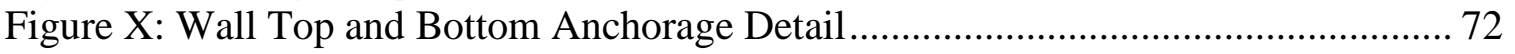

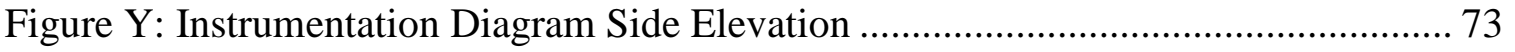

Figure Z: Instrumentation Diagram Front Elevation .................................................. 74

Figure AA: Pseudo-Static Displacement-Controlled Loading History ........................... 76

Figure BB: Force-Displacement Plots for All Cycles.................................................. 77

Figure CC: Select Force-Displacement Cycles Compared to Design Predictions ........... 78

Figure DD: Maximum Force-Displacement Backbone Plot ....................................... 79

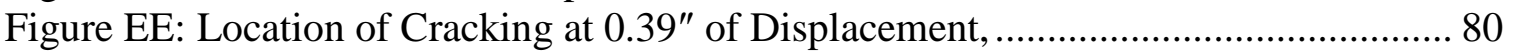

Figure FF: Displaced Shape of Tested Wall (Small Displacements) ............................ 82

Figure GG: Displaced Shape of Tested Wall (Large Displacements) ............................ 83

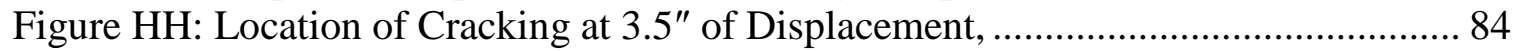

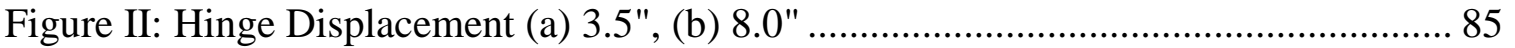

Figure JJ: Cracking and Masonry Crushing at Ultimate Displacement .......................... 86

Figure KK: Location of Cracking at 8.0" of Displacement, ........................................ 87

Figure LL: Percent Increase in Tendon Force over All Loading Cycles ........................ 88

Figure MM: Change in Tendon Force with Increasing Displacement Cycles.................. 88 


\section{LIST OF NOMENCLATURE}

$A_{g} \quad$ gross cross-sectional area of masonry, in ${ }^{2}$

$A_{n} \quad$ net cross-sectional area of masonry, in $^{2}$

$A_{p s} \quad$ area of prestressing steel, in ${ }^{2}$

$a$ depth of equivalent compression zone at nominal strength, in

$b \quad$ width of section, in

$d_{b} \quad$ post-tensioning tendon diameter, in

$d_{y} \quad$ distance from extreme compression fiber to centroid of tension reinforcement, in

$E_{m} \quad$ modulus of elasticity of masonry in compression, psi

$E_{s} \quad$ modulus of elasticity of steel, psi

$E_{v} \quad$ modulus of rigidity of masonry, psi

$F_{a} \quad$ allowable compressive stress due to axial load, psi

$f_{b} \quad$ calculated compressive stress in masonry due to bending, psi

$f_{m}^{\prime} \quad$ specified compressive strength of masonry, psi

$f_{p s} \quad$ stress in prestressing tendon at nominal strength, psi

$f_{p u} \quad$ specified tensile strength of prestressing tendon, psi

$f_{p y} \quad$ specified yield strength of prestressing tendon, psi

$f_{r} \quad$ calculated tensile strength of masonry bond, psi

$f_{\text {se }} \quad$ effective stress in prestressing tendon after all prestress losses have occurred, psi

$f_{v} \quad$ calculated shear stress in masonry, psi

$f_{y} \quad$ specified yield strength of steel for reinforcement, psi

$\gamma \quad$ URM wall density, $\mathrm{lb} / \mathrm{ft}^{3}$

$h_{w} \quad$ effective height of wall, in

$I_{c r} \quad$ moment of inertia of cracked cross-sectional area of a member, in ${ }^{4}$

$I_{g} \quad$ gross cross-sectional area moment of inertia, in ${ }^{4}$

$I_{n} \quad$ net cross-sectional area moment of inertia, in ${ }^{4}$

$L_{p} \quad$ plastic hinge length, in

$M_{c r} \quad$ nominal cracking moment strength, in-lb

$M_{h} \quad$ moment capacity at the onset of plastic hinging, in-lb 
$M_{n} \quad$ nominal moment strength, in-lb

$M_{u} \quad$ factored moment, in-lb

$P_{p s} \quad$ prestressing tendon force at time and location relevant to design, $\mathrm{lb}$

$P_{u} \quad$ factored axial load, lb

$P_{s w} \quad$ factored weight of wall area tributary to wall section under consideration, $\mathrm{lb}$

$r \quad$ radius of gyration, in

$S \quad$ section modulus of the net cross-sectional area of a member, in ${ }^{3}$

$s \quad$ spacing of reinforcing or prestressing tendons, in

$t$ nominal thickness of a member, in

$V_{m} \quad$ shear strength provided by masonry, psi

$V_{n} \quad$ nominal shear strength, lb

$V_{u} \quad$ shear demand, lb

$w_{u} \quad$ out-of-plane factored uniformly distributed load, lb/in

$\delta_{c r} \quad$ predicted cracking displacement, in

$\delta_{u} \quad$ predicted ultimate displacement, in

$\varepsilon_{u} \quad$ maximum strain of masonry at ultimate capacity, ${ }^{\mathrm{in}} /$ in

$\gamma \quad$ density of URM wall, $\mathrm{lb} / \mathrm{ft}^{3}$

$\theta_{p} \quad$ plastic rotation, rad 


\subsection{INTRODUCTION}

This section introduces the topic, purpose, and scope of this thesis project.

\subsection{Topic}

This project focuses on retrofitting slender unreinforced masonry (URM) clay brick walls for out-of-plane seismic accelerations using post-tensioning (PT) tendons. Slender walls are defined by table A1-B of the 2006 International Existing Building Code (IEBC) for regions of high seismicity as having a height-to-thickness $(h / t)$ larger than 13. This retrofit proposes vertical coring of existing URM walls to allow for the insertion of a single PT tendon. Cavities less than one inch in diameter are cored down the wall at a regular spacing. After tendons are inserted in the wall, they are anchored and then tensioned using a stressing jack. This process places the wall into compression. The presence of PT tendons along with the added axial force improves the system's resistance to seismic accelerations. Additionally, PT tendons can provide a restoring force returning the wall to its original position, thus reducing post-earthquake damage. This thesis project investigates this retrofit solution in the manner discussed in section 1.3.

An unreinforced masonry building, for the purposes of this project is defined in accordance with FEMA-310 as a structure having perimeter bearing walls consisting of unreinforced clay-brick masonry. Interior framing consists of straight or diagonal lumber sheathing supported by wood joists, while foundations are either concrete spread footings or entirely brick. Unreinforced masonry construction considered in this thesis project is discussed further in section 3.1.1. 
Figure A shows the proposed configuration of a retrofitted URM wall. The existing wall is vertically cored at its center at a spacing determined by the designer. A single PT tendon is placed in each core (a) and a small cavity is created at the lower diaphragm to allow for the assemblage of the PT anchorage and compression plate (b).

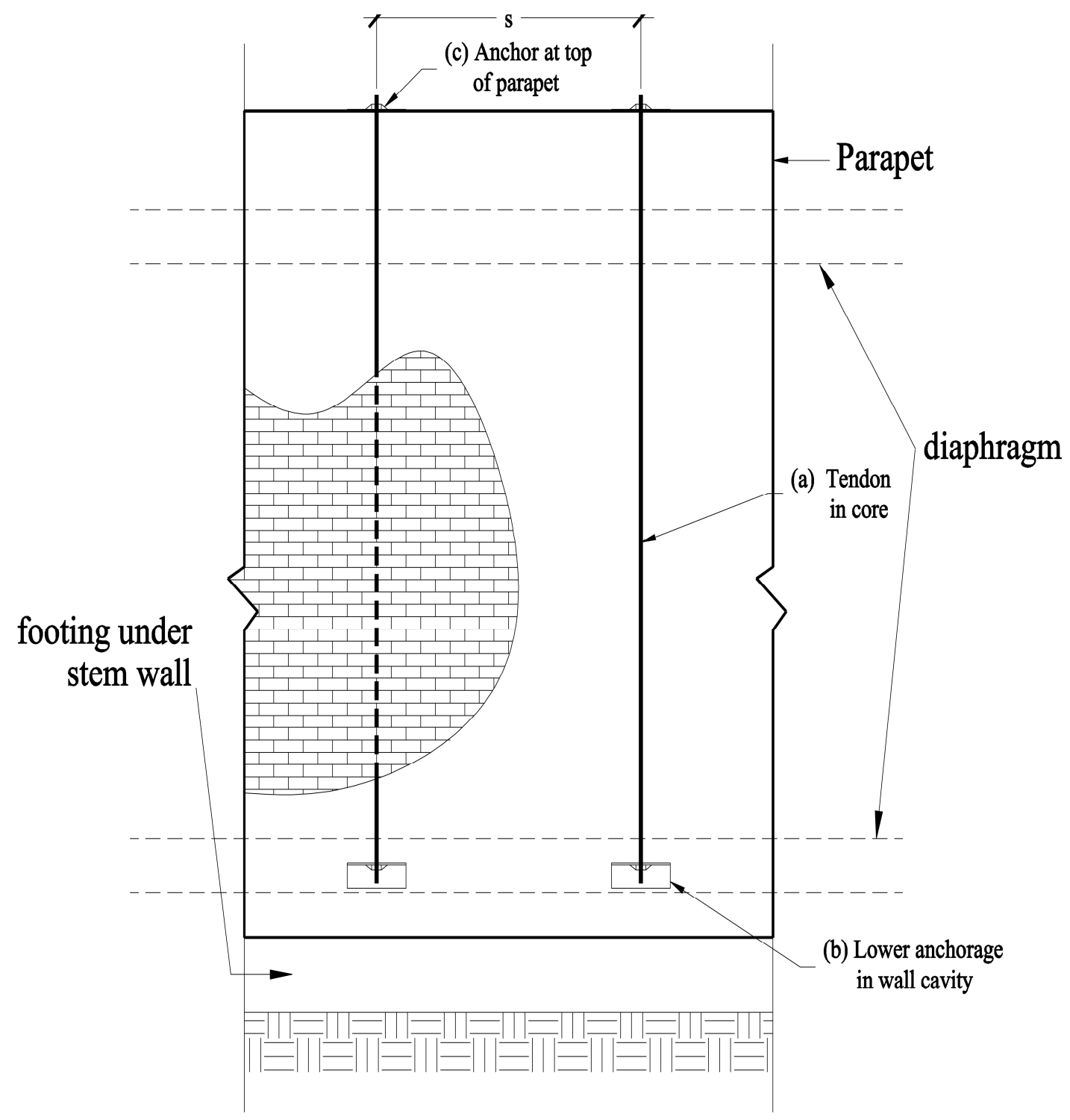

Figure A: Retrofitted URM Wall

Seismic Performance of Unreinforced Masonry Walls Retrofitted with Post-Tensioning Tendons 
Similarly, at the top of the wall, a cavity can either be created to house the stressing end of the PT anchorage or the tendon can be anchored at the top of the wall's parapet (c) with steel plates. After the tendons have been stressed by a hydraulic jack, these cavities can either be grouted closed or the previously removed bricks can be reinserted to preserve the structure's façade.

\subsection{Purpose}

The purpose of this thesis project is to begin the development of a more efficient option for building owners seeking to retrofit URM structures for out-of-plane ground motions. There are many potential benefits to the use of such a system over current retrofit methods discussed in FEMA-547. These benefits will be discussed in depth in Section 7.0 and Section 8.0. Additionally, FEMA-547 mentions, but presents very little information regarding the potential use of post-tensioning tendons in cores. If this project demonstrates the effectiveness of this technique for a particular wall configuration, further development on different wall configurations could result in a viable retrofit option found in a retrofit design guide like FEMA-547. This project develops a PT retrofit option for URM walls typical of those found in San Luis Obispo, California. The design process developed in this project is in accordance with the 2006 IBC and is supported by structural testing conducted at California State Polytechnic University, San Luis Obispo. 


\subsection{Scope}

This project includes the construction and testing of a URM wall built to accurately reflect construction methods and materials discussed in section 5.1. A static test will help determine the validity of PT retrofit design and construction. Testing will also help prove the benefits that post-tensioning can bring to URM structures. Test data will be analyzed and compared to design predictions to determine the benefits of PTretrofitted URM walls.

It is assumed that the URM walls retrofitted for out-of-plane loads are adequate for in-plane forces. Additionally, walls will not be designed or tested for loads other than strictly out-of-plane. Such design and testing is outside the scope of this project.

Extensive literature review has shown, however, that post-tensioning is a viable option for the design of walls for in-plane forces.

\subsection{Project Organization}

This thesis project is organized into the following main sections:

Background: Section 2 gives a brief overview of URM structures, their weak points in seismic events, and the methods by which they are evaluated for retrofit.

Literature Review: Section 3 serves as a literature review regarding the topics of post-tensioned masonry wall construction, testing, and design. Additionally, literature review focuses on material strengths for existing buildings considered in this project.

Seismic Performance of Unreinforced Masonry Walls Retrofitted with Post-Tensioning Tendons 
Material Properties: Section 4 discusses the structural properties of the URM wall material as well as PT tendons to be used in this retrofit application. Target material strengths are established for retrofit design and testing based on material strengths investigated in literature review.

Candidate Wall Configuration: Based on literature review, a wall size and configuration is selected and discussed for design and testing. The wall configuration determined in this section mimics the wall type that could benefit from a post-tensioning retrofit.

Design of Retrofit System: Section 6 covers the out-of-plane design and test predictions of a retrofitted URM wall of material properties and specifications determined in sections 4 and 5, respectively.

Retrofitted Wall Testing: Section 7 describes the construction of the tested wall, setup of testing equipment, testing procedure and results of experimentation.

Conclusions: Section 8 discusses the results from structural testing, and compares them to the design methods developed in section 6. Suggestions for further research are outlined as well 


\subsection{BACKGROUND}

This section consists of a brief background of URM structures in terms of their design, evaluation, typical weak points in seismic events, and codification.

\subsection{Historical Overview of URM Structures}

Unreinforced masonry structures have historically been regarded as structurally unsound in response to seismic events. The tendency for URM walls to collapse out-ofplane in a brittle manner is continually cause for concern. Retrofit of these walls is necessary in order to prevent severe damage and injury to occupants. Unreinforced masonry structures in California were traditionally identical to those of the rest of the country prior to the 1933 Long Beach earthquake (Bruneau 1994). Widespread damage to URM buildings in this earthquake prompted public outcry and eventually encouraged the first steps toward regulating the construction of masonry buildings and the repair of existing structures. The Field Act was created to regulate new construction of masonry buildings, yet only required a minimum seismic design load of about three percent of gravity (Green 1993). In the years following, various cities in California enacted ordinances to regulate seismic retrofit of at-risk buildings. Despite these early attempts to repair seismically unsound URM buildings, many such structures have presently not been retrofitted, and require attention.

Development of city ordinances to oversee the retrofit of URM buildings brought with it a need for research and testing data on such buildings. One method of damage mitigation for URM buildings was developed based on structural testing by a joint 
venture consisting of Agbabian and Associates S. B., Barnes and Associates and Kariotis and Associates (ABK) (Bruneau 1994). Full scale dynamic tests were conducted in the early 1980's by ABK in-situ on various URM structures to better understand the nature of URM wall failure. A design methodology was developed by ABK based on the results of these tests, which became known as the ABK methodology (Green 1993). The ABK methodology would be incorporated with other data into the National Earthquake Hazards Reduction Program (NEHRP) Handbook for Seismic Evaluation of Existing Buildings (later FEMA 178) and eventually into the International Building Code.

These design guidelines would later be incorporated into current design code and related documents. At present, many documents concerned with the repair and retrofit of URM structures in California exist. The 2006 IEBC is primarily considered regarding the retrofit of existing URM structures. Additionally, current FEMA documents are consulted regarding the implementation of the 2006 IBC and 2006 IEBC. Code provisions and design guidelines are further discussed in Section 2.3 and Section 2.4. 


\subsection{Typical Weak Points of URM Structures}

URM structures typically exhibit distinct failure modes when it comes to seismic accelerations. The following basic failure types are established based on the work of Rutherford and Chekene (1990), Green (1993) and Avvakumovits (1995). Readers seeking a more in-depth summary of the information presented may reference these sources as well as FEMA-306 and FEMA-547.

Separation of walls from diaphragms: Forces generated from out-of-plane seismic excitation have the potential to damage the gravity load path from diaphragm to wall. This form of failure is typically remedied by proper anchorage of walls to diaphragms at all floor levels.

Wall in-plane shear failure: Wall shear strength is compromised during a seismic event. Walls develop shear cracks and in some cases, depending on wall size and aspect ratio, walls can rock from side to side. In larger events, complete wall collapse is possible. See Figure B (a) following for an example of this failure mode.

Out-of-plane bending failure: In seismic events, inertial forces acting on a wall can compromise the wall's strength in bending. Due to masonry's minimal tensile capacity, walls are prone to collapse resulting from out-of-plane loading.

If a wall has a particularly high height-to-thickness ratio, it is even more 
susceptible to this form of failure and is required by code to be braced or reinforced. See Figure B (b) and (c) for an example of this failure mode.

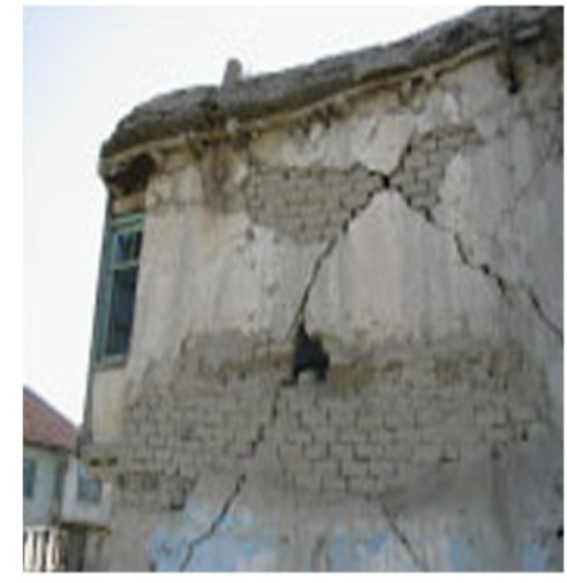

(a) In-plane shear failure

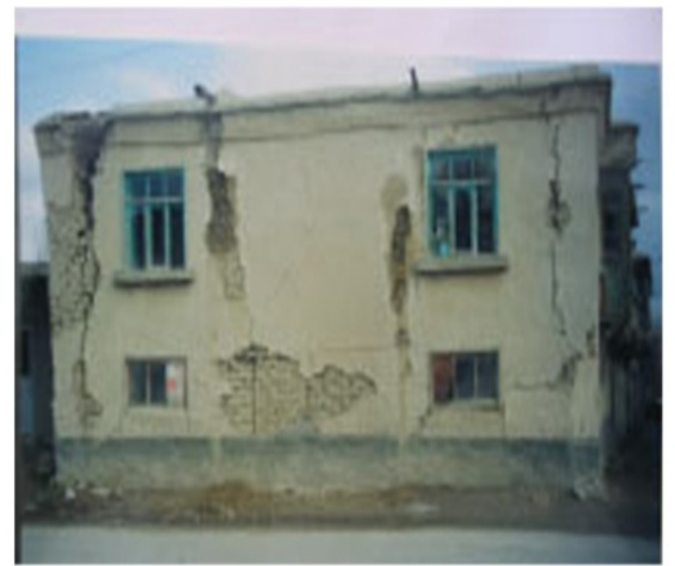

(b) Out-of-plane failure

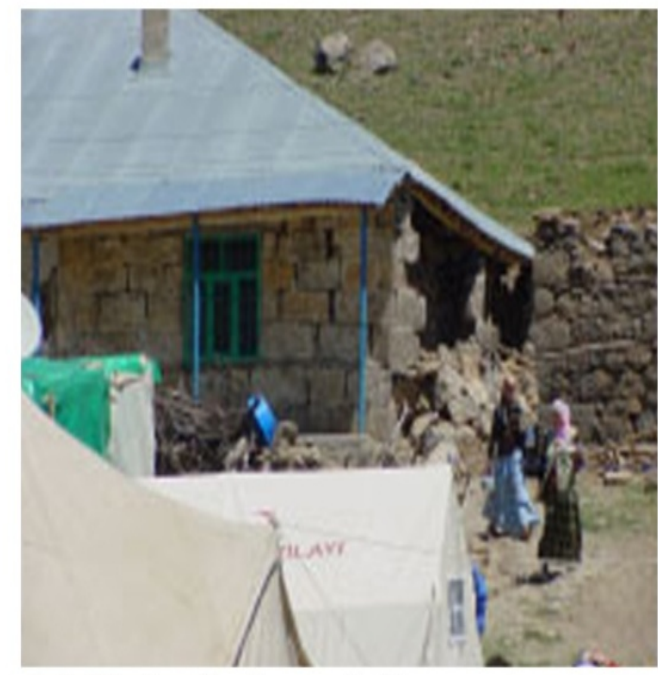

(c) Out-of-plane failure

Figure B: Common Failure Modes of URM Buildings

Source: Turer, Korkmaz and Korkmaz 2007 


\subsection{Evaluation of Existing URM Structures}

Existing URM structures are generally evaluated based on the FEMA-310

document. Evaluation consists of a determination of material strengths and dimensions of the URM walls. Typically, additional evaluation in the form of creating as-built drawings and establishing a post-earthquake Performance Level must be considered. In an evaluation of a given structure according to FEMA-310, material strengths can be determined by existing documentation or material testing. A thorough evaluation involves significant, yet relatively non-invasive testing to determine the strength of structural elements. It is important therefore, that this project reflect a retrofit design consistent with an evaluation specified by FEMA-310. Such an evaluation results in accurate material strengths that can then be considered for design and testing.

In accordance with sections A106.3.3.1 and A106.3.3.2 of the IEBC, mortar testing is required by means of an in-place bed joint shear test, unless coring of wall specimens is permissible. Schwein (1990) effectively outlines the methods used to determine mortar strength and wall composition. Testing of building materials must comply with A106.3.3.3 and A106.3.3.4 of the IEBC which outline the required locations and number of tests to be conducted, respectively. It is important to establish these criteria in order to obtain a good reflection of the building's strength throughout. Values for masonry compressive strength $f_{m}^{\prime}$ can then be established based directly on testing results. 


\subsection{Codification of Prestressed Masonry}

Research and codification of prestressed masonry originate from Switzerland and the United Kingdom. The Masonry Standards Joint Committee (MSJC) has rather recently incorporated design guidelines for the use of prestressed masonry as a structural system in the United States. In 1992, the Prestressed Masonry Subcommittee was formed within the MSJC to develop provisions for prestressed masonry (Scolforo 1996). Over the next decade, significant research and development of prestressed masonry took place in the form of multiple design code drafts (Scolforo). Proposals for prestressed masonry code provisions were officially recognized by the MSJC and implemented into the 2002 publication of Building Code Requirements for Masonry Structures. Presently, the MSJC 2005 includes provisions for the design of prestressed masonry members and shear walls. 


\subsection{LITERATURE REVIEW}

This literature review examines current research and testing involving unreinforced masonry, current retrofit options for URM structures, post-tensioned masonry walls, and post-tensioning considerations.

\subsection{Unreinforced Masonry}

The following section discusses the typical construction of unreinforced masonry in California in the early $20^{\text {th }}$ Century. In addition, the material properties and seismic behavior of URM walls will be discussed in detail so that a wall reflective of these properties can be tested to show the benefits of post-tensioning.

\subsubsection{URM Wall Construction}

A majority of URM structures in California cities established around the turn-ofthe-century consist of either one or two stories (Green 1993). Wall heights vary depending on the original intended use of the building. Most URM structures in San Luis Obispo, however, have a story-to-story height of 12-18 feet. Most of these structures consist of one story and also have parapet walls above roof framing. Posttensioning tendons anchored at the top of a parapet wall could potentially improve the strength of the parapet as well.

URM structures in urban settings follow typical layout patterns in terms of building footprint and location of perforations. Most urban URM structures are rectangular. This configuration leads to relatively short street and rear-facing walls with longer walls running perpendicular to the street face. Most of the perforations found in these URM buildings are located at the street front and at the rear of the structure for Seismic Performance of Unreinforced Masonry Walls Retrofitted with Post-Tensioning Tendons 
access. The longer walls of the structure typically do not have perforations because they serve as walls for adjacent structures. The main concern with out-of-plane bending in this configuration arises from the relatively long, unbraced longitudinal walls (Rutherford and Chekene 1990).

Wall construction and brick patterns vary widely across URM structures. A majority of construction of the early $20^{\text {th }}$ Century is characterized by running-bond brick masonry that is offset from one course to the next (FEMA-306). An example of this brick bond pattern is shown in Figure C following.

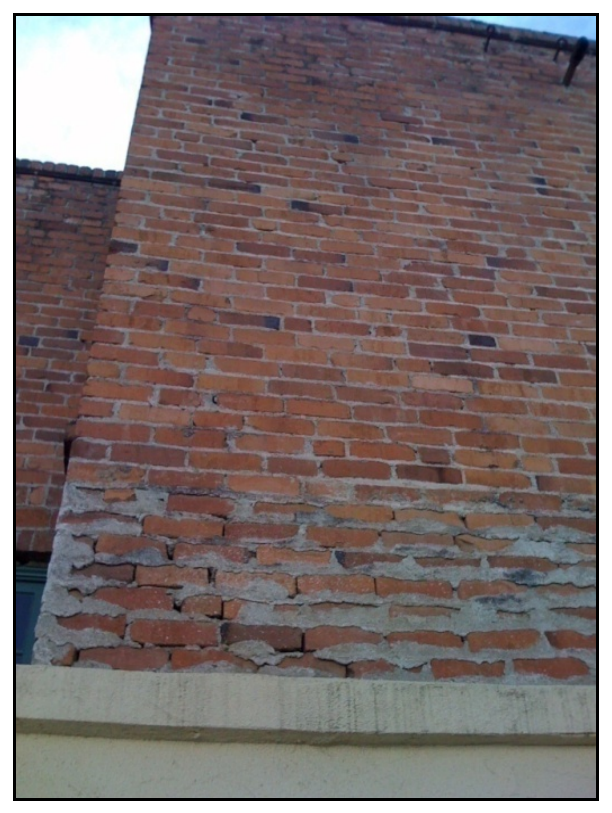

Figure C: Brick Bond Pattern- 778 Marsh Street, San Luis Obispo

This layout allows for a more monolithic performance of the wall due to vertical mortar joint discontinuity. In the city of San Luis Obispo, early clay-brick masonry construction typically adheres to these criteria. Therefore, it is necessary that the wall 
used for design and testing in this thesis project incorporates running bond brick courses that are staggered vertically.

In addition to the brick layout previously mentioned, unreinforced masonry construction is characterized by bond courses, usually spaced at regular intervals up the height of the wall. These bond courses consist of bricks turned crosswise, with the length of the brick extending through two wythes of wall, and serve to bond the wythes together (Green 1993). Bond courses in San Luis Obispo typically occur every five or six courses and tie the wall together so that it behaves in a more monolithic fashion. See Figure D following for depiction of bond courses.

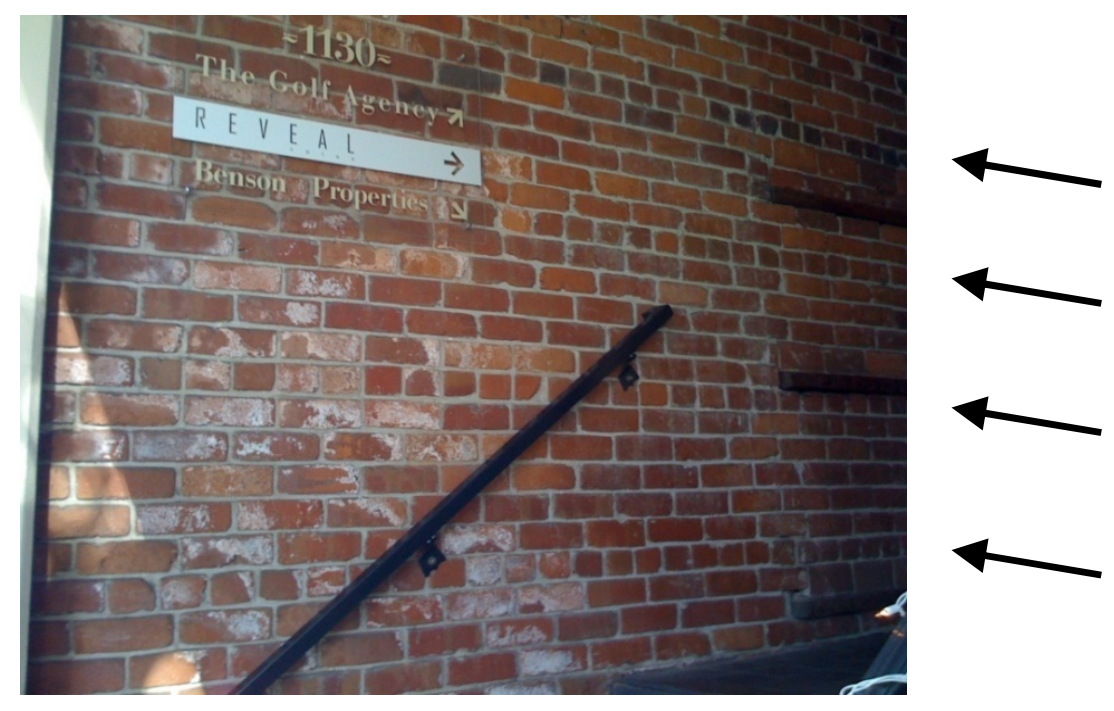

\section{Figure D: Bond Courses- 1130 Garden Street, San Luis Obispo}

Furthermore, bond courses actually improve the wall's performance in response to in-plane as well as out-of-plane loads (FEMA-306). The wall for this thesis project incorporates bond courses spaced every $6^{\text {th }}$ course. 
Unreinforced clay-brick walls vary in thickness as well. Wall thickness is reflective of building parameters such as weight and height. Typically, walls of one and two stories range from 8 to 12 inches thick (Green 1993). One-story structures surveyed by Rutherford and Chekene (1990) and Kariotis and Nghiem (1993) generally match these thicknesses.

URM buildings often use bricks that vary in size due to older construction techniques. Uneven firing results in voids and irregularities within the bricks themselves (Schwein 1990). Such irregularities are present in structures like the one located at 962 Monterey Street in San Luis Obispo, shown in Figure E.

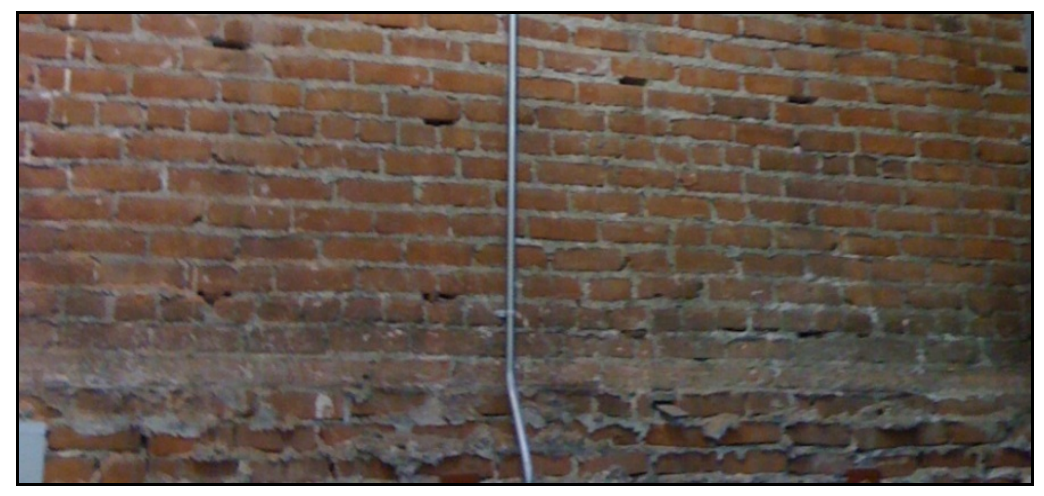

\section{Figure E: Brick Irregularities- 962 Monterey Street, San Luis Obispo}

URM wall homogeneity is disrupted by voids in wall collar joints resulting from poor construction techniques. The regular presence of these voids in URM structures requires inspection of collar joint density prior to retrofit. This is usually determined by visual inspection during mortar shear testing as described in Sections 2.3. Table A displays the typical collar joint fill percentage for a survey of URM structures in San Luis Obispo. 


\begin{tabular}{|c|c|r|}
\hline $\begin{array}{c}\text { Building Location in San } \\
\text { Luis Obispo, } \boldsymbol{C A}\end{array}$ & $\begin{array}{c}\text { Average Brick Dimensions } \\
\boldsymbol{w} \boldsymbol{x} \boldsymbol{x} \boldsymbol{h} \text { (inches) }\end{array}$ & $\begin{array}{c}\text { Estimated \% Collar Joint } \\
\text { Filled }\end{array}$ \\
\hline 1609 Osos Street & $3.85 \times 8.20 \times 2.75$ & 35 \\
\hline 1051 Nipomo Street & $3.90 \times 8.25 \times 2.70$ & 88 \\
\hline 798 Palm Street & $3.75 \times 8.30 \times 2.70$ & 58 \\
\hline 1131 Broad Street & $3.90 \times 8.30 \times 2.75$ & 80 \\
\hline 777 Marsh Street & $3.90 \times 8.20 \times 2.70$ & 18 \\
\hline 295 Higuera Street & $3.75 \times 8.35 \times 2.75$ & \\
\hline 659 Higuera Street & $3.95 \times 8.35 \times 2.75$ & \\
\hline
\end{tabular}

Table A: Average Brick Dimensions and Collar Fill Percentage for a Survey of URM Buildings in San Luis Obispo

Source: Robert Vessely Civil and Structural Engineering

Brick dimensions seen by Kariotis and Ngheim (1993) for clay-brick masonry were typically $2 \frac{3}{4}$ inches high, 3 3/4 inches wide and $81 / 2$ inches long. Brick dimensions in San Luis Obispo are usually within $1 / 4$ inch of the dimensions noted by Kariotis and Ngheim (1993). Data concerning the sizes of bricks for a survey of URM structures in San Luis Obispo is shown above in Table A, and is reproduced with the permission of Robert Vessely Civil and Structural Engineering.

\subsubsection{Seismic Behavior of URM}

In situ testing of unreinforced masonry by the joint venture $A B K$ provides valuable understanding of unreinforced masonry wall performance (Ewing and Kariotis 1981). The ABK program of the 1980s culminated in the formation of an improved dynamic model for URM buildings. ABK research led to the establishment of important criteria to help determine a URM wall's susceptibility to out-of-plane bending. Testing 
determined that walls with large height-to-thickness ratios $(h / t)$, usually greater than 13 , were considered to be most susceptible to out-of-plane flexural failure. Other important criteria such as the lack of crosswalls that serve to reduce the effective span were also established. Ultimately, testing determined that slender walls having few crosswalls are most likely to fail due to out-of-plane bending.

\subsubsection{Code Provisions}

Code provisions directly relating to URM structures are outlined in Chapter A1 of the 2006 IEBC. The provisions of this chapter apply to structures that contain URM bearing walls. Section A106 contains detailed information regarding the determination of URM material strengths. In typical retrofit designs, values for mortar strength and tensile strength of masonry are determined in accordance with section A106. More specifically, section A106.3.3.6 specifies the minimum acceptable quality of masonry to be used in design, including a minimum average tensile strength of 50 psi and a minimum value of $f^{\prime}{ }_{m}$ of 1000 psi. This project aims to construct a wall having material properties similar to those that would be achieved for a URM structure subjected to testing in Section A106.

The code also limits the amount of additional axial load that can be placed on URM walls. Section A108.3 states that for any increase in dead or live load, masonry compressive stress must not exceed 300 psi. This is especially pertinent to the addition of post-tensioning-induced compressive stresses on URM walls. A post-tensioned retrofit design, therefore, must consider this limit when determining the required amount of prestress. Additionally, section A108.4 states explicitly that unreinforced masonry shall be assumed to have no tensile capacity for purposes of design of a retrofit system. This 
project; however, will account for the tensile strength of masonry so that a comparison can be made between design predictions and testing outcomes.

Also critical to the development of a wall system for out-of-plane retrofit design are the provisions of section A110.2. This section states the conditions under which URM walls need to be strengthened for out-of-plane loads. This determination is made based on height-to-thickness ratios $(h / t)$ established by ABK testing discussed in section 3.1.3. Table A1-B of the IEBC states the limiting $h / t$ ratios for which URM walls do not need to be evaluated for out-of-plane loading. For regions of high seismicity, such as San Luis Obispo, where seismic parameter $S_{D 1}$ is greater than 0.4 and the one-story URM structure in question contains no crosswalls, a limiting $h / t$ ratio of 13 is given. Therefore, a URM wall matching these criteria must have a $h / t$ ratio greater than 13 in order to require out-of-plane retrofit. The single story wall considered for the retrofit design of this project is 8 inches (or two brick widths) in thickness, with height of 12-14 feet. Such a wall has an $h / t$ ratio of $18-21$, and thus requires out-of-plane strengthening per IEBC provisions.

\subsubsection{Material Properties}

Research regarding local URM structures in San Luis Obispo has been conducted. Data from many structures was surveyed so that design and testing in this project incorporates material strengths typical of URM structures. Testing results and research by Schwein (1990) have revealed an average shear strength of URM structures surveyed in California of $275 \mathrm{psi}$. These values were found to vary generally from 50 to 400 psi, when considering all of the data presented. Research by Kariotis Nghiem (1993) Seismic Performance of Unreinforced Masonry Walls Retrofitted with Post-Tensioning Tendons 
supports these values as well. The average shear strength of a variety of structures in Los Angeles, CA was found to be 340 psi, with a higher range of 200 to 450 psi. More pertinent to this project are the data accumulated for local URM structures in San Luis Obispo, seen following in Table B. This data is presented courtesy of Robert Vessely Civil and Structural Engineering.

\begin{tabular}{|c|c|c|c|c|}
\hline $\begin{array}{c}\text { Building } \\
\text { Location in San } \\
\text { Luis Obispo, CA }\end{array}$ & $\begin{array}{c}\text { Average } \\
\text { Shear } \\
\text { Strength (psi) }\end{array}$ & Range (psi) & $\begin{array}{c}\text { Number of } \\
\text { Tests }\end{array}$ & $\begin{array}{c}\text { Average } \\
\text { Compressive } \\
\text { Strength } \\
\text { (psi) }\end{array}$ \\
\hline 1609 Osos Street & 96 & $80-126$ & 3 & 1100 \\
\hline $\begin{array}{c}1051 \text { Nipomo } \\
\text { Street }\end{array}$ & 160 & $108-204$ & 8 & 1600 \\
\hline 798 Palm Street & 120 & $99-140$ & 4 & 1200 \\
\hline 1131 Broad Street & 230 & $126-265$ & 4 & 1800 \\
\hline $\begin{array}{c}295 \text { Higuera } \\
\text { Street }\end{array}$ & 150 & $61-205$ & 7 & 1300 \\
\hline $\begin{array}{c}659 \text { Higuera } \\
\text { Street }\end{array}$ & 50 & $34-76$ & 6 & 900 \\
\hline Average & 135 & $85-188$ & -- & 1320 \\
\hline
\end{tabular}

Table B: Material Strengths for a Survey of URM Buildings in San Luis Obispo Source: Robert Vessely Civil and Structural Engineering Data for the compressive strength of masonry has been collected as well from various sources. Schwein (1990) reports the average compressive strength for bricks in Seismic Performance of Unreinforced Masonry Walls Retrofitted with Post-Tensioning Tendons 
URM construction in a variety of California buildings. For fired, red-clay brick constructed with mortar incorporating Portland Cement, the average compressive strength $f^{\prime}{ }_{m}$ is 1200 psi. The specific mix proportions for the mortar used in this project are outlined in Section 4, and were selected because they resulted in compressive strengths similar to those presented in Table B. A range of values for compressive strength of masonry are listed by Schwein as 800 to 1800 psi for various URM structures surveyed. This range is well supported by the work of Kariotis and Nghiem (1993) and the work of Fattal and Cattaned (1977). For the average compressive strength of URM walls in the San Luis Obispo survey, the reader may consult Table B previously displayed. The compressive strength of masonry used in retrofit design is a rough approximation for the entire structure. There happens to be considerable variability in this value within a structure. This being the case, it is conservative to aim for the lower end of this range (between 900 to $1300 \mathrm{psi}$ ) when it comes to construction of a URM wall for testing.

\subsection{Current Retrofit Options for Out-of-plane Bending}

Current retrofit options used by designers generally originate from the FEMA-547 document. This section briefly comments on retrofit options outlined by FEMA-547 in regard to out-of-plane bending.

\subsubsection{Bracing}

FEMA-547 section 21.4.3 outlines two different approaches to bracing URM walls for out-of-plane bending in response to seismic events. Either diagonal braces can be installed to reduce the effective height of the wall or vertical braces can be installed on 
the inside face of the URM wall that span its entire height. Typically, diagonal braces are not favored because they can inadvertently take gravity load from the diaphragm and impart a horizontal force on the wall they are supposed to brace.

From an aesthetic standpoint, vertical braces are difficult to hide and they eliminate floor space. A stiffness compatibility issue can also arise with this form of retrofit as well. Due to the high stiffness of URM walls compared to steel frames, URM walls tend to draw the seismic load intended for the steel brace. To prevent this from occurring, designers are forced to insert large steel sections that are stiff enough to draw load away from the URM wall and prevent large deflections.

\subsubsection{Reinforcing Cores}

FEMA-547 section 21.4.4 discusses a more aesthetically sensitive approach to out-of-plane URM wall retrofit that involves vertical coring of walls and insertion of reinforcing bars. Typically a \#6 to \#9 bar is placed inside a 3" to 6" drilled core and grouted solid after placement (Breiholz 1993). Addition of rebar in this fashion allows the wall to perform as if it were a reinforced masonry wall. Reinforcing cores, therefore, allow retrofitted walls to be simply designed as reinforced masonry walls. The goal of the reinforcing core is to yield tension reinforcement prior to crushing of masonry as the wall is subjected to out-of-plane loads. An accurate value for $f^{\prime}{ }_{m}$ ensures this failure mode, which is considerably more ductile and is favored to crushing of masonry.

Unfortunately, a relatively large diameter core can disrupt and potentially damage the wall material around the core. Spalding and cracking of masonry during coring is also a concern associated with this approach.

Seismic Performance of Unreinforced Masonry Walls Retrofitted with Post-Tensioning Tendons 
This URM retrofit approach most closely relates to the proposed retrofit solution presented in this thesis project. The main difference in these two methods, however, is that post-tensioning is an active system that applies a stress to the wall, while reinforcing cores are passive systems. Reinforcing cores also require large diameter cores in order to fully develop added reinforcing and in order to engage existing masonry. These large diameters take time and skill to core and consequently, they are more expensive than $3 / 4^{\prime \prime}$ to 1 " diameter cores. This system is typically reserved for historic buildings where external strengthening is not feasible (Campi 1989).

\subsubsection{Concrete Overlay}

Section 21.4.5 of FEMA-547 discusses a method for retrofitting URM walls by overlaying them with new concrete walls. This method is used primarily to strengthen URM walls in-plane but offers out-of-plane strength as well. This system can either be cast-in-place or sprayed on in the form of shotcrete. The relative stiffness of the concrete compared to the masonry tends to shift the entire load to the new concrete overlay (FEMA-547). The disadvantage is that the masonry will crush as the concrete overlay carries the load.

The additional mass that concrete overlay walls add to the structure significantly increases seismic forces imposed on the structure. Additionally, concrete walls create a stiffness incompatibility in regards to in-plane loads. Special considerations in regard to the lateral load path must be made to avoid crushing of surrounding URM walls. 


\subsubsection{Fiber-Reinforced Polymer Overlay}

Fiber-Reinforced Polymer (FRP) overlays are another form of seismic retrofit suggested by FEMA-547. FRP overlays provide both in-plane and out-of-plane benefits to URM walls. An FRP overlay is an adhesive matrix of glass or carbon fiber that is applied directly to the face of URM walls.

FRP overlays can increase out-of-plane strength of URM walls, but they provide little ductility. However, overlays do add an insignificant amount of mass to a structure, giving them an advantage over other systems. FRP overlays incorporating carbon fiber are also expensive and require application on both sides of URM walls in order to be effective for out-of-plane bending.

\subsection{Post-Tensioned Masonry Walls}

The following section reviews literature concerning research, design, testing, and construction of post-tensioned masonry walls.

\subsubsection{In-Plane \& Shear Strengthening}

Significant research has been conducted to investigate the performance of posttensioned masonry walls in response to in-plane loads. If a unified post-tensioning retrofit system can be proven effective for in-plane and out-of-plane loads, retrofit costs could ultimately be reduced.

Ganz and Shaw (1997) present a case study involving the retrofit of Holy Cross Church in Santa Cruz, CA using post-tensioning tendons to improve in-plane wall response. The work of Ganz and Shaw draws upon techniques developed by VSL, which 
are further discussed in VSL's Experience with Post-Tensioned Masonry. PT tendons were successfully introduced as a retrofit solution for shear strengthening on a variety of projects. This added compressive stress effectively improved the shear strength of the retrofitted walls. These case studies are significant because they show that PT forces can be successfully introduced into URM walls with low strength $\left(f^{\prime}{ }_{m}\right.$ of 800 to $\left.1200 \mathrm{psi}\right)$.

Figure F shows a standard VSL post-tensioning retrofit. This retrofit detail resembles the anchorage detail of this project shown in Section 6.3.7.

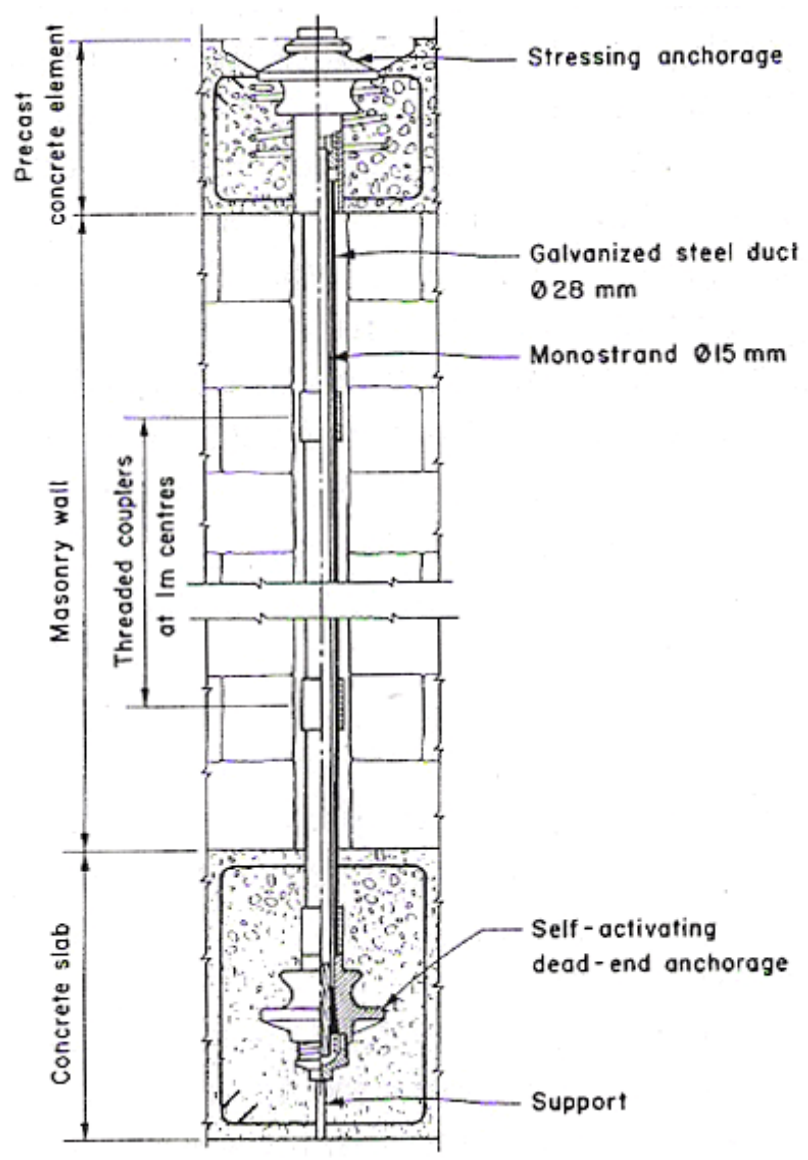

Figure F: VSL Post-Tensioning Retrofit Setup Source: Ganz and Shaw 1997 
One of the earliest experiments on post-tensioned masonry was conducted by Alper, Hacim and Aysoy in 1982. More recently, work has been conducted by Laursen, Wight and Ingham (2006), Wight, Ingham and Kowalsky (2006), Laursen and Ingham (2004), Rosenboom and Kowalsky (2003) and Laursen (2002) to test post-tensioned concrete masonry walls for in-plane forces. Primarily, these tests have shown that posttensioning tendons initiate a self-centering behavior at the conclusion of loading. Such behavior has great implication for damage mitigation and prevention of catastrophic collapse in regard to out-of-plane loading.

The work of Laursen (2002) and others previously mentioned was drawn upon by Rosenboom and Kowalsky (2003) in their experimental program for testing of posttensioned clay masonry walls. A prestress force for all the specimen walls was established so that sufficient moment capacity could be achieved in light of the determined design level earthquake. Their experiments revealed that the restoring nature of unbonded tendons is present in clay brick masonry as well as concrete masonry.

\subsubsection{Out-of-Plane Loading}

Testing has also been conducted to evaluate the performance of post-tensioned wall systems in response to out-of-plane loads. Extensive literature review suggests that no experimentation exists for the use of PT tendons specifically for out-of-plane retrofit of URM walls. The following are the summarized findings of some key experiments as they pertain to this thesis project.

The first significant series of tests concerning post-tensioned masonry walls was conducted by Al-Manaseer and Neis (1987). Their intent was to investigate the use of PT Seismic Performance of Unreinforced Masonry Walls Retrofitted with Post-Tensioning Tendons 
tendons to enhance wall flexural capacity. The masonry units used for structural testing were standard 8-inch Concrete Masonry (CMU) block. Six wall panels were constructed, measuring 4 feet wide by 8 feet high. Of the six panels constructed, four were posttensioned using various configurations of $3 / 8$ inch high strength steel strand. Tendons in the experimental program were stressed to $80 \%$ of their ultimate strength. Post-tensioned walls were constructed on $1 / 2$-inch-thick steel plates to provide adequate bearing for PT anchorage. The mortar used in construction conformed to ASTM C270 type M specifications, using volumetric proportions of $3: 1: 1 / 2$ of sand : cement : lime. Average 28-day mortar strength was based on construction of mortar cubes, and was found to be 2670 psi. PT tendons were placed inside conduits and walls were then grouted solid. Grouting around a greased conduit ensured that tendons would remain unbonded.

Monotonically increasing load was applied to the walls at mid-height until failure was achieved. Mortar joints on the tension side of the tested wall panels were seen to open prior to ultimate failure as expected. Cracking in this manner was generally restricted to the center of the wall at the location of maximum moment, resulting in formation of a hinge. This failure pattern is typical of out-of-plane load tests reviewed for this project. See Figure $\mathrm{G}$ following for the failure mode of the post-tensioned walls. 


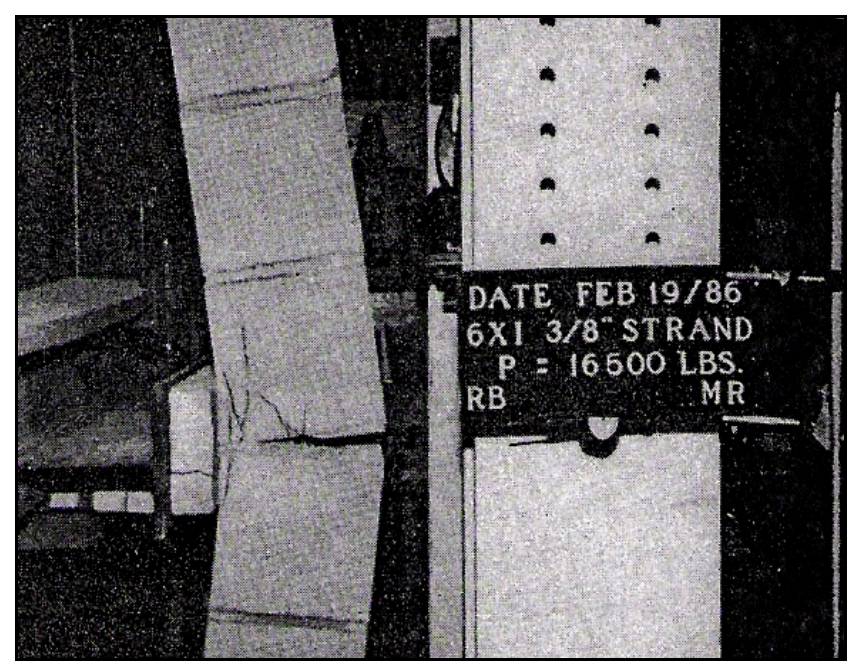

Figure G: Failure of Post-Tensioned CMU Wall Source: Al-Manaseer and Neis 1987

It is important to note that upon unloading, tested walls nearly returned to their original positions. It was also found that the allowable load that could be withstood by the wall increased with an increase in post-tensioning force. An increase in posttensioning force (while remaining in acceptable compressive stress ranges) effectively offsets the development of the wall's cracking moment capacity. Force-Displacement curves for the post-tensioned walls reveal that load capacities of the wall panels can be increased upwards of 200 percent by incorporating post-tensioning tendons.

Testing conducted by Krause, Devalapura and Tadros (1996) shows that posttensioned wall panels can be designed using standard prestressed concrete assumptions to resist out-of-plane pressures. Their project consisted of two-cored brick units aligned to allow for a continuous cavity for PT tendons. This wall configuration was then loaded in the out-of-plane direction at the third points of the specimen. Designs were built according to current code provisions of the time (1995 MSJC). The design incorporated Seismic Performance of Unreinforced Masonry Walls Retrofitted with Post-Tensioning Tendons 
high strength $120 \mathrm{ksi}$ 5/8" threaded steel rods used for post-tensioning. A prestressing force of 19 kips was applied to all panels, which had a 28-day prism strength of 2845 psi. The testing setup described here is shown in Figure $\mathrm{H}$ on the next page.
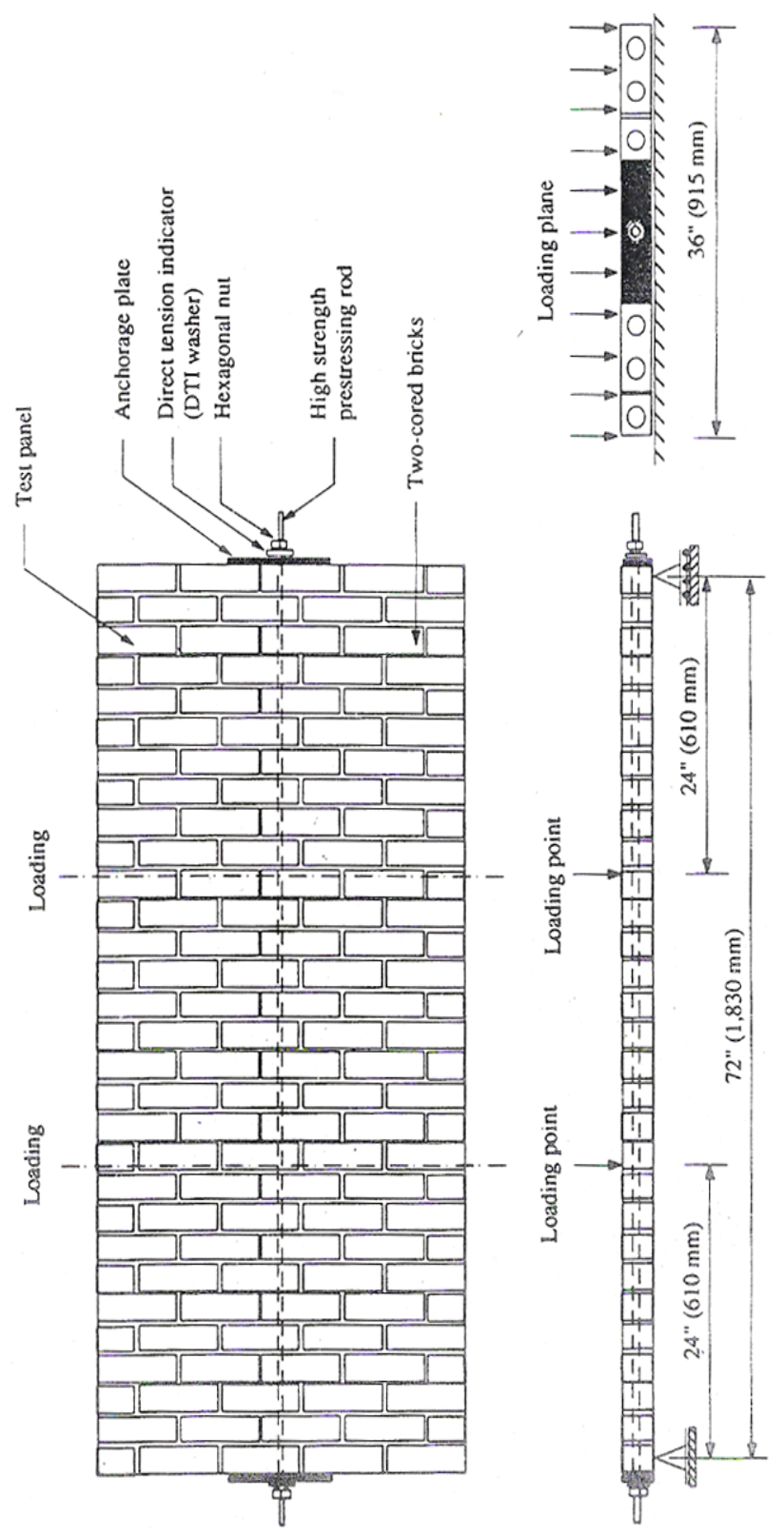

Figure H: Prestressed Test Specimen Detail Source: Krause, Devalapure and Tadros 1996 
The results of the Krause, Devalapura, and Tadros experiments revealed that a $12^{\prime \prime} \times 3 \%_{8}^{\prime \prime} \times 1 "$ plate was sufficient to adequately distribute the prestressing force to the wall specimen. More importantly, it was concluded that it is feasible to introduce prestressing forces into unreinforced clay-brick masonry walls. These tests, however, used new materials for the construction of test specimens.

Development of post-tensioned brick masonry walls in the form of multiple experiments has been conducted by Schultz, Bean Popehn, Drake and Stolarski (Schultz et al. 2004, Schultz et al. 2003 and Bean Popehn et al. 2007). In their most recent experimental program, 12 simply supported 11'-6" tall walls with 32 "x 4 "cross sections were tested under transverse load. Half of the tested walls were built using clay brick. Three of the brick walls incorporated unbonded tendons while the others used bonded tendons. It is important to note that threaded steel post-tensioning bars were attached to the walls at their outermost edges and not inside wall cavities. Figure I shows the testing setup.

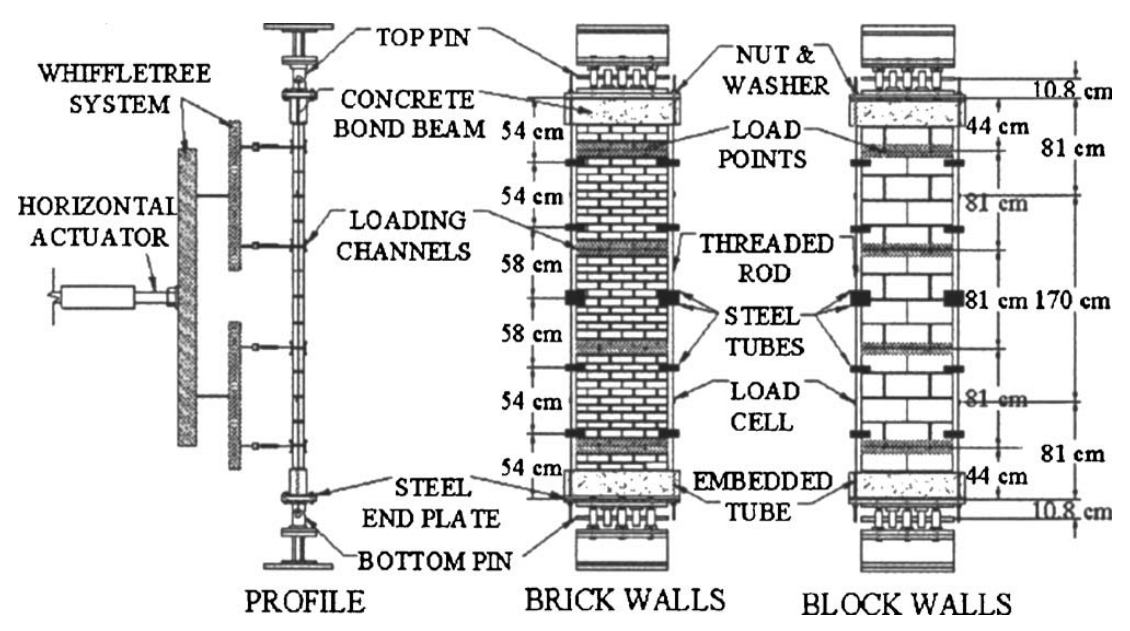

Figure I: Wall Specimen Setup

Source: Bean Popehn, Schultz and Drake 2007

Seismic Performance of Unreinforced Masonry Walls Retrofitted with Post-Tensioning Tendons 
The objective of testing by the authors mentioned above was to test posttensioned masonry walls with large $h / t$ ratios (28-45) to understand their response to outof-plane loading. Their work conceptualizes this response using three benchmark events. The first benchmark event is referred to as the crack penetration, where a flexural crack appears on the tension side of the wall and proceeds to penetrate the bed joint. This event is important because it implies that the wall's response is no longer elastic. After this event, cracking continues to propagate until a hinge forms at the initial location of cracking (see Figure $\mathrm{J}$ following). This hinge formation is the second event of interest. The third event is the formation of a plastic section and represents the maximum moment capacity of the wall.

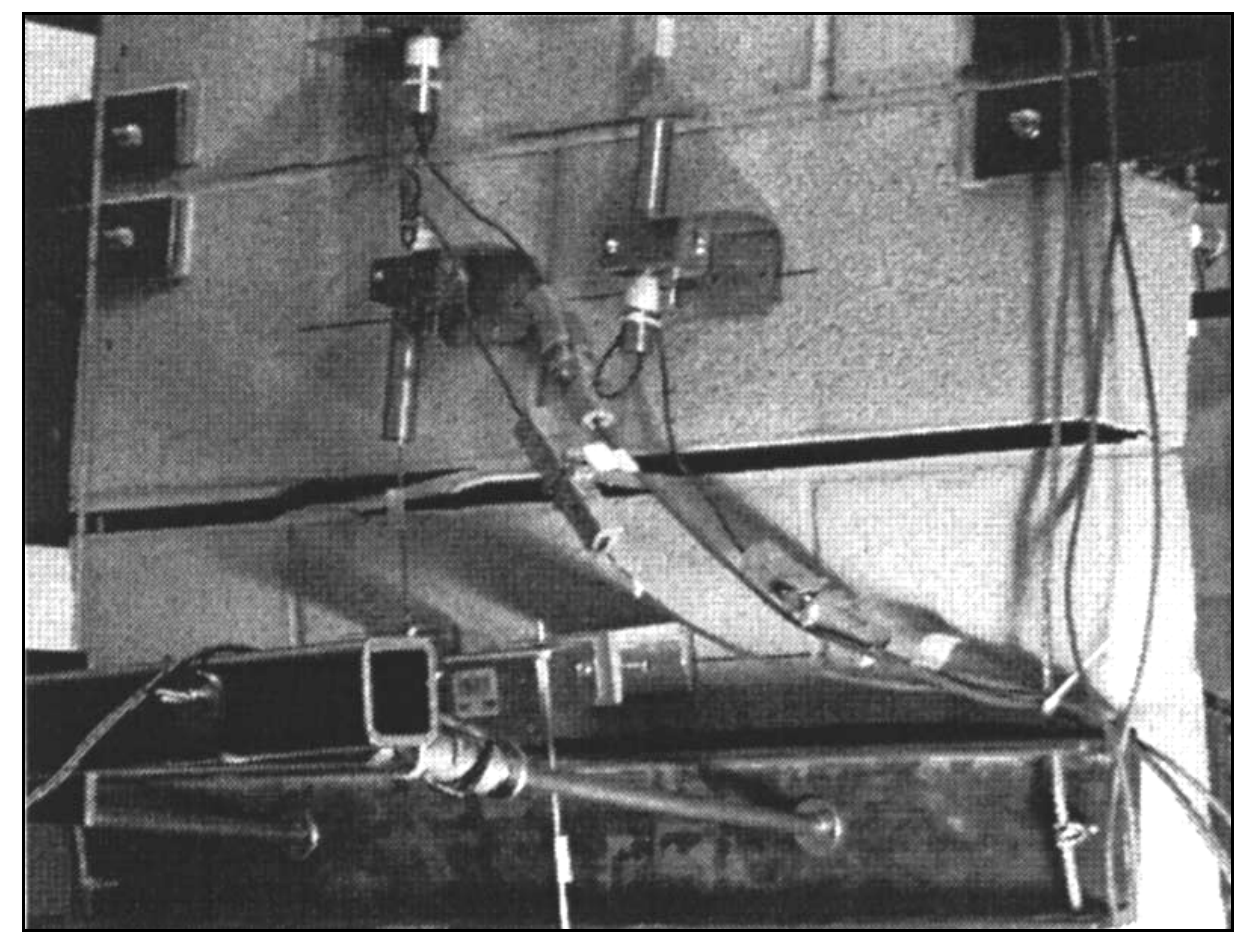

Figure J: Formation of Plastic Hinge at Mid-Height of Tested Wall Source: Bean Popehn, Schultz and Drake 2007

Seismic Performance of Unreinforced Masonry Walls Retrofitted with Post-Tensioning Tendons 
The following equation is based on fundamental mechanics, and effectively defines the wall's cracking moment capacity:

$$
M_{c r}=\frac{I_{n}}{c}\left[f_{r}+\left(\frac{P_{u}+P_{s w}+A_{p s} f_{s e}}{A_{n}}\right)\right],
$$

where $I_{n}$ is the net moment of inertia $\left(\mathrm{in}^{3}\right)$,

$c$ is the distance from the neutral axis to the extreme fiber of the cross section (in), $f_{r}$ is the modulus of rupture (psi),

$P_{u}$ is applied service axial loading (lb),

$P_{s w}$ is the wall's self weight at the location of maximum moment (lb),

$A_{p s} f_{s e}$ is the post-tensioning force (lb), and

$A_{n}$ is the net area of the wall $\left(\mathrm{in}^{2}\right)$.

This equation proves accurate if the following assumptions are made: (1) the wall is solely in one-way bending; (2) the cross section is uncracked up to this point; and (3) stresses follow a linear distribution.

The moment capacity at hinging can be calculated if one assumes: (1) a linear stress distribution; (2) negligible masonry tensile strength; and (3) an extreme fiber compressive stress in the masonry equal to a fraction of the compressive strength $\lambda_{h} f^{\prime}{ }_{m}$. The fraction $\lambda_{h}$ is taken as 0.5 resulting from the assumed linear stress distribution (Bean Popehn, Schultz and Drake 2007). The stress distribution at the cross-section inherently shifts as axial load is added to the section. Studies by Bean Popehn, Schultz and Drake show that for low levels of axial stress (less than $10 \%$ of $f^{\prime}{ }_{m}$ ) these effects are minor and 
need not be considered. Thus, the moment capacity at hinging can be calculated as an axial force in the masonry multiplied by a moment arm:

$$
M_{h}=\left[P_{u}+P_{s w}+A_{p s} f_{s e}\right]\left(d_{e f f}-\frac{2\left[P_{u}+P_{s w}+A_{p s} f_{s e}\right]}{3 \lambda_{h} f^{\prime}{ }_{m} b}\right), \quad \text { Eq. } 2
$$

Where $d_{e f f}$ is the distance from the face to the center of the PT tendon (in),

$f^{\prime}{ }_{m}$ is the masonry compressive strength (psi), and

$b$ is the width of the wall tributary to one PT tendon (in).

The ultimate moment capacity at the third event can be calculated using the

following assumption: the compression stress distribution can be represented using a rectangular stress block with stress-block parameter $\lambda_{h}=0.85$ (Bean Popehn, Schultz and Drake 2007). Thus, the strength of the wall at the development of the plastic section is:

$$
M_{p}=\left[P_{u}+P_{s w}+A_{p s} f_{s e}\right]\left(d_{e f f}-\frac{\left\lfloor P_{u}+P_{s w}+A_{p s} f_{s e}\right\rfloor}{2 \lambda_{h} f^{\prime}{ }_{m} b}\right)
$$

Eq. 3

The assumed stress distributions at the three events of interest are shown in Figure K following. Event (a) signifies crack penetration, while event (b) represents the formation of the hinge and event (c) represents the development of the plastic section. 

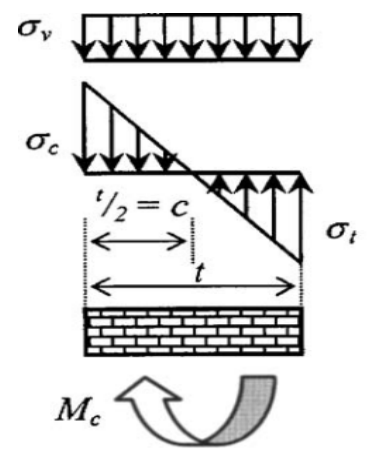

a)

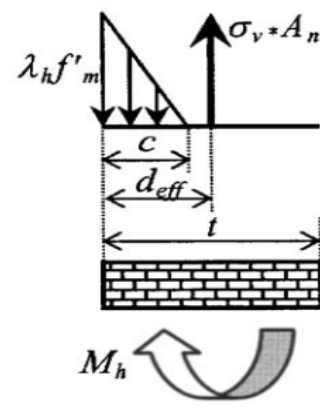

b)

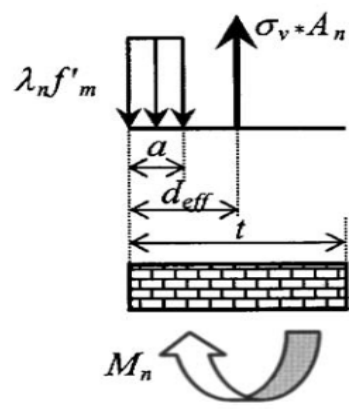

c)

Figure K: Stress Distributions at Benchmark Events

Source: Bean Popehn, Schultz and Drake 2007

Masonry strength $f_{m}{ }_{m}$ used for testing was 3920 psi. The modern materials used for these tests represent relatively high strength values when compared to the retrofitted walls tested in this project.

The walls exhibited linearly elastic responses up to the point of cracking, as revealed by plots of load versus deflection. The tested masonry walls were able to achieved final drifts of about $3 \%$ to $5 \%$ of the pin-pin wall height. Tendon stresses were found to increase throughout the duration of lateral loading. For walls with unrestrained tendons, tendons moved toward the compression face as the neutral axis of the wall shifted during hinging. These findings are drawn upon further for the predictions of the tested retrofit system in Section 6.0.

\subsection{Post Tensioning Losses and Masonry Creep}

Post-tensioning losses and masonry creep are important factors that will inherently influence the design and longevity of an adequate retrofit. The main cause for concern with the post-tensioning of old unreinforced masonry is the potential for PT 
losses as a result of compressive strain in the masonry. Thus, this section briefly discusses these factors and outlines further research.

In this thesis project, long-term creep is not considered for the purposes of design or testing. Creep should ultimately be examined, however, when considering the lifespan of a PT retrofit. The force in the PT tendon will be monitored during testing through a load cell. In this fashion, prestress losses can be captured as the wall is loaded by the tendon and later in the out-of-plane direction.

Testing by Krause, Devalapura and Tadros (1996) briefly investigated prestress losses occurring in post-tensioned masonry walls. Over a span of 180 days, multiple test specimens were analyzed in regards to losses in prestress. These losses were mainly attributed to the use of medium-strength 120ksi prestressing steel. Modern anchorages and low-relaxation $270 \mathrm{ksi}$ tendons like the ones used in this project are proven to suffer much smaller losses (Ganz and Shaw 1997).

Prestress losses during seismic events were examined by Rosemboom and Kowalsky (2003). In their in-plane testing of PT masonry walls, it was determined that the main sources of prestress losses occur from cycling of the PT bars into the inelastic range and degradation of the masonry. The primary sources for long-term losses in the retrofit design of this project stem only from degradation of masonry since tendons are designed to remain elastic. Immediate losses due to elastic shortening of the URM wall, anchor slip and tendon relaxation will need to be accounted for in the implementation of this retrofit technique on structures. The ultimate capacity of a retrofitted URM wall depends on the maintenance of prestress levels in the wall. 


\subsection{MATERIAL PROPERTIES}

The red-clay bricks used in this thesis project come from a demolished warehouse that was located in San Jose, California. Built in the 1920's, the unreinforced masonry warehouse ironically housed the manufacture of seismic engineering hardware. The bricks used in this thesis project are on average $23 / 4$ " high, $3 \frac{3 / 4}{\prime \prime}$ wide and $81 / 4$ " long. While mostly all of the bricks were $23 / 4^{\prime \prime}$ high, the width of bricks varied from $3 \frac{1 / 2}{2}$ to 4

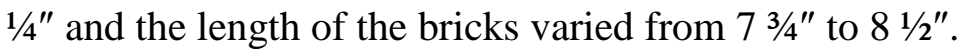

As stated previously, the purpose of this project is to accurately approximate material strengths typical of early $20^{\text {th }}$ Century URM structures. This being the case, iterations were conducted with regard to mortar mix to achieve a 28-day compressive strength comparable to the strength of an 80-year-old URM wall. For each iteration, three masonry prisms were constructed using the mortar mix design specified. A mix design was selected once the average value for compressive strength entered the desirable range set forth in Section 3.1.4. Specimens for compressive strength $f^{\prime}{ }_{m}$ were tested in accordance with ASTM C-1314. Specimens for tensile bond strength of masonry $f_{r}$ were tested in accordance with ASTM C-1072.

Seismic Performance of Unreinforced Masonry Walls Retrofitted with Post-Tensioning Tendons 


\subsection{Masonry Properties}

For the first series of tests, a mortar mix design using the proportions of $1: 1: 6$ cement : lime : sand was used. Water was added to each mix until the desired level of workability was achieved. Addition of water in this fashion is consistent with traditional masonry practices and was confirmed through the assistance of local masons (Mission Masonry of San Luis Obispo). A set of 3 mortar cubes were constructed for each mix design according to ASTM C-109. The 1: 1: 6 mix design resulted in an average compressive strength of 1694 psi for the three tested prisms. In order to bring the value for $f^{\prime}{ }_{m}$ lower into the acceptable range, a new mix design using proportions of $1: 1: 9$ cement : lime : sand was used. This mix design was selected for the construction of the URM testing wall and serves as a good reflection of URM material strengths for local buildings. Testing results for masonry prisms using the $1: 1: 9$ mix design are given below in Table $\mathrm{C}$.

\begin{tabular}{|c|r|r|}
\hline Sample Number & $\begin{array}{r}\text { Compressive Strength } \boldsymbol{f}^{\prime}{ }_{\boldsymbol{m}} \\
(\mathbf{p s i}) \text {-ASTM C-1314 }\end{array}$ & $\begin{array}{c}\text { Tensile Bond Strength } \boldsymbol{f}_{\boldsymbol{r}} \\
\text { (psi) -ASTM C-1072 }\end{array}$ \\
\hline 1 & 1,224 & -- \\
\hline 2 & 1,340 & -- \\
\hline 3 & 1,315 & -- \\
\hline 4 & 1,101 & -- \\
\hline 5 & 1,411 & -- \\
\hline 6 & 1,180 & 39 \\
\hline 7 & -- & 41 \\
\hline 8 & -- & 43 \\
\hline 9 & -- & $\mathbf{4 1}$ \\
\hline Average & $\mathbf{1 2 6 2}$ & - \\
\hline
\end{tabular}

Table C: Material Properties of URM Used in Design and Testing

Seismic Performance of Unreinforced Masonry Walls Retrofitted with Post-Tensioning Tendons 
Additional masonry properties such as modulus of elasticity $E_{m}$, shear modulus $E_{v}$, and shear strength $V_{m}$ are calculated empirically based on provisions in the 2006 IEBC. Modulus of elasticity was determined based on Section 1.8.2.2.1 of the MSJC 2005. Shear modulus was determined based on Section 1.8.2.2.2 of the MSJC 2005. Shear strength was determined based on Section A108.2 of the IEBC. These values are grouped with $f_{m}^{\prime}, f_{r}$, and post-tensioning steel properties in Table D found in Section 4.2. Figure L below shows a masonry sample being tested in accordance with ASTM C-1314.

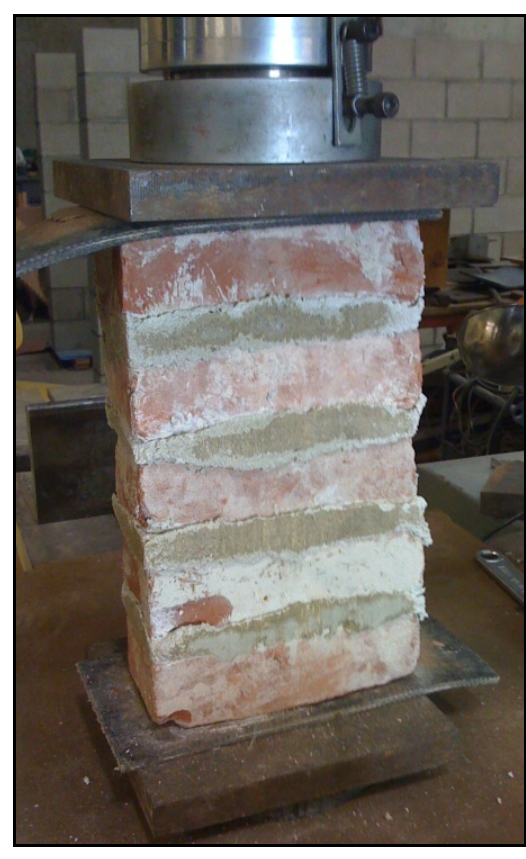

a) Masonry Specimen

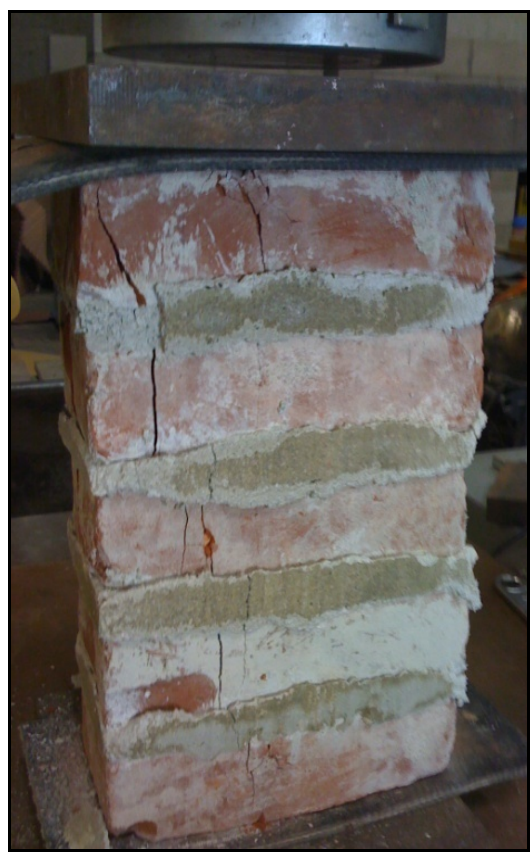

b) Tested Specimen

Figure L: Typical Testing of a Masonry Specimen 


\subsection{Steel Properties}

The post-tensioning tendon used in this project was donated by Dywidag Systems International. This tendon is a standard, high-strength steel 7-wire strand used primarily in post-tensioned concrete design. Aside from being placed in a plastic conduit, the tendon was greased and coated to ensure no bonding occurred between the tendon and the masonry. The material properties for the type of PT tendon used in this retrofit are listed in Table D located at the bottom of this page.

Standard steel barrel anchors and wedges were used to transfer the prestress of the tendon to the URM wall. Barrel anchors were locked off onto steel plates at the top and bottom of the wall. See Section 7 for a detailed description of the test setup.

\begin{tabular}{|l|r|}
\hline \multicolumn{2}{|c|}{ Masonry Properties } \\
\hline$f^{\prime}{ }_{m}(\mathrm{psi})$ & 1,262 \\
\hline$f_{r}(\mathrm{psi})$ & 41 \\
\hline$V_{m}(\mathrm{psi})$ & 89 \\
\hline$E_{m}(\mathrm{ksi})$ & 883 \\
\hline$E_{v}(\mathrm{ksi})$ & 353 \\
\hline \multicolumn{2}{|c|}{ Steel Properties } \\
\hline$A_{p s}\left(\mathrm{in}^{2}\right)$ & 0.153 \\
\hline$f_{p y}(\mathrm{ksi})$ & 243 \\
\hline$f_{u}(\mathrm{ksi})$ & 270 \\
\hline$E_{s}(\mathrm{ksi})$ & 28,500 \\
\hline
\end{tabular}

Table D: Material Properties Used in Design and Testing 


\subsection{CANDIDATE WALL CONFIGURATION}

This section outlines the URM wall type that would benefit from a PT retrofit scheme. For information regarding the generic layout of URM structures considered in this project, the reader may consult Section 3.1.1.

\subsection{Wall Configuration in a Typical URM Building}

The unreinforced masonry wall considered in this project is reflective of a wall located in a typical one-story structure situated in San Luis Obispo, California. The wall may either be situated on a concrete spread footing or a brick stem-wall. The building height for this project was considered as 18 feet from top of grade to the top of the parapet. Thus, an acceptable wall span between diaphragms can be taken as 12 to 14 feet. The wall is located in the long direction of the structure, perpendicular to the street. The wall in question is not braced by any crosswalls. The wall specimen incorporates a running bond pattern, bond courses every sixth course, and a two-brick thickness. The compressive strength and other material properties of this wall correspond to those discussed in Section 4. Figure M represents the configuration of the URM wall to be retrofitted in such a structure. 


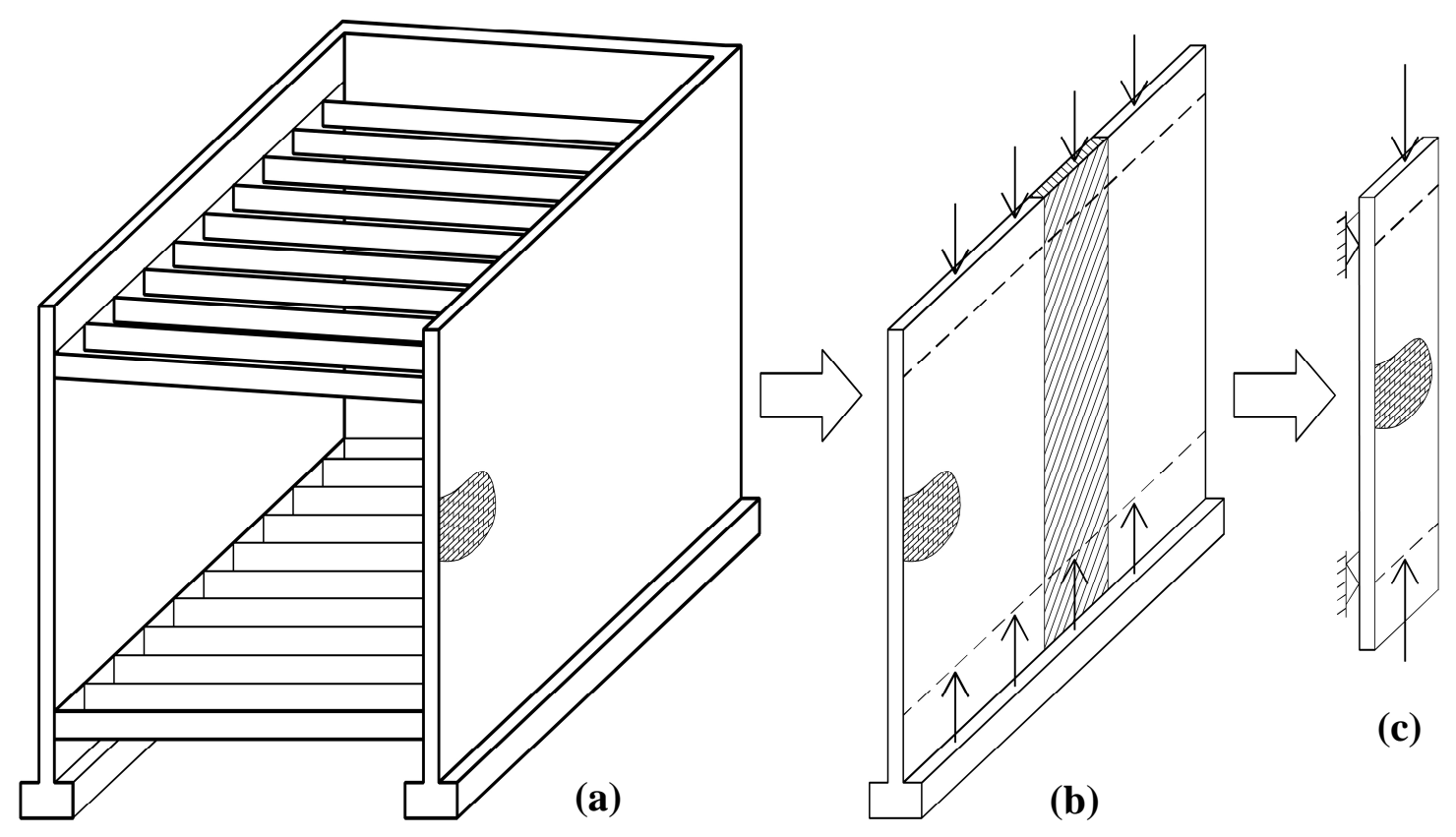

Figure M: Wall Configuration in a Typical URM Structure

Figure M represents the location of the wall to be retrofitted with PT tendons.

Image (a) shows a generalized configuration of a URM structure considered in this project. In (b), the wall is shown removed from the structure with the location of PT tendons indicated by vertical arrows. Note that the point of application of PT stress is at the top of the parapet and at the lower diaphragm indicated by the dashed line. The area tributary to one PT tendon is hatched. This area is extruded from the wall in (c) and represents the segment of the wall to be designed and tested. Similar to traditional outof-plane design methods, this tributary width is considered in the design of a PT retrofit scheme. End restraints are shown in (c) and are discussed in detail in Section 5.2.1 following. 


\subsection{Wall Modeling and Assumptions}

This section discusses the important modeling assumptions made that pertain to the testing program and retrofit design of this project. One of these assumptions is that the wall material remains linearly elastic until crushing begins. It was also assumed that the wall hinges only at mid-height and that the two resulting segments rotate as rigid bodies. These assumptions are consistent with similar testing conducted on URM and post-tensioned walls previously referenced in Section 3.3.2 (Nanni and Tumialan 2003, and Schultz, Bean and Drake 2004).

\subsubsection{End Restraint}

There is a certain degree of variability in the support conditions of URM walls. This variability primarily results from factors including the foundation system (if present), diaphragm anchorage, and degradation of masonry. Depending on the construction of the URM building, boundary conditions of the structural model may provide different degrees of rotational restraint. Thus, the resulting moment diagram of the model resulting from a uniform out-of-plane load may be shifted to account for these boundary conditions. The location of inflection points in the moment diagram will, in turn, shift to accommodate moment capacity at boundary conditions. These effects are displayed graphically in Figure $\mathrm{N}$ on the next page. 


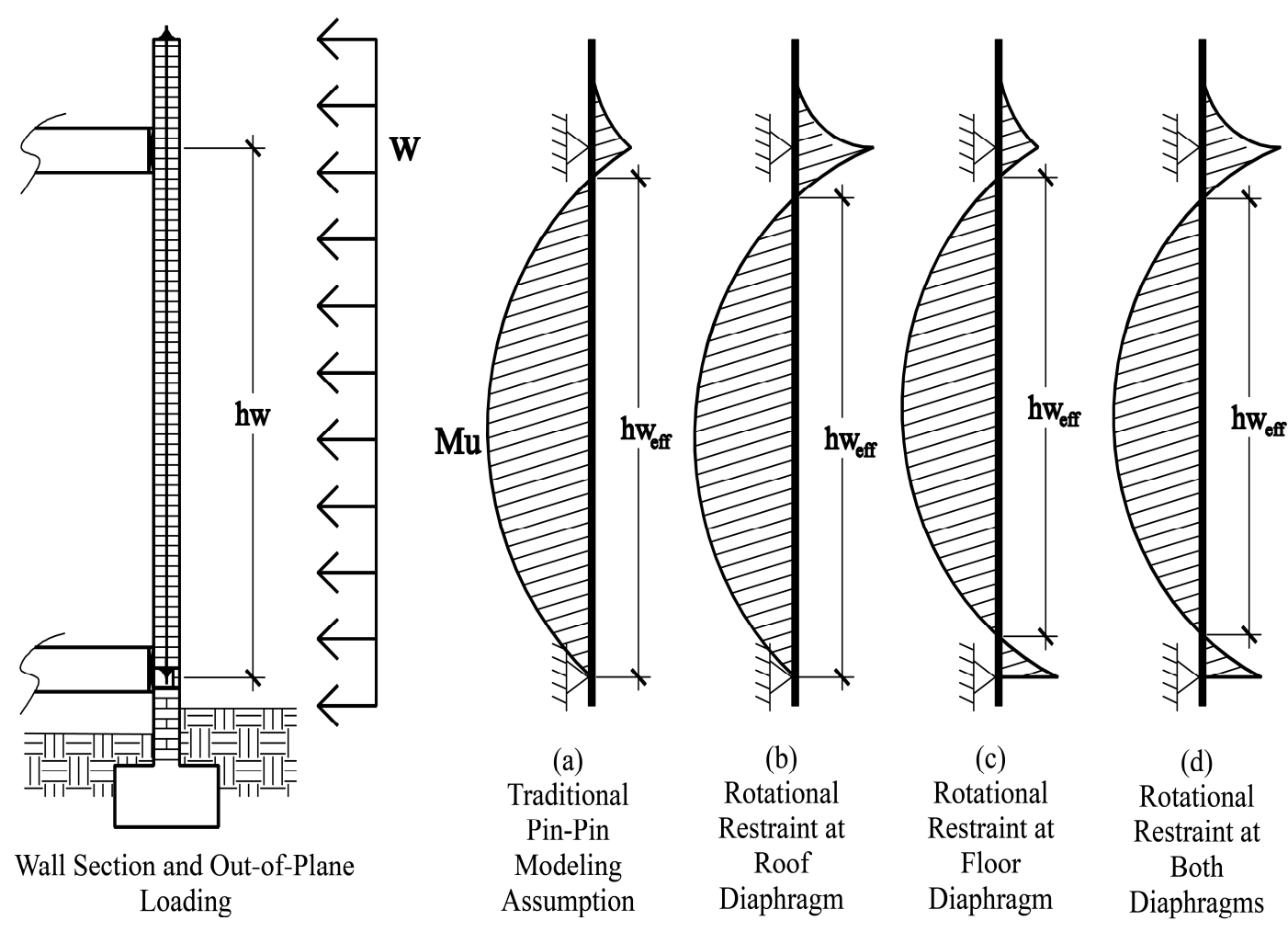

Figure N: Moment Diagrams Depicting Varying Levels of End Restraint in Wall Modeling

Traditionally, masonry walls are designed for out-of-plane loads assuming simply-supported end conditions. This configuration is illustrated in Figure N (a). Figure N (b-d) illustrates the resulting shift in the moment diagram for varying levels of rotational restraint at the roof diaphragm (b), the floor diaphragm (c), and at both the roof and floor diaphragms (d). The effective height of the wall $h w_{\text {eff }}$ (distance between inflection points in the moment diagram) consequently changes, as shown in the figure. The wall is unlikely to develop significant moment at its base, due to the construction of the foundation, and due to the potential for rocking of the wall at the foundation level (Kariotis and Nghiem 1993). This is especially the case if the foundation system for the 
wall consists of only a brick stem wall and no concrete footing. If the development of moment at the wall's base were a significant issue, post-tensioning could be inserted further down into the wall by excavating around the wall's base. A cavity for PT anchorage could be created under the footing itself with minimum excavation. This detail is shown in Figure T of Section 6.3.7.

To eliminate variability in the moment diagram of the design wall, the effective height of the wall $h w_{\text {eff }}$ is taken between the inflection points of any of the potential moment diagrams shown in Figure N. Thus, a 12 to 14 -foot wall can be modeled as a slightly shorter wall having pinned boundary conditions. This design approach is more consistent with traditional structural modeling (Nanni and Tumialan 2003). In the design and test program of this project, an 11-foot pin-pin height is used for $h w_{\text {eff. }}$ This height effectively approximates a story-to-story height of 12-14 feet, and gives the double-wythe wall a slenderness ratio $(h / t)$ of 18 to 21 . In accordance with the provisions of the IEBC previously discussed, this slenderness ratio range requires out-of-plane retrofit.

\subsubsection{Location of Tendons, Propagation of Forces and Tendon Restraint}

Tendons are placed in the wall at regularly-spaced intervals. This spacing is conservatively taken as half the effective height of the wall. By assuming that the load from the tendons spreads at a 45 degree angle, full development of PT axial stresses is achieved at mid-height of the wall. This assumption is well supported by theory (Shaw 1996, and Schultz, Bean and Stolarski 2003, MSJC 2005), and is shown in Figure O. 


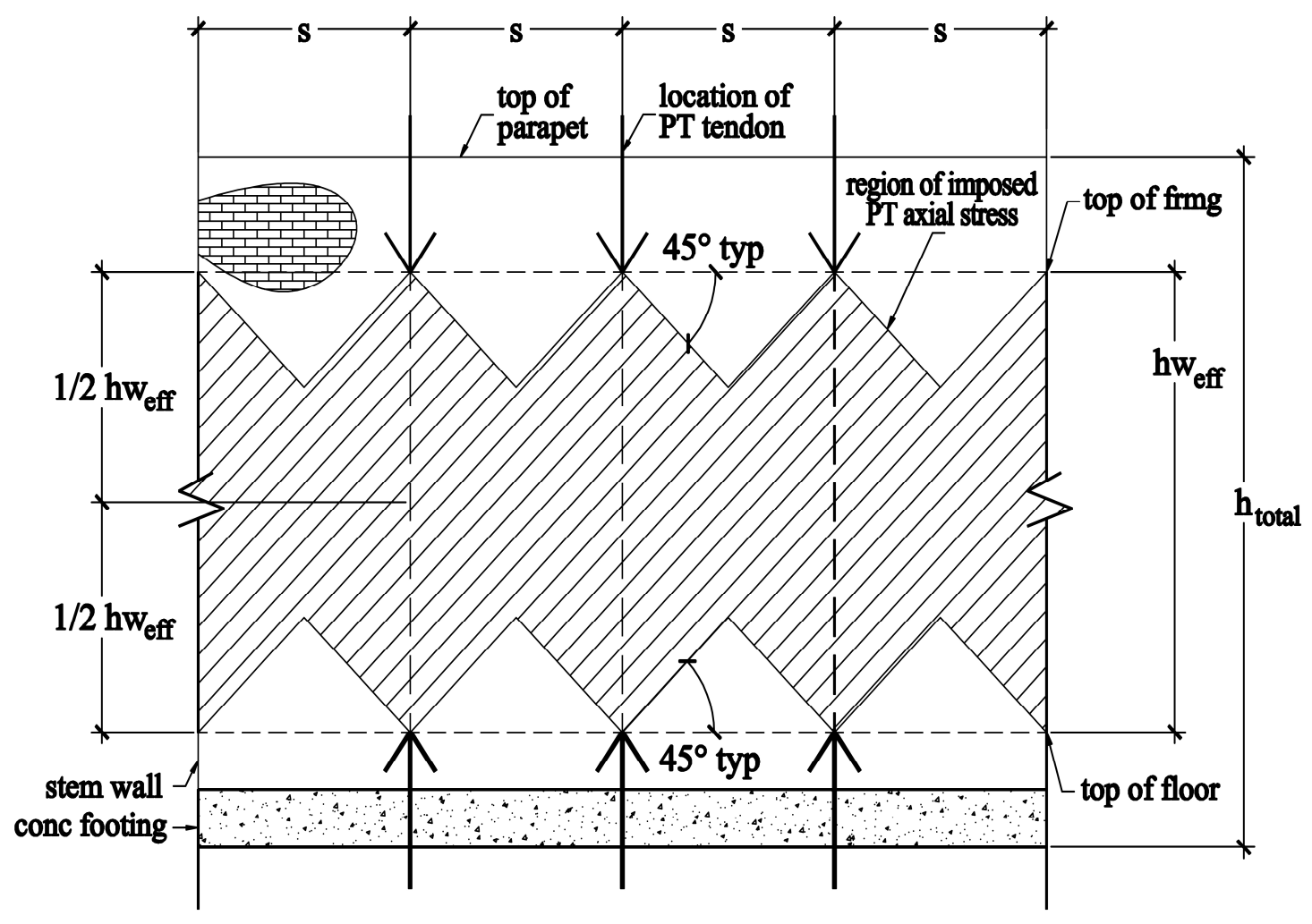

Figure O: Propagation of Post-Tensioning Stresses in a Retrofitted URM Wall

Figure $\mathrm{O}$ also illustrates the fact that significant development of axial stresses is obtained before reaching the mid-height of the wall. In these regions, overlap for adjacent tendons results in sufficient axial stresses as the moment in the wall increases towards mid-height.

For this project the maximum desired tendon spacing $(s)$ for a total wall height of between 12 and $14^{\prime}$ is $s=6^{\prime}$. Therefore, the designer would assume this spacing in retrofit design. Ideally, testing would reflect this tributary width to one tendon. Due to a limited supply of bricks, however, the tested wall could only be constructed having a width of 5 bricks, equal to $3^{\prime}-6^{\prime \prime}$. This being the case, the amount of initial posttensioning was proportioned so that the axial stress in the wall was analogous to post- 
tensioning at $6^{\prime}$ intervals. Ultimately, further testing should be conducted to demonstrate the validity of this system incorporating different tendon spacing configurations.

Tendons in this retrofit design were considered unbonded because they are not directly attached to the wall through the use of grout. In construction of the testing wall, tendons were both greased and coated in addition to being placed inside the core cavity to ensure an unbonded behavior. Therefore, tendons were not grouted after being inserted into cores. Not grouting in this fashion was done to avoid potential problems associated with rebar cores discussed in FEMA-547 and to reduce potential retrofit costs.

Due to the small diameter of the cores in this retrofit, tendons while unbonded, are considered laterally restrained. Tendons are assumed to come into direct contact with the wall upon displacing. In actuality, the tendon comes into contact with the inside of its core after $1 / 8$ " of wall deformation. This does not influence test predictions because the wall remains elastic through this deformation level. Because the wall is elastic at this point, the tendon is not yet engaged in resisting lateral load and only serves to increase the wall section's cracking moment.

Lateral restraint of PT tendons is important when considering second-order effects. Typically, additional axial load exacerbates the bending stresses in URM walls as they displace due to $\mathrm{P}-\Delta$ effects. Ensuring that tendons are laterally restrained; however, eliminates additional $\mathrm{P}-\Delta$ effects because the line of action of the PT load does not change with respect to the neutral axis of the wall (Ganz 1996). 


\subsection{RETROFIT DESIGN AND PREDICTIONS}

This section contains the preliminary design of the retrofit solution presented in this project. In order to compare design predictions to testing, no vertical load other than that from the PT tendon is considered in the design. Additionally, no strength-reduction or safety factors are used in design in this section to allow for comparison to test results. All of the parameters used in the design following are listed in Table E below. Values represent a wall constructed of vintage brick and mortar. This wall has all of the properties and dimensions determined in preceding sections. Symbol notation is provided on page xii.

\begin{tabular}{|c|r|}
\hline$h_{w}(\mathrm{ft})$ & 11 \\
\hline$s(\mathrm{ft})$ & 3.56 \\
\hline$b(\mathrm{ft})$ & 3.56 \\
\hline$\gamma\left(\mathrm{lb} / \mathrm{ft}^{3}\right)$ & 140 \\
\hline$d_{y}(\mathrm{in})$ & 8.25 \\
\hline$A_{n}\left(\mathrm{in}^{2}\right)$ & 352 \\
\hline$I_{g}\left(\mathrm{in}^{4}\right)$ & 2,000 \\
\hline$S\left(\mathrm{in}^{3}\right)$ & 485 \\
\hline$r(\mathrm{in})$ & 2.38 \\
\hline$h / r$ & 55 \\
\hline$d_{b}(\mathrm{in})$ & 0.5 \\
\hline$A_{p s}\left(\mathrm{in}{ }^{2}\right)$ & 0.153 \\
\hline$f_{m}^{\prime}(\mathrm{psi})$ & 1,262 \\
\hline$f_{r}(\mathrm{psi})$ & 41 \\
\hline$V_{m}(\mathrm{psi})$ & 88.81 \\
\hline$E_{m}(\mathrm{ksi})$ & 883.4 \\
\hline$P_{p s}(\mathrm{lb})$ & 20,500 \\
\hline$E_{s}(\mathrm{ksi})$ & 28,500 \\
\hline
\end{tabular}

Seismic Performance of Unreinforced Masonry Walls Retrofitted with Post-Tensioning Tendons 
Table E: Design Parameters

\subsection{Development of Equivalent Lateral Force}

This design is developed based on the equivalent static force procedure outlined in ASCE 7-05 Section 12. The site in downtown San Luis Obispo had the parameters in Table F below.

\begin{tabular}{|c|r|}
\hline Site Class & $\mathrm{E}$ \\
\hline$S_{D S}=$ & 0.864 \\
\hline$S_{D 1}=$ & 0.960 \\
\hline$I$ & 1.25 \\
\hline
\end{tabular}

Table F: Seismic Parameters

Site Class E was chosen to reflect the soft clay soil found in downtown San Luis Obispo. An importance factor of 1.25 was chosen to reflect a structure having potential historic significance. A ground acceleration $C_{s}$ is generated for the out-of-plane design of walls in accordance with ASCE 7-05 Section 12.11.1 as follows:

$$
C_{s}=0.4 \cdot S_{D S} \cdot I=0.432
$$

Eq. 4

This base shear coefficient is multiplied by the weight of the wall panel tributary to one PT tendon to determine the out-of-plane base shear seen by one wall panel. For this project, the wall density $\left(\mathrm{lb} / \mathrm{ft}^{3}\right)$ was determined by weighing prism samples before testing for compressive strength. The panel base shear is then converted into a uniform distributed load $w_{u}$ that will be applied to the panel:

$$
w_{u}=\gamma \cdot C_{s} \cdot\left(\frac{d_{y}}{12}\right) \cdot b=148 p l f
$$

Eq. 5 
Based on a pin-pin height of $11^{\prime}$, this demand results in a strength-level demand moment $M_{u}$ of

$$
M_{u}=w_{u} \cdot h_{w}^{2} / 8=2,240 l b \cdot f t
$$

Eq. 6

Finally, the shear demand at the top and the bottom of the wall panel is given by

$$
V_{u}=w_{u} \cdot h_{w} / 2=814 l b
$$

\subsection{Unreinforced Wall Subject to the Design-Level Ground Motion}

In order to establish a basis for comparing the retrofitted wall to an unreinforced wall also constructed of vintage brick and mortar, the cracking moment capacity of the URM wall panel is calculated. The following calculations consider strength-level demands and the unadjusted, predicted strength capacities of the wall. Assuming a linear stress-strain relationship and using basic mechanics of materials, the cracking moment capacity of the unreinforced section is found as follows:

$$
M_{c r}=\frac{I_{n}}{c}\left[f_{r}+\left(\frac{P_{s w}}{A_{n}}\right)\right],
$$

where $c$ is half $d_{y}$, and

$$
P_{s w}=\left(\frac{1}{2}\right) \gamma \cdot h_{w} \cdot\left(\frac{d_{y}}{12}\right) \cdot b=1,886 l b
$$

Thus, the cracking moment capacity of the unreinforced section is

$$
M_{c r}=1,874 \mathrm{lb}-\mathrm{ft} .
$$


Comparing this capacity with the demand moment in Equation 6 reveals that the URM wall does not have sufficient strength to resist the design-level earthquake elastically. This cracking moment capacity corresponds to a uniform distributed load of $124 \mathrm{lb} / \mathrm{ft}$ and a ground acceleration $C_{s}$ of $0.362 \mathrm{~g}$, which is lower than that of the design-level ground motion. Furthermore, the allowable moment capacity of the unreinforced section will ultimately be lower than the value presented here due to safety factors. This means that the URM wall is even less adequate to resist the forces associated with the design-level ground motion. The pre-retrofitted wall is therefore considered slender $(h / t>13)$ and structurally too weak to resist the expected design-level ground motion. Out-of-plane retrofit is required and will be accomplished by introducing post-tensioning to the URM wall.

\subsection{Out-of-Plane Analysis and Retrofit Design}

This section covers the preliminary design process for an out-of-plane PT retrofit solution for the wall established previously. Predictions are made as to the retrofitted wall's ultimate moment capacity that will be compared to test results.

\subsubsection{Initial Tendon Stress}

Since the goal of the retrofit design is to reflect a wall incorporating tendons spaced at regular 6'-0" intervals, initial prestress levels had to be proportioned for the width of the tested wall since it was only $3^{\prime}-6^{\prime \prime}$ wide. In accordance with provision 4.3.2 of the 2005 MSJC, the target design-stress for the inserted tendon was considered to be no more than $82 \%$ of $f_{p y}$. This value was proportioned based on the tested wall width 
divided by the desired tendon spacing of 6'-0", giving a target initial stress level of 118 ksi. This initial stress translates to a target tendon force of 18.4 kips for the 5-brick-wide test wall. Due to the limitations of the stressing equipment on-hand, the initial prestress in the tendon ended up being 20.7 kips. After all losses over a period of 7 days, the force in the PT tendon stabilized at 20.5 kips. This value represents an initial prestress of 134 ksi that is slightly higher than the target stress for the tested wall. In order to properly compare design predictions to laboratory testing results, an initial prestress of 20.5 kips was considered for design. An actual retrofit design would consider an initial prestressing tendon stress of $118 \mathrm{ksi}$.

\subsubsection{Transfer of Prestress Force to Wall and Initial Masonry Axial Stress}

Steel plating is used at the anchorage points of the PT tendon in order to transfer the tendon force to the wall. Steel plates are inserted and leveled using a layer of grout at the top and bottom anchors, as previously discussed in Section 1.1 and shown in Section 6.3.7 following. It is important to size the metal plating so that the induced axial stresses in the wall are minimal and conform to Section A108.3 of the IEBC. Section A108.3 of the IEBC states that any axial load increase on an existing URM wall shall not exceed 300psi. This provision includes any axial stresses placed on the wall from the PT tendon. If a $3 / 4 "$ thick plate $8 " \mathrm{x} 16^{\prime \prime}$ is used at the PT anchor points, the corresponding axial load from post-tensioning is 160 psi, which meets this requirement. Since this stress occurs at the location of zero moment in the wall, the stress at the center of the wall is used when checking the interaction of bending and axial stresses per Equation 2-10 of the MSJC. Thus, the stress at mid-height of the wall is found by dividing the PT force by the wall's 
net area. The axial stress at mid-height $\left(f_{a}\right)$ is 58 psi. A thick plate should be used to eliminate the possibility of local deformations in the steel plate.

It is important to note at this point that Section 4.4.1.2 of the MSJC allows for a 20 percent increase in the allowable bearing stress of the masonry when post-tensioning is used. The allowable bearing stress for this design is computed below only to show that the PT force does not exceed stress levels permitted by the MSJC. For walls with $h / r$ less than 99, the allowable bearing stress (increased for the use of PT tendons) is given by Equation 2-12 of the MSJC as

$$
F_{a}=1.2 \cdot\left(\frac{1}{4}\right) f^{\prime}{ }_{m}\left[1-\left(\frac{h}{140 r}\right)^{2}\right]=378 \text { psi }
$$

Thus, the use of PT tendons to retrofit a URM wall does not violate allowable axial stress levels permitted by the code.

\subsubsection{Cracking Moment Capacity}

Once a tendon spacing and initial stress has been selected, the cracking moment capacity of the retrofitted wall is computed. Assuming a stress distribution shown in Figure K (a) and using Equation 1 as discussed in Section 3.3.2, the cracking moment capacity of the retrofitted wall can be found as

$$
M_{c r}=\frac{I_{n}}{c}\left[f_{r}+\left(\frac{P_{u}+P_{s w}+A_{p s} f_{s e}}{A_{n}}\right)\right]=4,228 \mathrm{lb} \cdot f t
$$

To put this value in perspective, the cracking moment capacity corresponds to a $C_{s}=$ $0.815 \mathrm{~g}$, or roughly twice the design-level ground motion demand. 
At this event, it is appropriate to check the corresponding stresses in the wall resulting from the induced cracking moment. The maximum compressive stress in the wall at this point results from the addition of bending stress from the out-of-plane loading, and the axial stress from the PT tendon and wall self-weight. Since the section is still considered to be in the elastic range, the bending stress can be taken as $M_{c}$ divided by the section modulus $S$. This computation results in a bending stress equal to 105 psi. Thus, the total axial stress in the wall upon reaching the cracking moment is $163 \mathrm{psi}$, when the axial stress from the PT tendon is included at mid-height. If the maximum allowable stress is considered to be one third of $f^{\prime}{ }_{m}$ as prescribed in Section 2.3.3.2.2 of the MSJC, it becomes clear that the wall is not compromised in terms of allowable compressive strength. This allowable stress is found to be 421 psi, or roughly 2.6 times larger than the demand stress at this stage.

\subsubsection{Hinging and Nominal Moment Capacity Predictions}

This section predicts the flexural strength of the retrofitted wall at events beyond initial cracking using studies discussed in the literature review and the MSJC. The formation of the plastic hinge occurs as the extreme compressive fiber of the crosssection reaches its crushing strain. At this stage, a stress distribution like the one in Figure K (b) exists at the location of maximum moment. The moment capacity at the formation of the plastic hinge (onset of crushing) is predicted by Equation 2 and can be computed as

$$
M_{h}=\left(P_{s w}+A_{p s} f_{s e}\right)\left(d_{y}-\frac{\left(2 P_{s w}+A_{p s} f_{s e}\right)}{3 \lambda_{h} f_{m}^{\prime} b}\right)=6,180 \mathrm{lb} \cdot f t
$$

Seismic Performance of Unreinforced Masonry Walls Retrofitted with Post-Tensioning Tendons 
where, as previously discussed, $\lambda_{h}=0.5$.

The hinging moment capacity corresponds to a uniform distributed load $w_{u}$ of $409 \mathrm{lb} / \mathrm{ft}$ and a $C_{s}$ of $1.19 \mathrm{~g}$. This capacity represents a strength level 2.76 times greater than the demand of the design-level ground motion.

The ultimate (nominal) flexural strength of the wall can be predicted using the MSJC provisions for prestressed masonry. This event has a stress distribution shown in Figure K (c) and represents the complete development of the plastic section. At this point, every fiber in the compression block has reached the crushing strain of the masonry. Any additional load beyond this point is characterized as failure and is representative of complete crushing of the mortar and/or brick. Section 4.4 .3 of the MSJC contains provisions for the computation of the nominal strength of a prestressed masonry wall. This approach is used here and results in the same moment capacity as presented in Equation 3 and Section 3.3.2 of this report. Both methods assume the same stress distribution previously discussed.

Equations 4-1 and 4-2 of the MSJC result in the nominal moment capacity of a prestressed, or in this case post-tensioned, masonry wall. The same equations are used here to predict the nominal strength of the tested wall. Reduction factors are not considered, and the actual properties of the tested wall are used as follows:

$$
M_{n}=\left(P_{s w}+A_{p s} f_{s e}\right)\left(d_{y}-\frac{a}{2}\right)
$$

where $a$ represents the depth of the compression block shown in Figure K (c), and is given by; 


$$
a=\frac{f_{p s} A_{p s}+P_{s w}}{0.8 f^{\prime}{ }_{m} b}
$$

Thus, inserting for known values in Table $\mathrm{E}$, the depth of the compression block is found as

$$
a=0.519^{\prime \prime}
$$

and the nominal moment capacity of the wall in the out-of-plane direction is found to be

$$
M_{n}=6,620 \mathrm{lb}-\mathrm{ft}
$$

$M_{n}$ represents the theoretical flexural capacity of the wall section and corresponds to a uniform distributed load of $438 \mathrm{lb} / \mathrm{ft}$ and a $C_{s}=1.28 \mathrm{~g}$. Thus, the flexural capacity of the URM wall retrofitted with post-tensioning tendons represents a strength level roughly 2.95 times larger than that required to resist the design-level ground motion for this site in San Luis Obispo.

\subsubsection{Shear and Deflection Estimates}

Section A108.2 of the IEBC provides for the computation of masonry shear strength $V_{m}$. The equations presented in this section for determining this property are empirical and are based on a variety of parameters including masonry compressive strength $f^{\prime}{ }_{m}$ and amount of axial load. The addition of axial load from post-tensioning increases the frictional shear capacity of the wall significantly. In this project, the shear strength of the wall was controlled by the masonry compressive strength $f^{\prime}{ }_{m}$ and was $V_{m}=$ 89 psi. This correlates to a shear strength $V_{n}=31,250 \mathrm{lb}$ when multiplying $V_{m}$ by the wall's net area. The maximum shear force occurring at either support of this wall results at the onset of the ultimate moment capacity, and is equal to 2,408 $\mathrm{lb}$. Since the failure 
mode of this wall is governed by flexure, it is acceptable to not consider the potential for shear failure.

It proves much more difficult and speculative at this point to predict the ultimate deformation capability of this retrofit wall system. Of course, the displacement of the wall at the cracking moment is easily computed using fundamental beam theory. While the section remains elastic, the displacement can be computed using the following equation:

$$
\delta=\frac{5 w h_{w}{ }^{4}}{384 E I}
$$

Using this equation, the displacement at the onset of the cracking moment is computed to be $\delta_{c r}=0.052^{\prime \prime}$.

If considering this retrofit from a strength-based design approach, an estimate of the displacement of the wall at its nominal capacity can be made. Such an approach would consider the maximum usable compressive strain of masonry $\left(\varepsilon=\varepsilon_{m u}=0.0035^{\mathrm{in}} /\right.$ in $)$ as is permitted using Chapter 3 of the MSJC. With an assumed plastic hinge length and a strain configuration similar to Figure $\mathrm{P}$ on the next page, the displacement of the wall at nominal strength could be estimated. Of more importance to this project, however, is the ultimate displacement of the wall. This ultimate displacement state considers the maximum compressive strain achievable before rupture. This strain will inherently be larger than the maximum allowable strain prescribed in the MSJC for design purposes. The strain diagram like the one shown in Figure Q is assumed when the section reaches its ultimate capacity. At this stage however, $\varepsilon$ is not taken equal to $0.0035^{\text {in }} /$ in. To select Seismic Performance of Unreinforced Masonry Walls Retrofitted with Post-Tensioning Tendons 
a suitable ultimate strain of the masonry, Stress-Strain plots created for clay brick masonry by Kaushik et al. (2007) are consulted.

Masonry prism samples from Kaushik were composed of clay brick units and lime mortar joints, having an average compressive strength $f_{m}^{\prime}=1000$ psi. A plot of the Stress-Strain data for this material from Kaushik is given below in Figure P. Figure P (a) reveals the average Stress-Strain plot for a sample of bricks, mortar cubes, and masonry prisms. Figure P (b) reveals the Stress-Strain plots for masonry prisms of different mortar mixes. The masonry prism of interest to this project used mortar with a $1: 0.5$ : 4.5 ratio of cement : lime : sand. This mix is similar in composition and had a compressive strength close to that of the $1: 1: 9$ mortar mix used in this project.

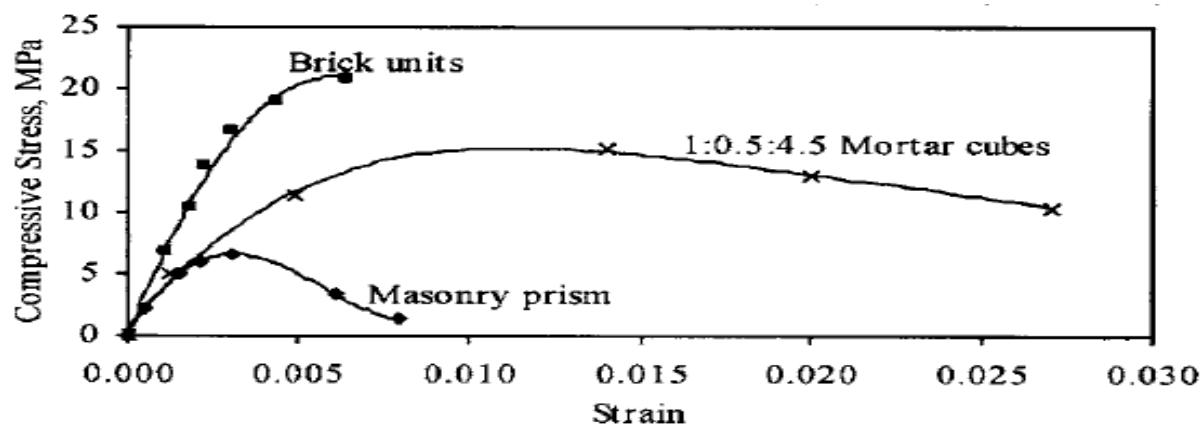

(a)

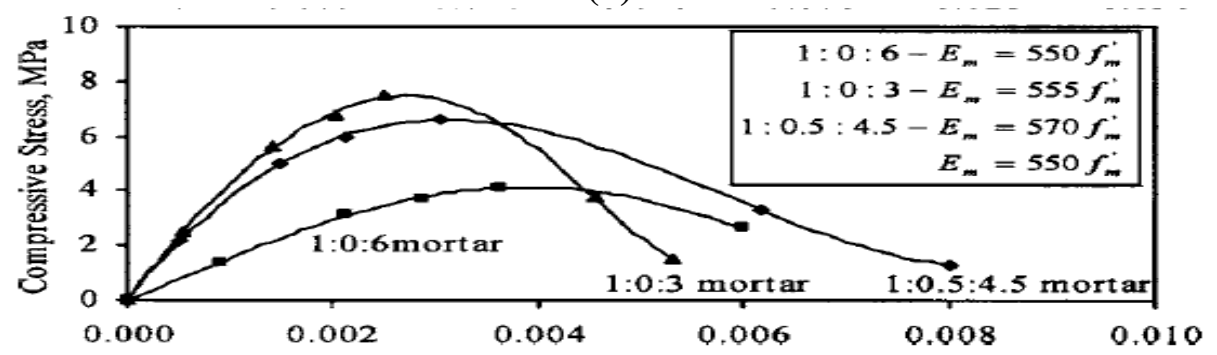

(b)

\section{Figure P: Stress-Strain Diagram for URM Test Samples}

Source: Kaushik et al. 2007 
The ultimate strain obtained through compressive testing is shown above and ranged between $0.007^{\mathrm{in}} /$ in and $0.011^{\mathrm{in}} /$ in for the prisms using a $1: 0.5: 4.5$ mortar mix. Based on additional testing data by Kaushik, it was determined that mortar mixes using a higher cement content ultimately failed at lower strain levels. Mortars that used relatively more lime and sand than cement achieved ultimate strains larger than specimens with higher cement contents. The disadvantage of these mixes is their relatively low compressive strength. Based on this testing data, an average maximum strain for the wall in this thesis project was taken as $0.0045 \mathrm{in} / \mathrm{in}$. This value is slightly larger than that presented for the specimen in Figure $\mathrm{P}$ because the specimen in Figure $\mathrm{P}$ has twice the cement content of the mortar used in this project. Since the strain profile shown in Figure Q is linear, an average cross-sectional strain of $0.0045^{\text {in }}$ in results in a maximum strain of twice $0.0045^{\mathrm{in}} /$ in or $0.009^{\mathrm{in}} /$ in in the extreme fiber of the compression block.

These strain levels are much larger than those typically used in the design of unconfined concrete. These values are considered acceptable for this project however because material crushing is restricted to the mortar joints. Brick units themselves continue to remain elastic after mortar joints have begun to crush. Thus, it is not likely that large amounts of mortar will spall from mortar joints until very large rotations are reached. Because mortar does not immediately spall from the cross-section upon crushing, the cross-section continues to resist load (after the peak load has been reached). Thus, URM sections with low cement contents can potentially reach larger strains after achieving their peak compressive stress when compared to unconfined concrete sections. 
Consequently, the Stress-Strain relationship at the wall's cross-section is shown in Figure Q and was assumed using an extreme fiber strain of $0.009 \mathrm{in} /$ in.

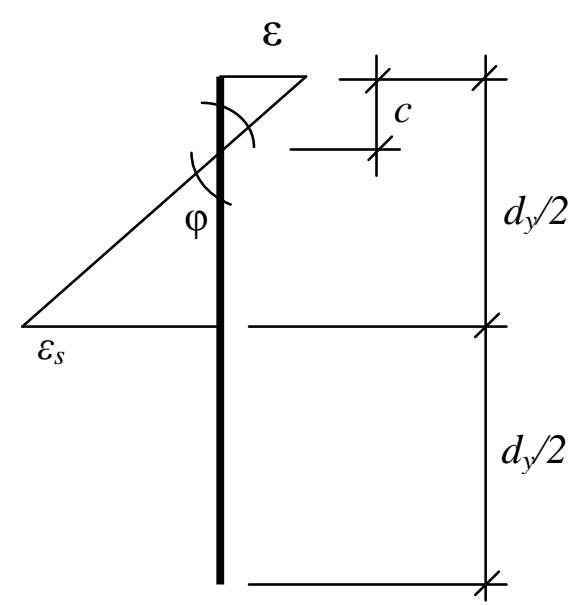

(a)

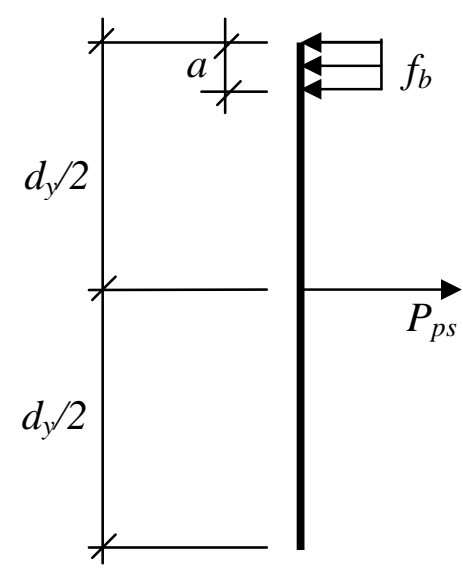

(b)

\section{Figure Q: Strain (a) and Stress (b) Profile at Ultimate Capacity}

Using this strain profile, the curvature at the expected ultimate strength can be defined as

$$
\begin{gathered}
\varphi=\frac{\varepsilon}{c}=\frac{0.009}{0.611^{\prime \prime}}=0.016 \mathrm{rad} / \mathrm{in}, \\
c=\frac{a}{\lambda_{h}}=\frac{0.519^{\prime \prime}}{0.85}=0.611 \mathrm{in} .
\end{gathered}
$$

$\lambda_{h}$ is previously discussed in Section 3.3.2 and is the stress block parameter used at the nominal strength capacity of the wall. Next, a plastic hinge length must be assumed. In this case, a plastic hinge length was selected based on visual inspection of the tested wall after it reached nominal capacity. With multiple future tests, a range for the plastic hinge length for this type of wall can be established for use in future retrofit designs. Figure JJ in Section 7.5 reveals that mortar above and below two brick courses crushed upon 
reaching the wall's nominal strength. An appropriate plastic hinge length reflecting this pattern of crushing is diagrammed in Figure $\mathrm{R}$ below.

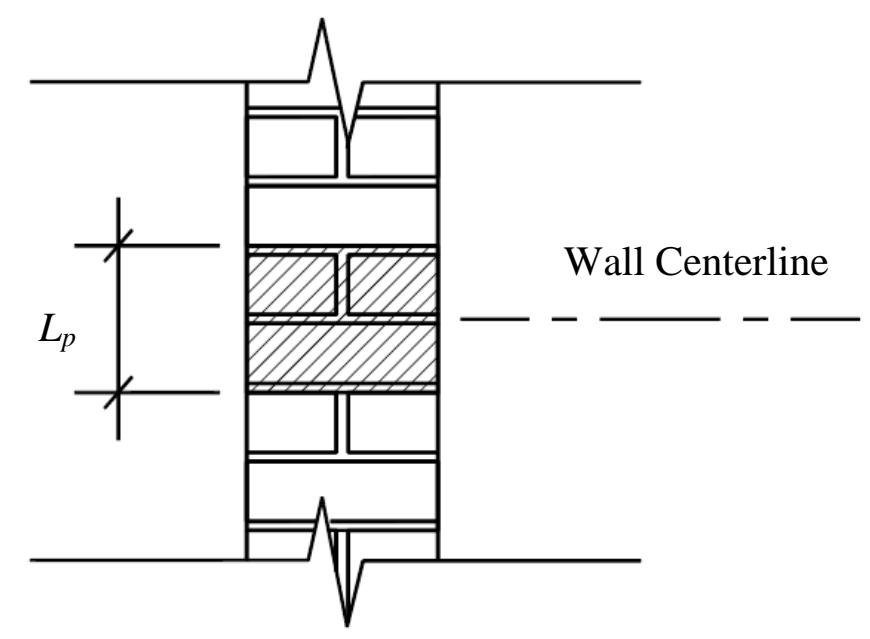

Figure R: Assumed Plastic Hinge Length

The plastic hinge length $L_{p}$ for these predictions thus becomes 2 bricks at $21 / 2$ " each, plus 3 mortar joints at $1 / 2^{\prime \prime}$ each, for a total of $6 \frac{1}{2} 2^{\prime \prime}$. At this point, the total rotation of the wall that occurs at this plastic hinge is calculated as follows:

$$
\theta=\varphi \cdot L_{p}=0.105 \mathrm{rad}
$$

This rotation $\theta$ is twice the rotation that occurs at either restraint of the wall because it is the total rotation the wall undergoes at this ultimate state. Therefore, if the wall is assumed to deform as two rigid bodies hinging at mid-height, the mid-height displacement corresponding to this event can be computed as follows in Equation 19. This plastic deformation is then added to the elastic deformation previously computed to give the ultimate displacement prediction: 


$$
\delta_{u}=\left(\frac{\theta}{2}\right) \cdot\left(\frac{h_{w} \cdot 12}{2}\right)+\delta_{c r}=3.497^{\prime \prime}+0.052^{\prime \prime}=3.549^{\prime \prime}
$$

This ultimate strain-based approach results in a more realistic estimate for the ultimate displacement capacity of the retrofitted wall. This approach also suggests that the retrofit has the potential to provide much more ductility to the wall by increasing ultimate displacement capacity. Ultimately, however, further material testing on the URM used in this project would offer a better understanding of the ultimate strain state of the material. The predictions made in this section are related to testing results in Section 7.5 and further discussed in Section 8.1.

\subsubsection{Elongation of Post-Tensioning Tendon}

Based on the predicted rotation at the restraint of the wall found previously, predictions regarding the elongation of the post-tensioning tendon can be made. Using the geometry shown in Figure $S$ on the next page, the length of the tendon at the predicted displacement of $\delta_{u}$ can be found. Once the total tendon length is found with the wall deformed to $\delta_{u}$, the elongation of the tendon in the displaced configuration can be computed. This model, however, does not account for vertical shortening in the wall resulting from spalling of mortar from mortar joints. Realistically, the wall shortens slightly at this deformation state. Observations of testing data reveal that shortening did occur. 


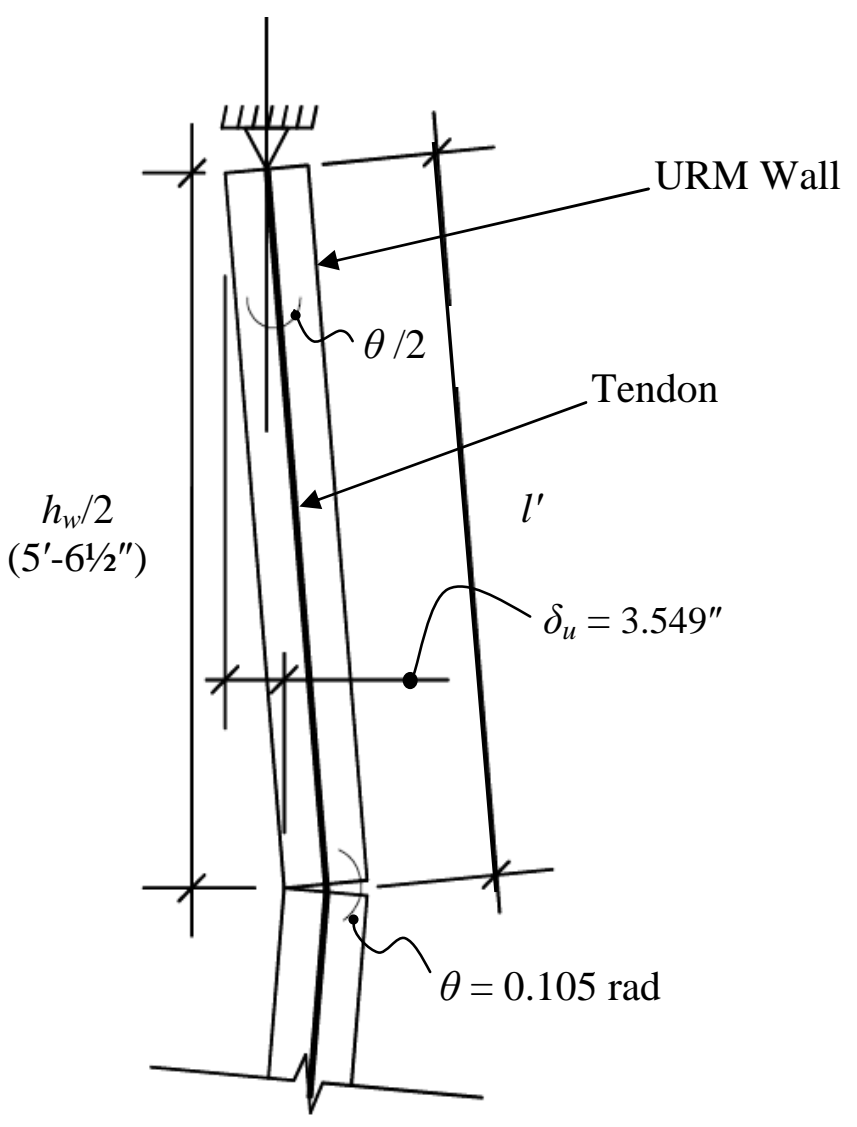

Figure S: Wall Geometry at Predicted Ultimate Displacement

Using Figure $\mathrm{S}$ as a reference, the length $l^{\prime}$ can be computed using geometry:

$$
l^{\prime}=\sqrt{\left(h_{w} / 2\right)^{2}+\left(\delta_{u}\right)^{2}}=66.595^{\prime \prime}
$$

$l^{\prime}$ represents half the tendon length in the deformed configuration. Thus, the initial tendon length of $11^{\prime}-1^{\prime \prime}$ (or 133") subtracted from twice $l^{\prime}(133.189 ")$ results in the predicted tendon elongation at the wall's mid-height displacement of $\delta_{u}=3.549^{\prime \prime}$. The tendon elongation is thus $\delta_{P T}=0.189^{\prime \prime}$. Since the tendon is elastic at this point, the force 
increase in the tendon in this deformed shape can be found using the principles of engineering mechanics:

$$
\delta=\frac{P l}{A_{p s} E_{s}} \quad \text { or } \quad P_{\text {increase }}=\frac{\delta_{P T} \cdot A_{p s} E_{s}}{l}
$$

Inserting known values and the recently computed $\delta_{P T}$ into Equation 21 gives $P_{\text {increase }}=$ 6.20 kips. Thus, at 3.549" of mid-height wall displacement, it is predicted that the tendon will experience an increase of 6.20 kips in force, or a 30 percent increase from its initial force of 20.5 kips.

\subsubsection{Proposed Tendon Anchorage Detail}

Due to variability in the foundation conditions of URM walls, different posttensioning anchorage solutions may be necessary in this retrofit. As part of the design of this retrofit, tendon anchorage configurations were developed. Figure T on the following page illustrates potential anchorage configurations for this retrofit design.

Seismic Performance of Unreinforced Masonry Walls Retrofitted with Post-Tensioning Tendons 


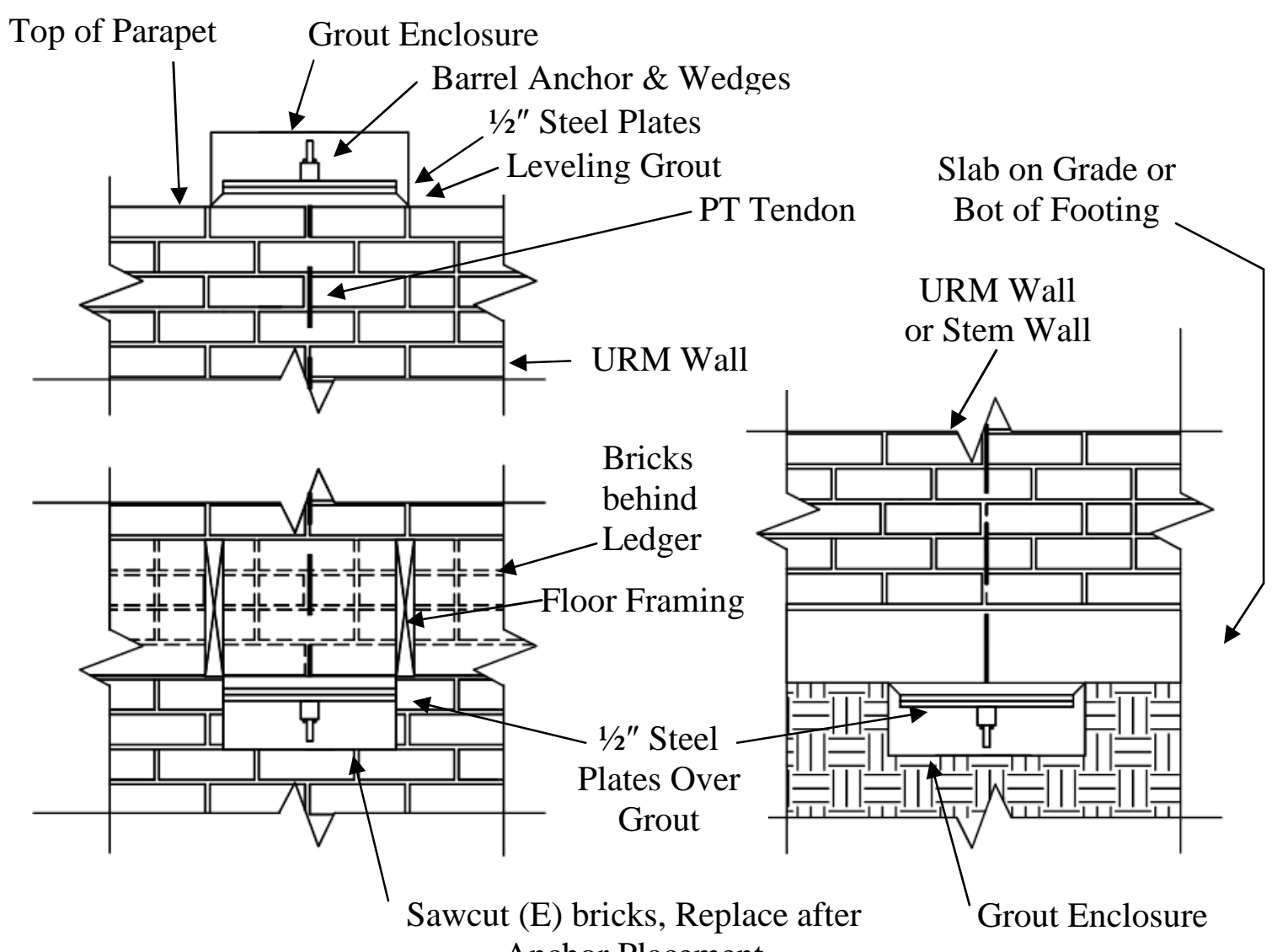

Anchor Placement

(a)

(b)

Figure T: Retrofit Anchorage Details

Option (a) in Figure T represents an anchorage solution for a wall that is to be restrained at its lower diaphragm. This may be the desired approach for the tendon anchorage if the wall rests on a brick stem wall. This detail may also be preferred if the condition of the stem wall is unknown or if the stem wall is not accessible. In this configuration, the wall is sawcut at the location where the steel plating is inserted. Steel plating is placed on top of non-shrink grout to allow for a smooth load-spreading surface. The PT tendon itself anchors to the steel plating by means of a barrel anchor and wedges. A similar setup is used at the top of the wall's parapet. After the tendon is tensioned, the 
cavity at the base of the wall can be grouted closed, or bricks can be trimmed and put back into their original position. At the top of the wall, the steel anchorage system is enclosed in grout to protect it from wear and corrosion.

The retrofit configuration shown in Figure $\mathrm{T}(\mathrm{b})$ presents an option for retrofitting a wall that sits on a slab-on-grade or concrete footing. Efforts must be taken in order to secure the existing footing or slab on grade prior to excavation. Temporary bracing may have to be incorporated to prevent any undermining of the foundation. Soil should only be excavated at the location of the tendon anchors, no more so than required to insert steel plating. Steel plating is then placed similar to the previous configuration. In this fashion, the tendon anchorage compresses the bottom of the slab-on-grade or footing. After the tendon is stressed and locked off, the cavity at the base can be grouted closed to protect the steel anchorage. These details represent some possible options for the successful implementation of an out-of-plane post-tensioning retrofit for URM walls and should be developed through further testing. 


\subsection{RETROFITTED WALL TEST}

This section describes the testing that was conducted to prove the viability of an out-of-plane post-tensioning retrofit for URM walls. An unreinforced masonry wall was constructed using brick from the early 1900s and a mortar mix design reflective of early $20^{\text {th }}$ century URM wall construction. The wall was retrofitted with a post-tensioning tendon, and loaded in the out-of-plane direction. Data was collected so that the wall's response to loading could be well quantified.

\subsection{Wall Configuration}

This section discusses the physical dimensions of the tested wall, along with material properties and initial tendon stress levels. The wall conforms to the target configuration previously set forth in Section 5.

As mentioned in Section 5.2.2, the testing wall had a width of five bricks, or $3^{\prime}-6 "$. The thickness of the wall throughout was one brick length, and varied between 8 " and 9". This variation in wall thickness resulted from the dissimilarity in brick length and width. The pin-pin height of the tested wall was 11'-1/2", reflecting a story height of between 12 and 14 feet. This extrapolation is made based on the observations discussed in Section 5.2.1. These dimensions correlated to a wall with height-to-thickness ratio $h / t$ of between 18 and 21 .

The wall was constructed of salvaged bricks and contained the low strength mortar previously discussed that was typical of URM buildings constructed around the turn-of-the-century. The material properties of the tested wall are given in Table D in Section 4, and are identical to those used for design of the retrofit system in Section 6. 
As discussed in Section 6.3.1, the initial amount of prestress after losses was $133 \mathrm{ksi}$, which translates to a tendon force of $20.5 \mathrm{k}$. Losses in the prestress tendon were recorded using a load cell from the time of anchorage setting to wall testing. These losses were minor and occurred entirely within 7 days of setting. The amount of prestress in the tendon at each load step during testing was monitored as well. The setup for tensioning of the tendon is shown below in Figure $\mathrm{U}$.

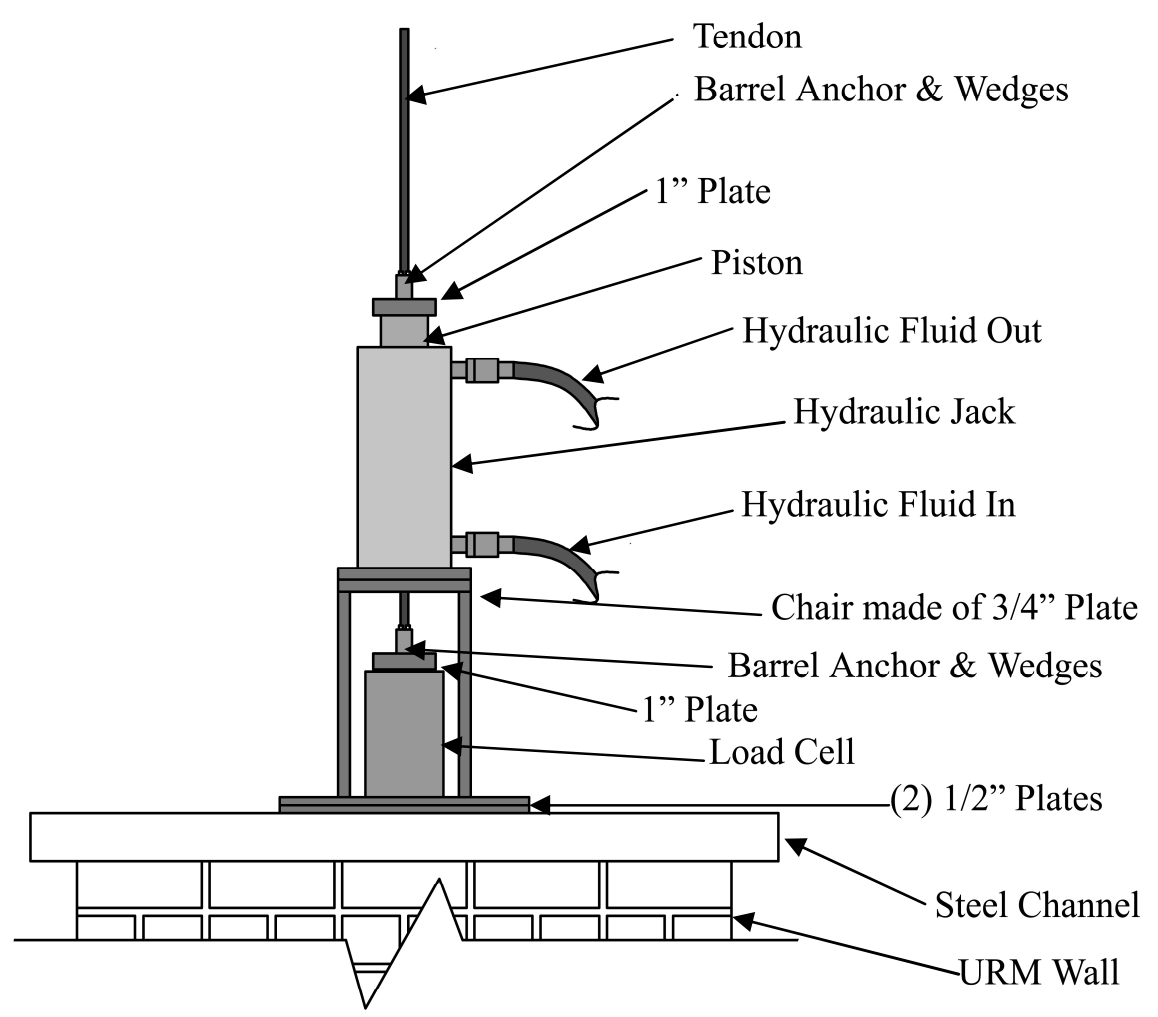

Figure U: Tendon Stressing Apparatus 


\subsection{Wall Construction}

The unreinforced masonry wall used for testing was constructed in the tradition of turn-of-the-century masonry buildings. With the help of a professional mason in San Luis Obispo, the wall was constructed over the span of four weeks. The wall was located inside the High Bay Lab of the Architectural Engineering Department at Cal Poly.

Scaffolding was erected around the wall to aid in the construction process, and to later secure testing instruments. Plumb lines were hung at the corners of the wall, and a level line was hung at the face of the wall to maintain consistency in each brick course. Every three inches was marked on the scaffold where the level line was attached so that each horizontal mortar joint would have identical thickness. Each brick was placed within the guidelines and leveled in each direction. Each course was set by first placing the outer bricks and filling in the remaining space towards the center of the wall. Each course was frequently checked for level in both directions.

A typical work day began by mixing a batch of mortar by hand, as was done in the early 1900's. 5-gallon buckets were marked with the proper proportions of sand, cement, and lime as to eliminate significant variation in mortar strength from batch to batch. Water was added to the mortar batch until the desired level of workability was achieved to the satisfaction of the mason. Mortar was moved from the wheelbarrow where it was mixed onto a mortar board on the scaffold. From there, courses were placed as previously discussed, no more than 12 courses, or 3'-0" per day. Courses were staggered so that there were a minimum number of continuous vertical mortar joints. 
Additionally, bond courses were placed every sixth course. Figure V on the next page shows the setup and construction process of the first half of the wall.

As opposed to coring the wall after construction, the wall was built around the post-tensioning tendon. The tendon was placed inside a flexible conduit roughly $3 / 4$ " in diameter. The conduit and tendon were hung vertically, made plumb and affixed to the scaffold. Bricks had to be cut as necessary so that they could be fit around the conduit and tendon. This was done using a combination of a brick saw and mason's hammer. Building the wall around the tendon in this fashion correlates directly to coring the wall in the manner discussed previously. Since no mortar or brick comes into direct contact with the tendon during construction, the flexible conduit allows the tendon to behave exactly as if it were placed inside a cored cavity. During loading, the tendon comes into contact with the inside of the conduit in the same fashion that it would come into contact with the inner wall of a cored cavity. 


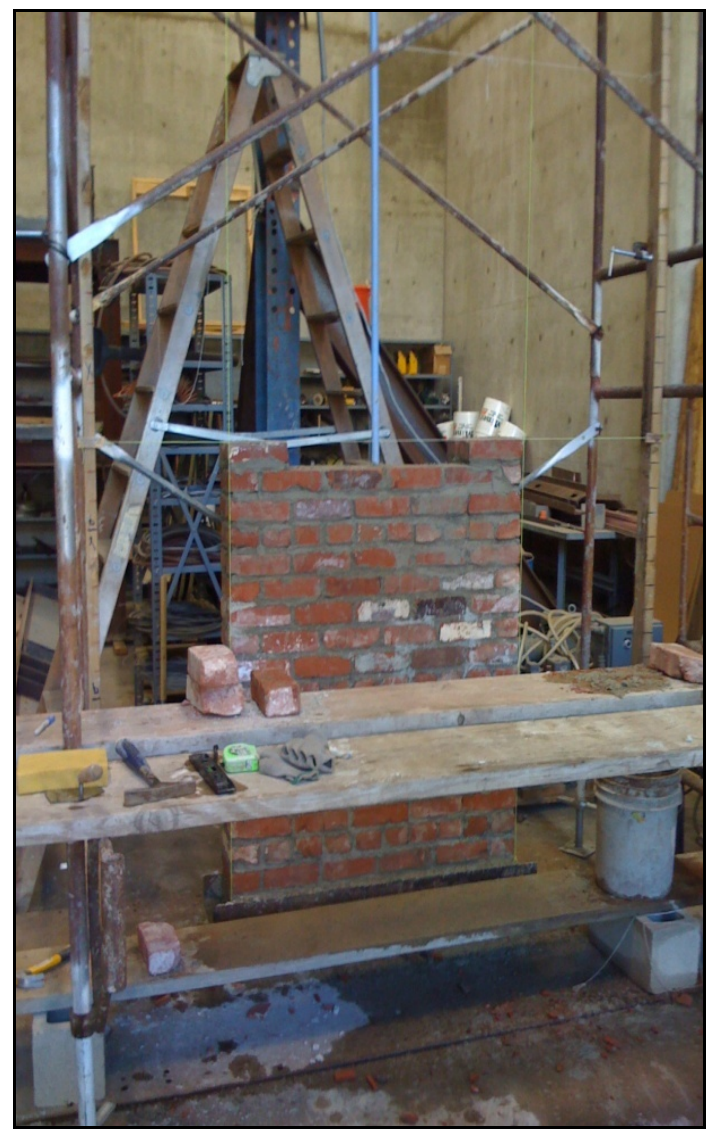

(a)

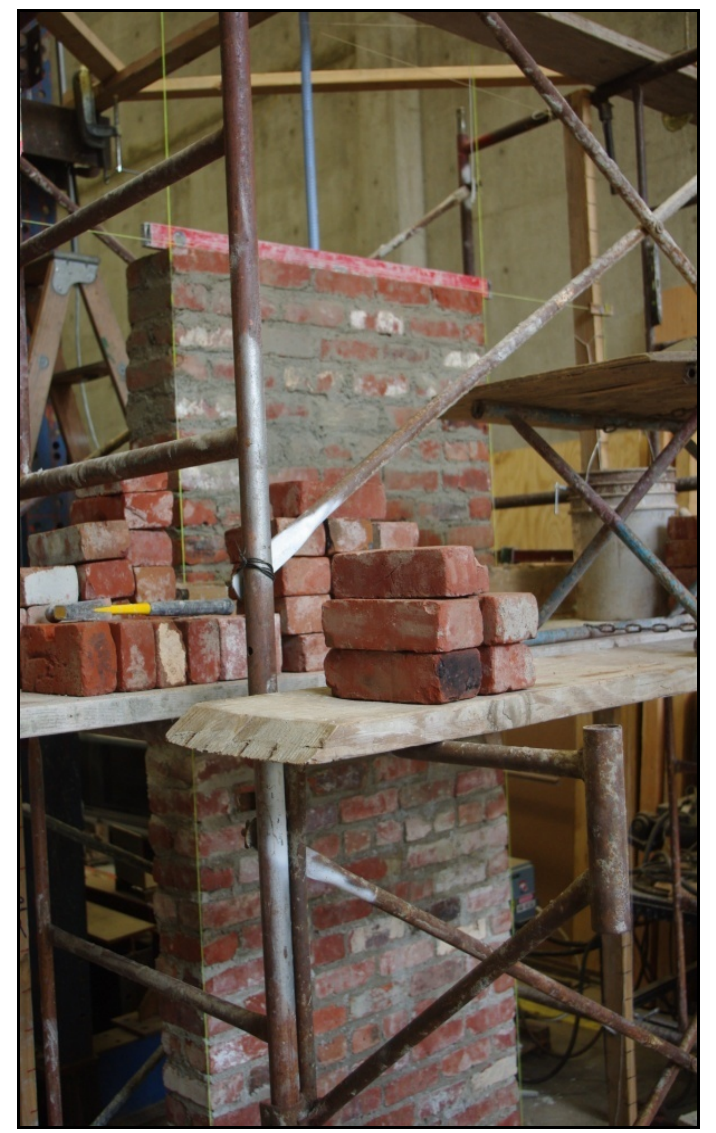

(b)

Figure V: Wall Setup and Construction: (a) First Stage, (b) Second Stage

\subsection{Test Setup}

This section describes the setup of static testing conducted to validate a PT retrofit solution for URM walls.

\subsubsection{Basic Test Setup}

The testing apparatus was designed so that four equal point loads could be applied to the wall in the out-of-plane direction. The test setup is illustrated in Figure W. 


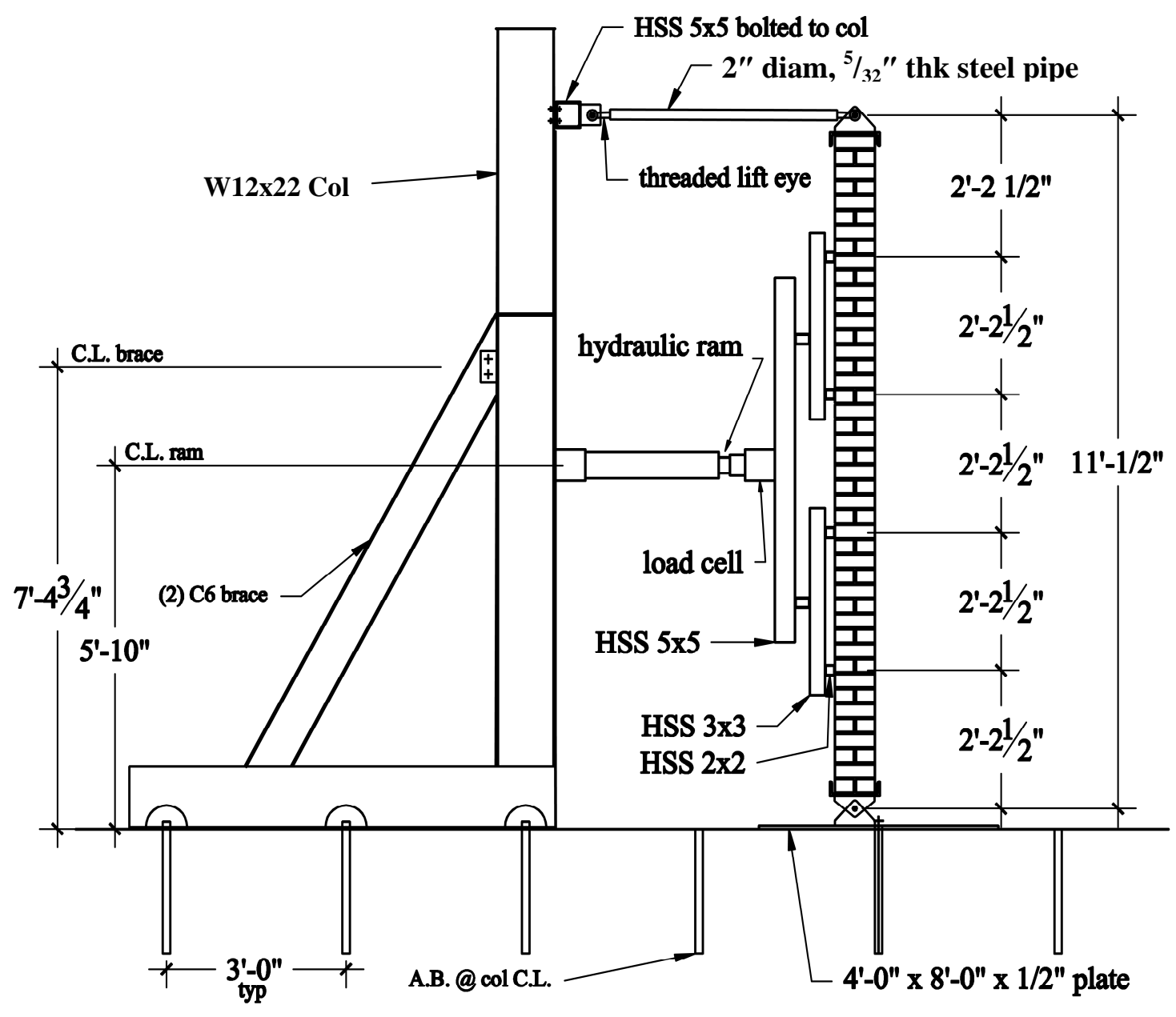

Figure W: Testing Setup- Side Elevation

The braced frame in the testing lab was used as the reaction frame for this test.

The reaction frame is anchored to a reinforced thickened slab at its base. This slab, having anchor points on a 3' square grid, also served to restrain the base of the wall. Anchorages for the wall are discussed in more detail in Section 7.3.2 following.

The load spreading system shown in Figure W above consisted of steel tube sections mounted with hinges to allow for even loading as the wall displaces. Pivoting of the load spreader was successfully achieved in testing (See Figure II in Section 7.5) 
allowing for even loading of the wall. The load spreader was hung from a crane in the laboratory so that it would not come into contact with the instrument frame. Load was applied monotonically through a hydraulic ram bolted to the reaction frame. The hydraulic ram was operated using a hand pump. Load was recorded through a load cell placed on the end of the hydraulic ram in contact with the load spreader.

\subsubsection{Wall Anchorage}

Before the wall could be constructed, anchorages had to be fashioned so that the wall could rotate freely at its base and at its top. These anchors were constructed using simple pins made from 1 " steel plates and greased steel rods. The wall was constructed inside a steel channel so that the first course would not shear off the base anchor.

Elevating the wall off the ground by using pins also allowed for room to anchor the posttensioning tendon at the base. Details of the wall anchorage systems are shown in Figure $\mathrm{X}$ on the next page.

Seismic Performance of Unreinforced Masonry Walls Retrofitted with Post-Tensioning Tendons 


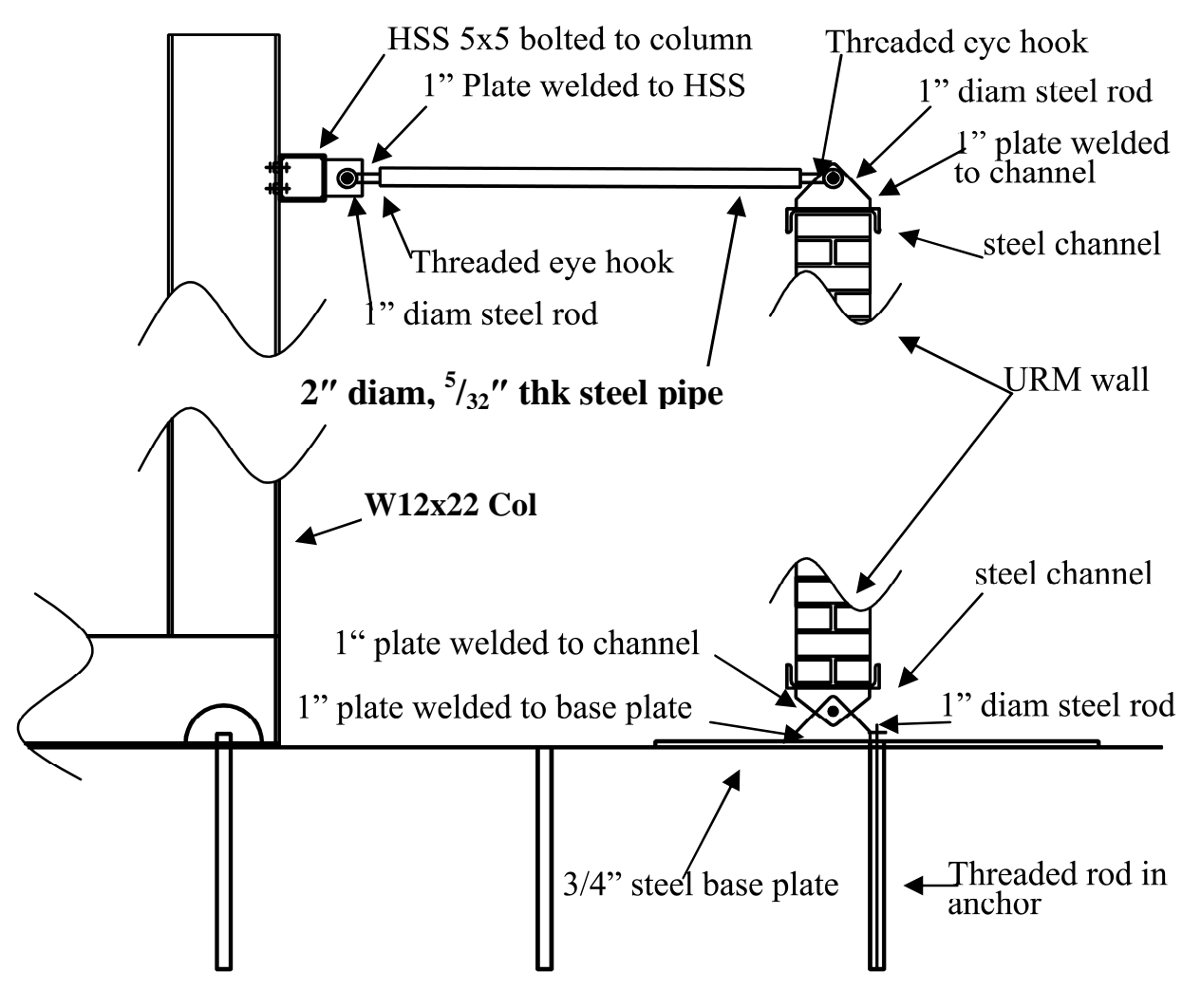

Figure X: Wall Top and Bottom Anchorage Detail

A total of four pin assemblies were used at the base of the wall to adequately transfer the weight of the wall to the floor. These pins were welded to the underside of the steel channel holding the wall and to a base plate at the floor. The base plate was anchored to the foundation at three points. Two pin assemblies were used at the top of the wall because they were only required to transfer half the load placed on the wall to the reaction frame. These assemblies consisted of pins welded to a steel channel affixed to the top of the wall. Eye hooks were threaded into both sides of steel pipe sections to transfer the load from the top of the wall to a horizontal tube section on the reaction frame. Pins were welded to the tube section that was in turn bolted to the reaction frame. 
Inserts were machined to eliminate gaps between the 1" diameter steel rods and the threaded steel eye hooks. This system proved effective in restraining the top and bottom of the wall. Displacements of the anchorage systems proved minor (less than $1 \%$ of the maximum displacement) upon inspection of the testing data.

\subsubsection{Data Acquisition}

A total of 14 channels were used to record displacement and load data from the wall test. All instruments were calibrated by the lab technician prior to being connected to the data acquisition program LabView. The instrumentation on the wall is shown in Figure $\mathrm{Y}$ and Figure $\mathrm{Z}$ following.

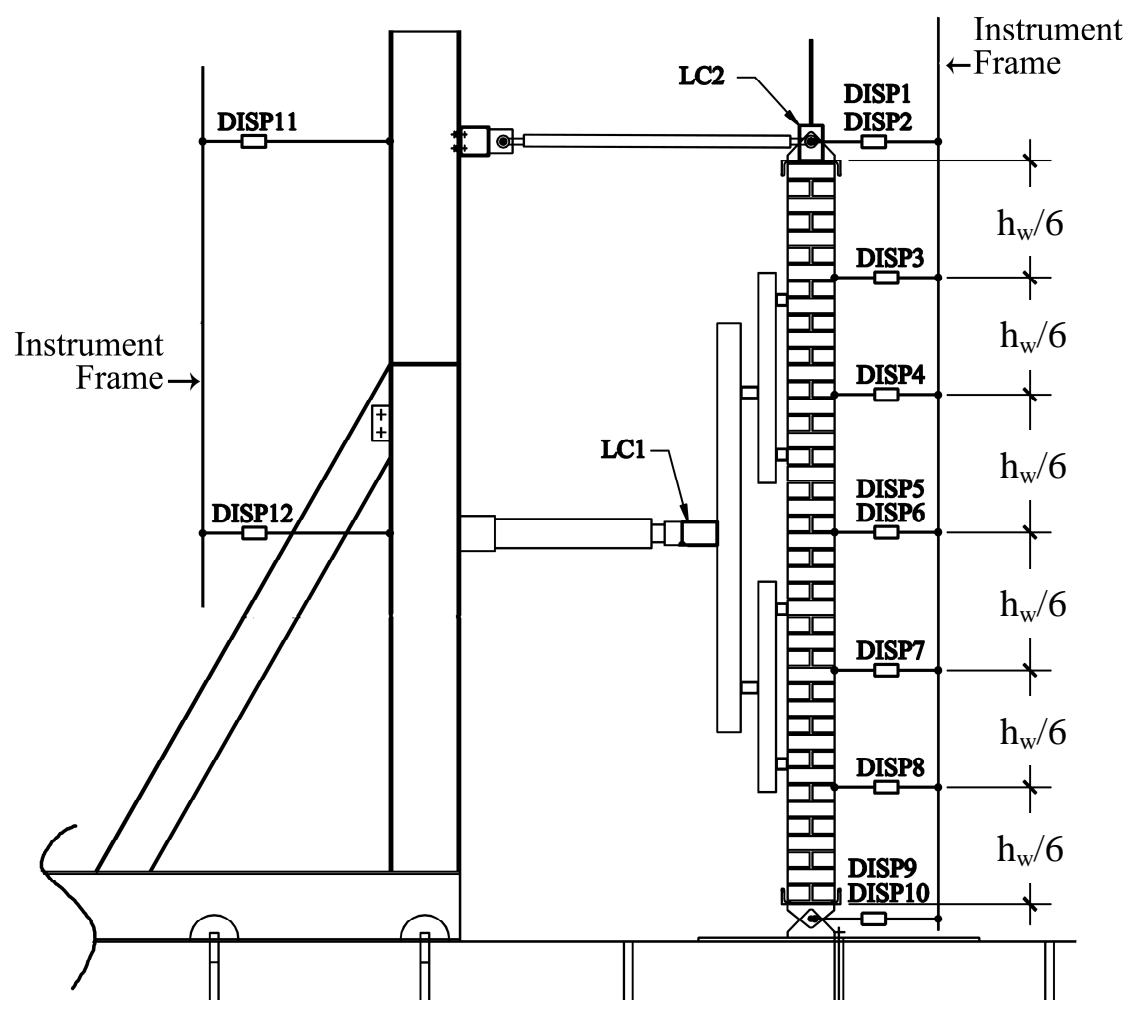

Figure Y: Instrumentation Diagram Side Elevation 


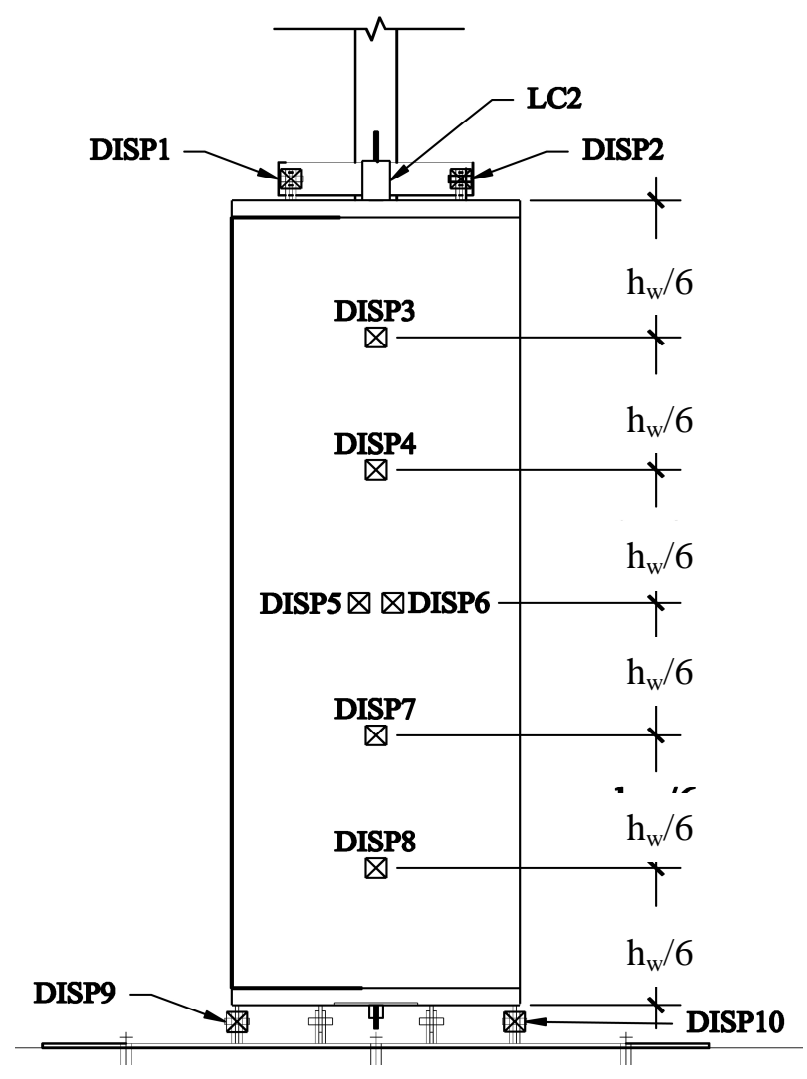

\section{Figure Z: Instrumentation Diagram Front Elevation}

The total lateral force entering the wall was recorded between the hydraulic ram and the steel load spreader through the load cell LC1. This force was then divided into four equal point loads by the steel load spreader. An additional load cell LC2 was located between the tendon anchorage and the top of the wall and thus, provided the force in the post-tensioning tendon. This allowed the change in the post-tensioning force to be monitored during setting of the PT anchorage and throughout the duration of the test.

Displacement gauges were located at the sixth-points on the tension face of the wall. Two pull-string pots each with a displacement range of $20^{\prime \prime}$ and calibrated to an accuracy of $0.001 "$ were placed at the center of the wall. Two displacement gauges 
DISP5 and DISP6 were placed at the center of the wall to ensure no torsion occurred in the wall and to double-up displacement data at this location. All other displacement gauges on the wall itself were located at the wall's centerline. DISP3 and DISP8 each had a 11/2" displacement range, while DISP4 and DISP7 each had a displacement range of 5". Gauges were also placed on the left and right at the top and bottom anchorage of the wall, each having a 1.5" stroke in order to monitor any settling of the wall end restraints. DISP11 and DISP12 each had a 11/2" stroke and were placed on the reaction frame in case it experienced any displacement. This was merely a precaution, and testing proved that there were negligible displacements in the reaction frame at the peak load placed on the wall. These displacements were at most less than $0.005^{\prime \prime}$ compared to upwards of 7 " of wall displacement. Section 7.5 discusses test results in further detail.

Data entries for each channel were recorded simultaneously by clicking a record button on the program interface. In this fashion, many data points were recorded with each load cycle. Data points were easily collected while the hydraulic ram was pumped up by hand and while the pressure was released upon unloading of the wall. Thus, loading and unloading cycles were both captured in the force-displacement plot. The program also consisted of a real-time force-displacement plot so that the behavior of the wall could be better understood during the testing procedure. 


\subsection{Loading History}

The loading history for this test consisted of cycling the wall to either a target force level or to a target displacement two times. After two cycles were achieved at a particular force or displacement level, the wall was unloaded and then pushed to the next target force or displacement. Loading was pseudo-static, incorporating a monotonically increasing load. Displacements above 1 " were achieved at roughly a rate of 1 " per minute. Unloading was slightly quicker due to the nature of the release valve on the hydraulic ram and was thus conducted at roughly 1" every 30 seconds. Figure AA below shows the loading history for this test. The drift of the wall corresponds to the maximum displacement of the wall relative to the wall's pin-pin height.

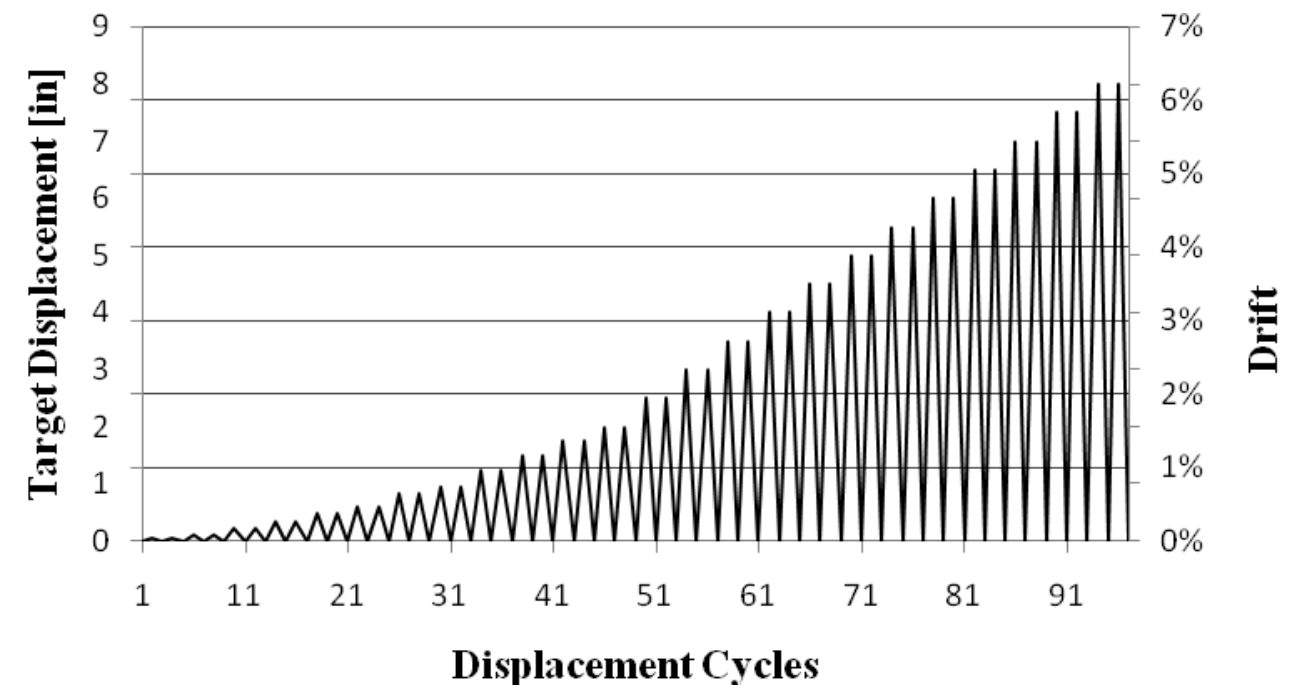

\section{Figure AA: Pseudo-Static Displacement-Controlled Loading History}

While in the elastic and service load level, the wall was cycled to target force levels. These force levels corresponded to the formation of the cracking moment and 
$60 \%$ of the predicted nominal wall strength. Once $60 \%$ of the predicted nominal strength of the wall had been achieved, loading continued based on displacement. At $60 \%$ of the predicted nominal strength of the wall, a displacement of 0.122 " was achieved. The following target displacements were thus $0.244^{\prime \prime}, 0.366^{\prime \prime}$, and so on until 1.000" displacement was reached. From 1.000" to 2.000", target displacements were established every $0.250 "$. Beyond 2.000", targets were established every $0.500^{\prime \prime}$.

\subsection{Test Results}

A plot including every displacement cycle the wall specimen underwent is given below in Figure BB.

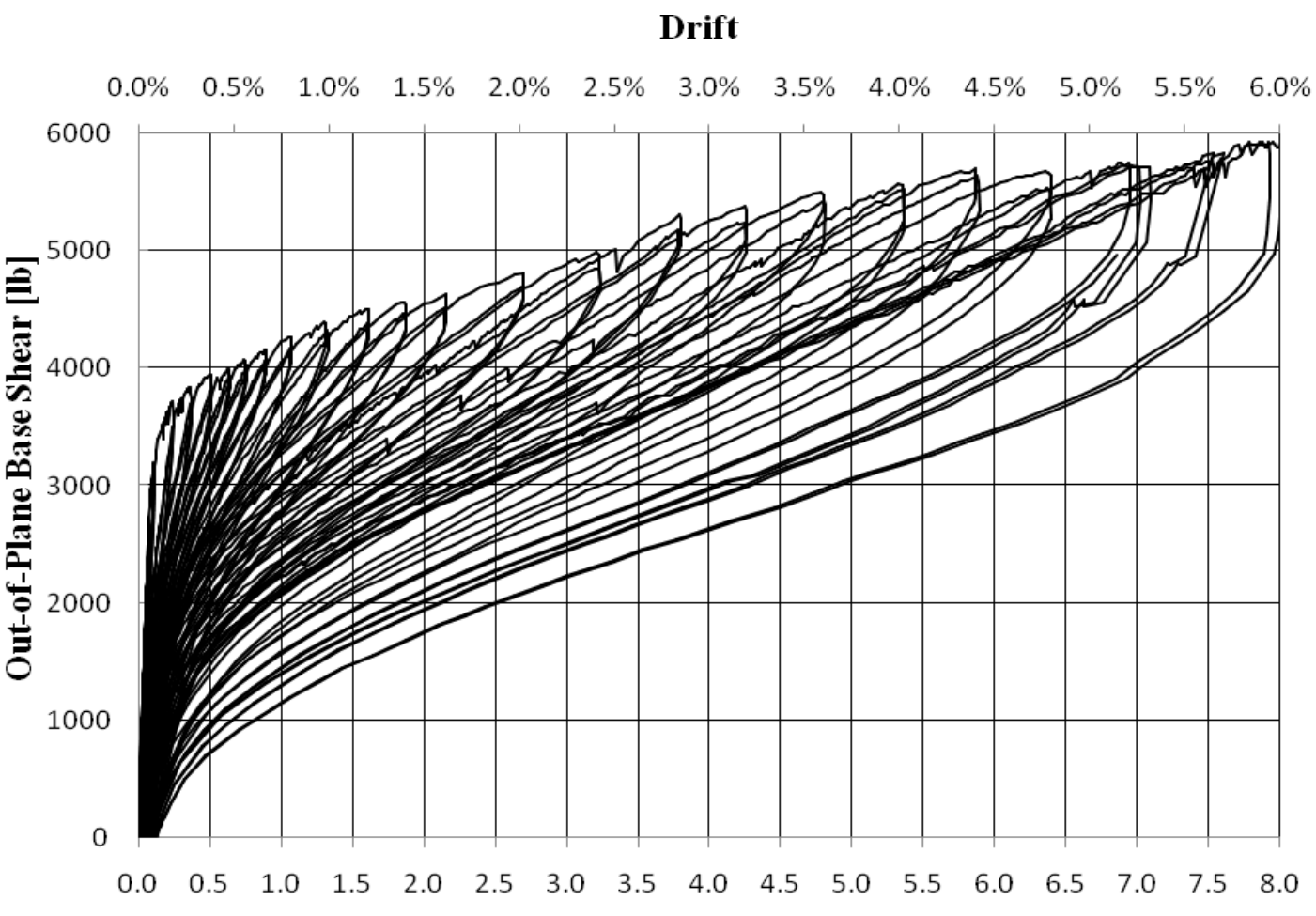

Displacement at Hinge Location[in]

Figure BB: Force-Displacement Plots for All Cycles

Seismic Performance of Unreinforced Masonry Walls Retrofitted with Post-Tensioning Tendons 
Figure BB reveals an expected decrease in wall stiffness as a result of repeated loading cycles. Figure CC below compares select Force-Displacement cycles with predictions made in Section 6.0. Figure DD on the next page presents the overall backbone curve for the retrofitted wall and also compares predictions to maximum obtained values. Since the wall hinged at 9" above its centerline and rotated about this point as two rigid bodies, the maximum displacement occurring at the point of hinging was found using geometry. It is the displacement at the hinge location that is plotted in all Force-Displacement graphs. Out-of-plane base shear values for the wall's different moment strengths are based on a model having four equal point loads as shown in the test setup.

\section{Drift}

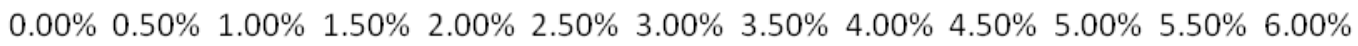

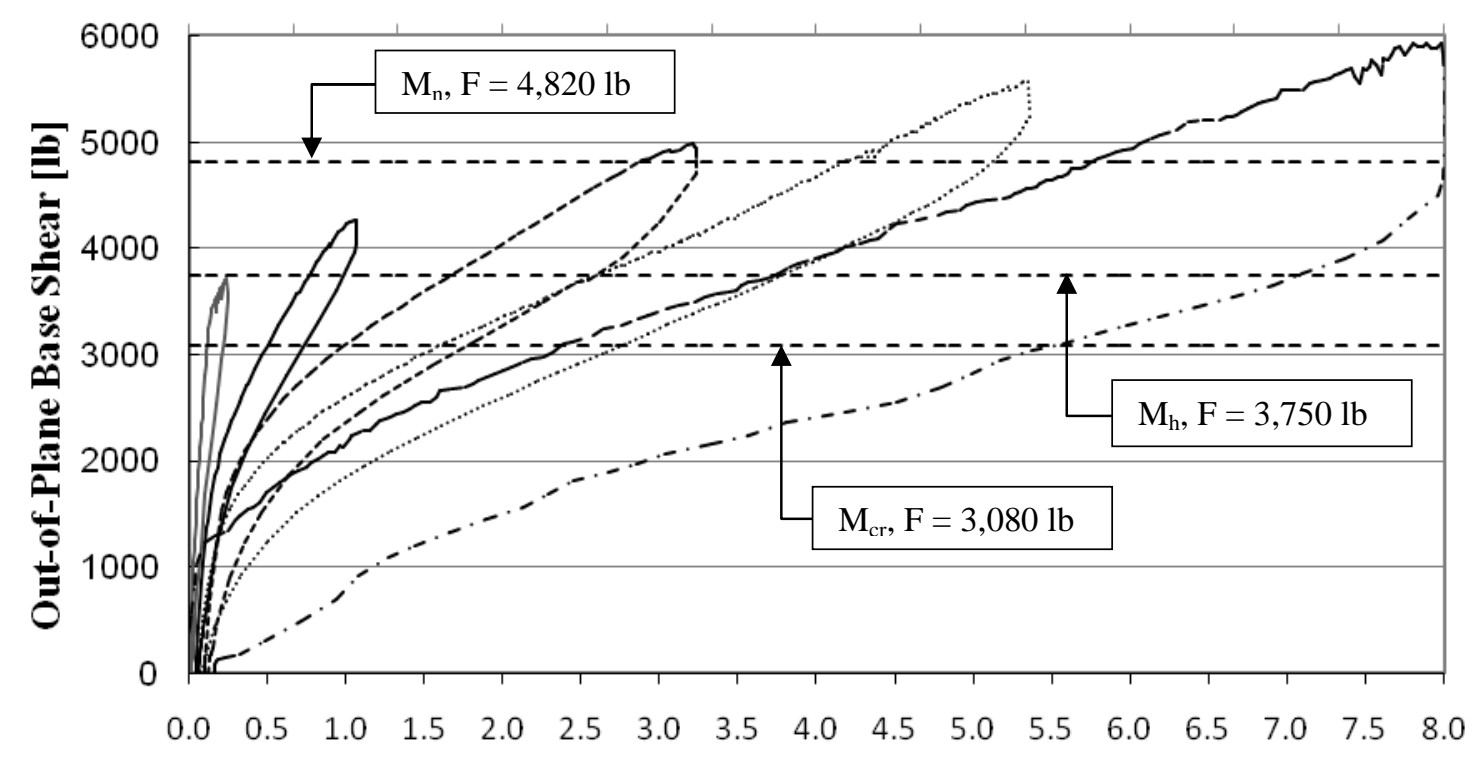

Displacement at Hinge Location[in]

\begin{tabular}{|c|c|c|}
\hline$\ldots \ldots \ldots \ldots . \cdots\left(5.361^{\prime \prime}, 5263 \mathrm{lb}\right)$ & - $\left(3.235^{\prime \prime}, 4712 \mathrm{lb}\right)$ & $-\left(1.070^{\prime \prime}, 4061 \mathrm{lb}\right)$ \\
\hline$-\left(0.246^{\prime \prime}, 3564 \mathrm{lb}\right)$ & $\ldots-\cdot-\left(7.928^{\prime \prime}, 5465 \mathrm{lb}\right)$ & \\
\hline
\end{tabular}

\section{Figure CC: Select Force-Displacement Cycles Compared to Design Predictions}


The prediction for the cracking moment strength of the wall appears to correlate well with a change in stiffness at the loading phase of the first cycle. The wall reached displacements in the first cycle that correspond to the elastic displacement calculated using fundamental beam theory. As predicted, the wall had twice the strength required to resist the force associated with the design-level ground motion elastically.

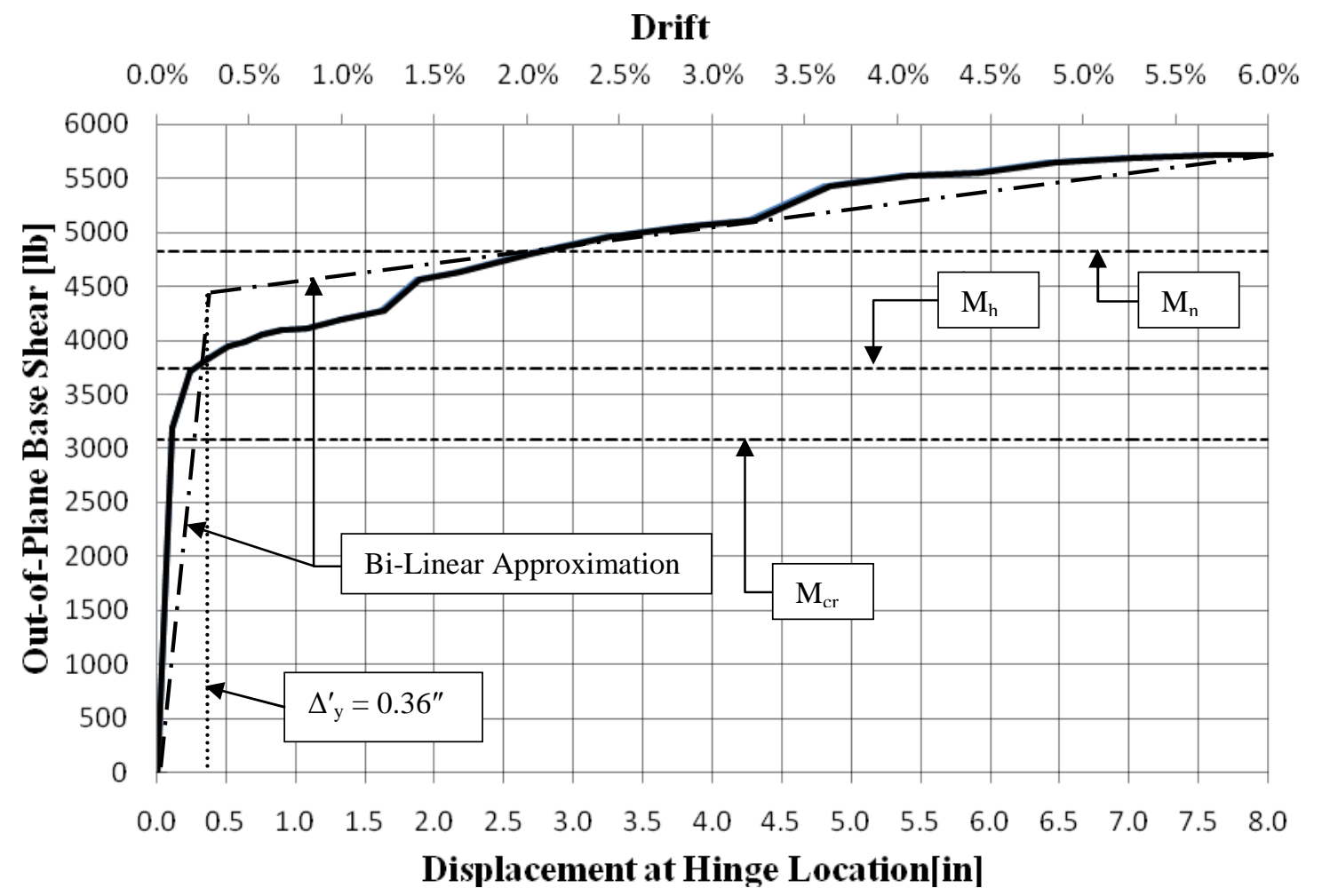

Figure DD: Maximum Force-Displacement Backbone Plot

A bi-linear Force-Displacement approximation was constructed in Figure DD with the intention of finding the pseudo-yield displacement $\Delta_{\mathrm{y}}^{\prime} . \Delta_{\mathrm{y}}^{\prime}$ corresponds to the displacement at the pseudo-yield point of the bi-linear approximation. The phrase pseudo-yield is used to describe the displacement associated with the formation of the 
hinge within the wall. This displacement is not actually a true yield displacement since the PT tendon remains elastic. At this point, however, the extreme fiber in the masonry has begun to reach its crushing strain. The first line in the bi-linear approximation runs through the origin and the force on the actual Force-Displacement plot corresponding to the theoretical prediction of the hinging moment. The second line of the approximation intersects the first line in a manner resulting in two equal areas in the regions between the second line and the actual Force-Displacement plot. This bi-linear approximation and the pseudo-yield displacement of $\Delta^{\prime} y=0.36^{\prime \prime}$ is used in Section 8.1.2 in regards to displacement ductility of the retrofit system.

The exact point corresponding to the onset of cracking was difficult to determine. It was only by looking at the real-time Force-Displacement plot that this point could be determined. After displacing $1 / 4^{\prime \prime}$, cracking was clearly visible. Cracking at this stage was difficult to see with the eye, and thus is diagrammed in Figure EE for easy viewing.

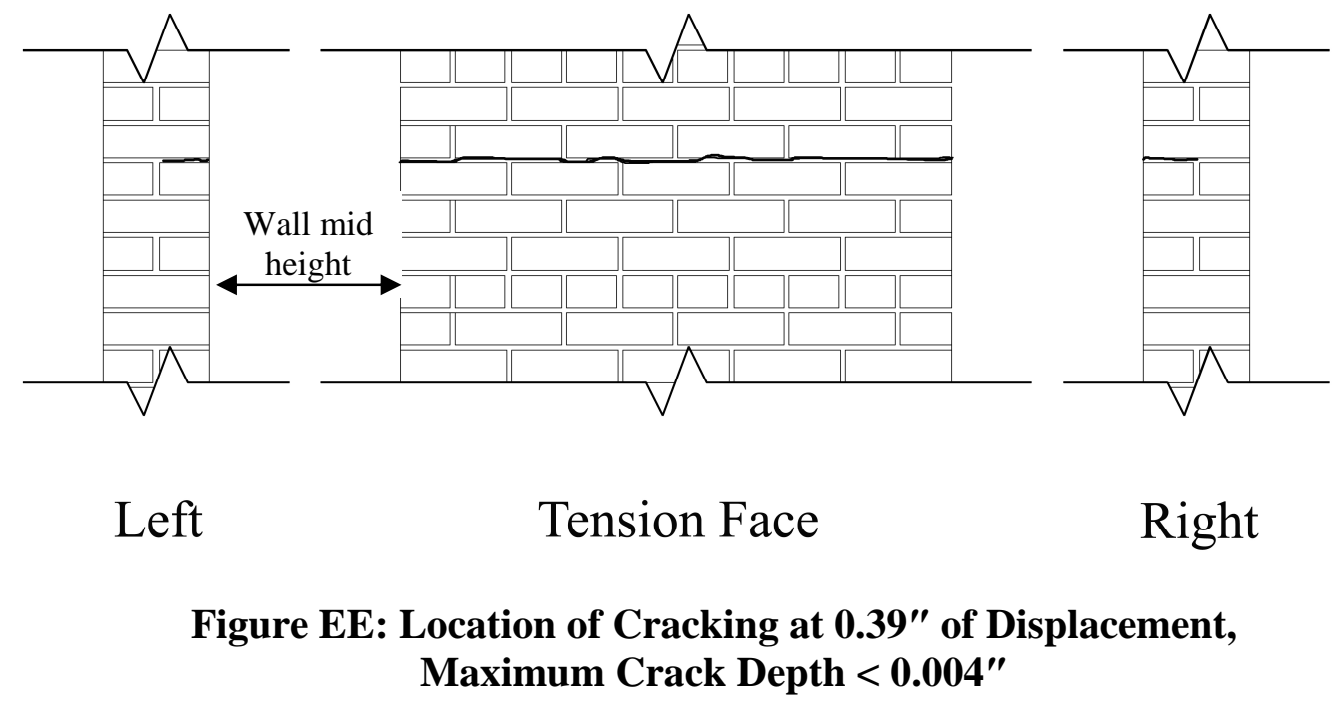

Seismic Performance of Unreinforced Masonry Walls Retrofitted with Post-Tensioning Tendons 
The bold line in Figure EE is an accurate display of the location and relative size of cracking.

Gradually, the backbone curve begins to level out as the mortar crushes and the wall, in turn, loses stiffness. The predicted moment capacity at the onset of hinging compares favorably with the results from the test. This is evident in Figure DD previously shown. Around this point, the wall loses significant stiffness and begins to displace large amounts with relatively smaller additions of load. This event can also be related to changes in the displaced shape of the wall. Figure FF on the next page shows the deflected shape of the wall for loads in the elastic range, up to the point of theoretical hinging. 


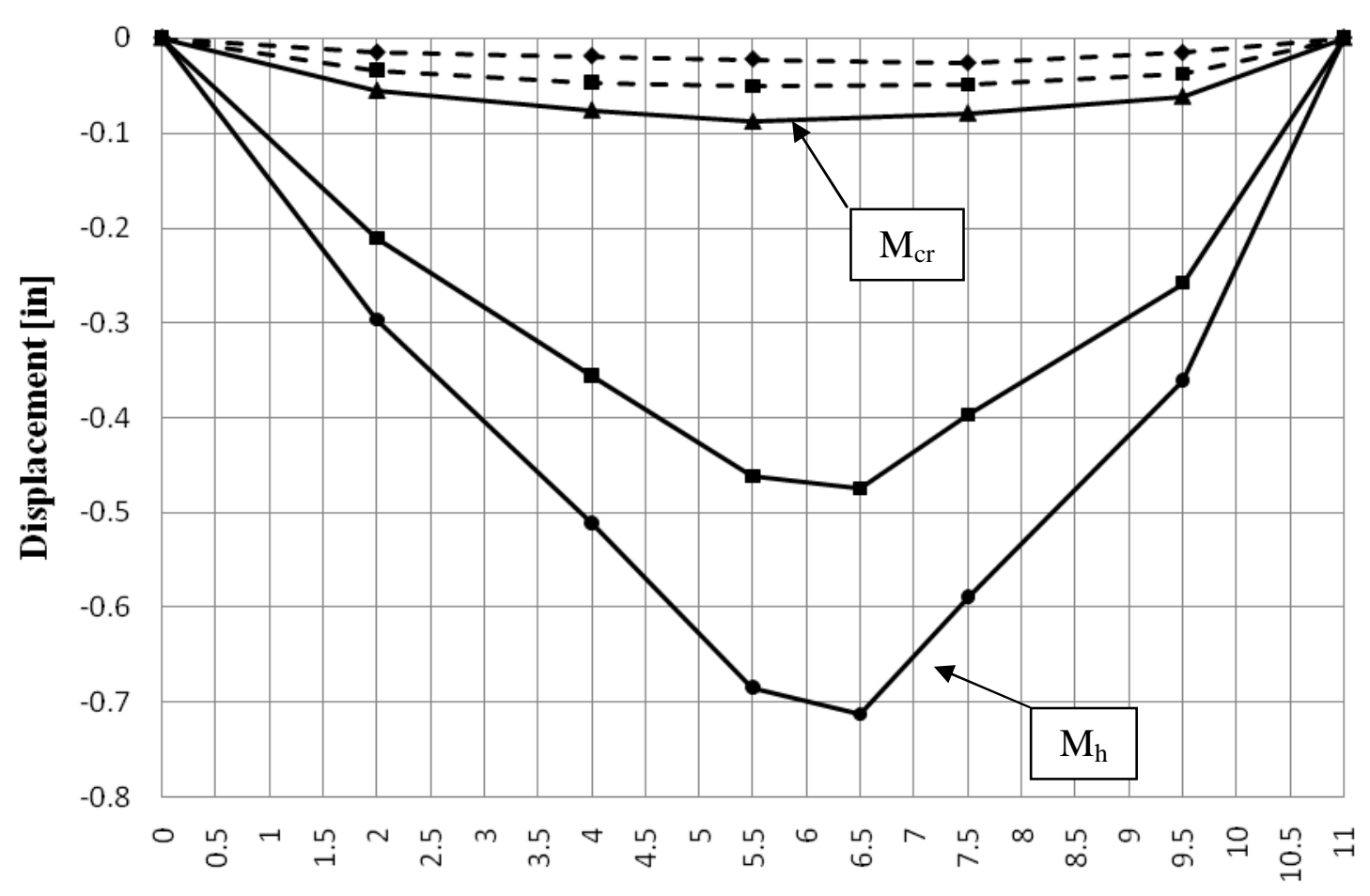

Location Along Wall [ft]

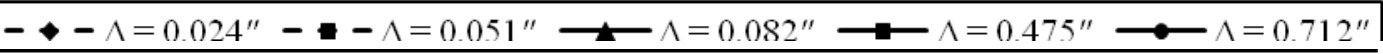

Figure FF: Displaced Shape of Tested Wall (Small Displacements)

Up until the theoretical point of hinging, the displaced shape of the wall is generally parabolic. This displaced shape is expected while the wall remains elastic in its response. Once hinging occurs, the displaced shape of the wall is progressively less parabolic, because it reflects the rotation of two rigid bodies hinging about one point. Figure GG displays the wall's deflected shape for given distributed loads above the hinging moment capacity. Note that the first plot in the figure is also the plot with the largest displacement in Figure FF, previously shown. 


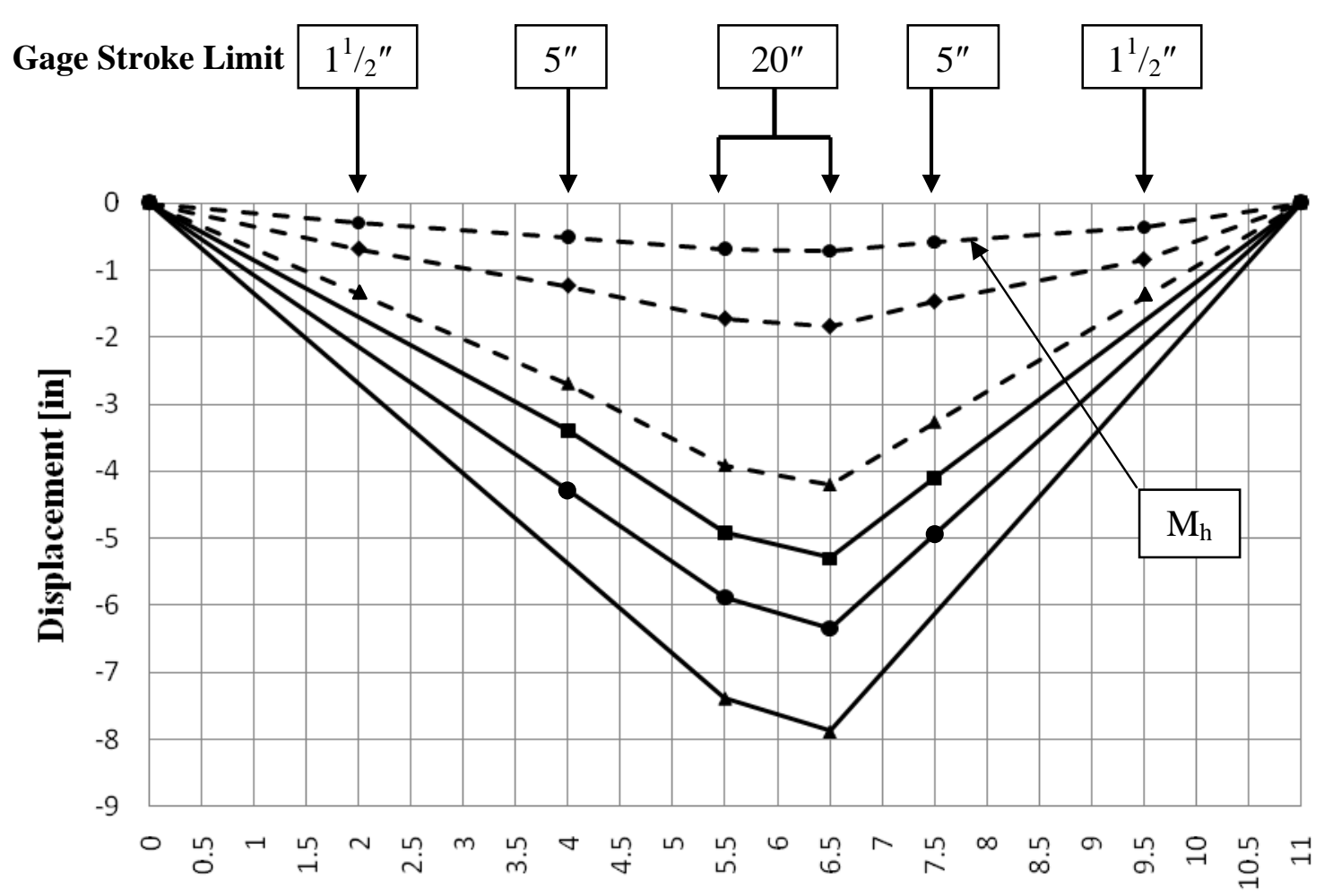

Location Along Wall [ft]

\begin{tabular}{|c|c|c|}
\hline$\bullet \bullet-\Delta=0.712^{\prime \prime}$ & $-\bullet-\Delta=1.831^{\prime \prime}$ & $- \pm-\Delta=4.201^{\prime \prime}$ \\
\hline$\longrightarrow-\wedge=5.293^{\prime \prime}$ & $\multimap \wedge=6.334^{\prime \prime}$ & $\longrightarrow \wedge=7.877^{\prime \prime}$ \\
\hline
\end{tabular}

\section{Figure GG: Displaced Shape of Tested Wall (Large Displacements)}

Figure GG shows the rigid-body rotation of the two segments of wall after

hinging. As the wall reached larger displacements, particular instruments reached their displacement capacity and were therefore removed from the test. The last 4 plots in Figure GG have missing markers in the locations where gauges were removed due to displacements beyond their measurable range. As evident in Force-Displacements plots and the above deflected shapes, the wall was able to achieve large displacements before compromising the masonry's strength. Maximum displacements of almost 8" $6.0 \%$ 
drift) were achieved, with the wall returning to nearly its initial position after unloading. After displacing upwards of 1", cracking propagated as shown in Figure HH below.

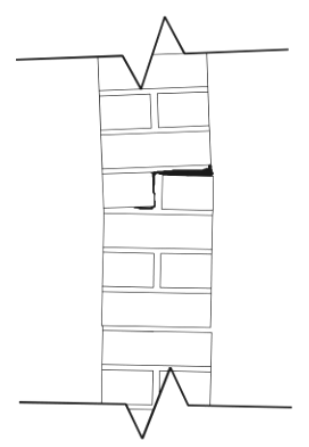

Left

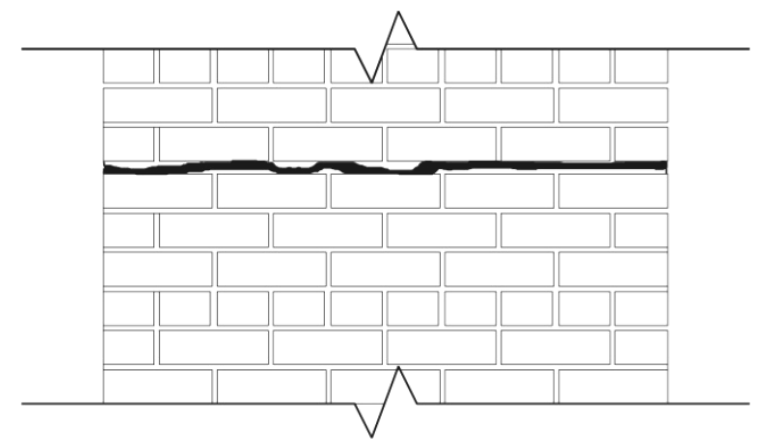

Tension Face

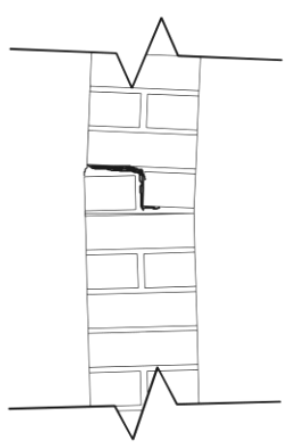

Right

\section{Figure HH: Location of Cracking at 3.5" of Displacement, Maximum Crack Depth $=0.70^{\prime \prime}$}

As seen above, cracking spread across one mortar joint and traveled vertically

down to the mortar joint below. This occurred possibly because the brick on the compression face was better adhered to the course below. The void shown by the thick black line in the figure represents the amount the previously formed crack opened at this displacement step. In some regions at the location of cracking, mortar remained adhered to the top course, while in other locations, mortar adhered to the bottom course. This is also shown in Figure HH. Figure II on the next page is an image taken of the wall at 3.5" (a) and 8.0" (b) of displacement. A plumb line was hung on the tension face of the wall to better observe the drift the wall experienced relative to its equilibrium position. 

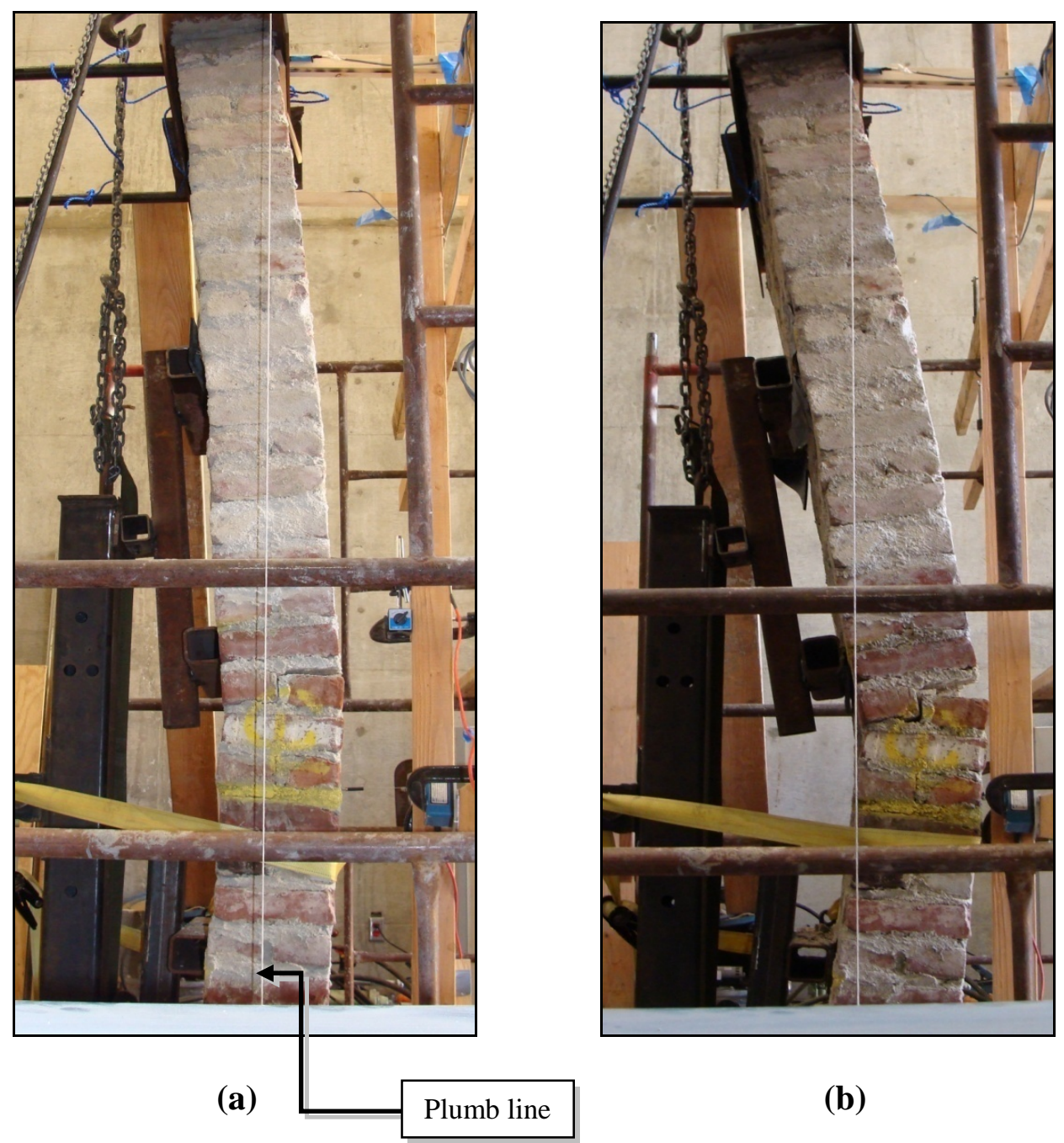

(b)

Figure II: Hinge Displacement (a) 3.5", (b) 8.0"

The ultimate displacement the wall achieved was limited to the range of the hydraulic loading ram. At a maximum displacement of $8.0^{\prime \prime}$, the loading ram was fully extended. Investigation of the Force-Displacement plots reveals that the wall had lost almost all of its stiffness at this point.

The ultimate moment capacity and the ultimate displacement predictions in Section 6.0 under-approximated the performance of the retrofitted wall. Ultimately, the wall was able to withstand a distributed load of $w_{u}=546 \mathrm{lb} / \mathrm{ft}$, correlating to a ground Seismic Performance of Unreinforced Masonry Walls Retrofitted with Post-Tensioning Tendons 
acceleration $C_{s}=1.60 \mathrm{~g}$. At this force level, the wall underwent displacements that were 4 times larger than predicted for ultimate strength. This discrepancy could be better explained with further testing and design development. At the onset of the fully plastic section, significant crushing was experienced in the mortar and the brick. Figure JJ below shows (a) the size of cracking at ultimate, and (b) the extent of masonry crushing at the location of the hinge. As a reference, the crack gauge in Figure JJ (a) measures a maximum crack size of $15 \mathrm{~mm}$, or $0.591^{\prime \prime}$.

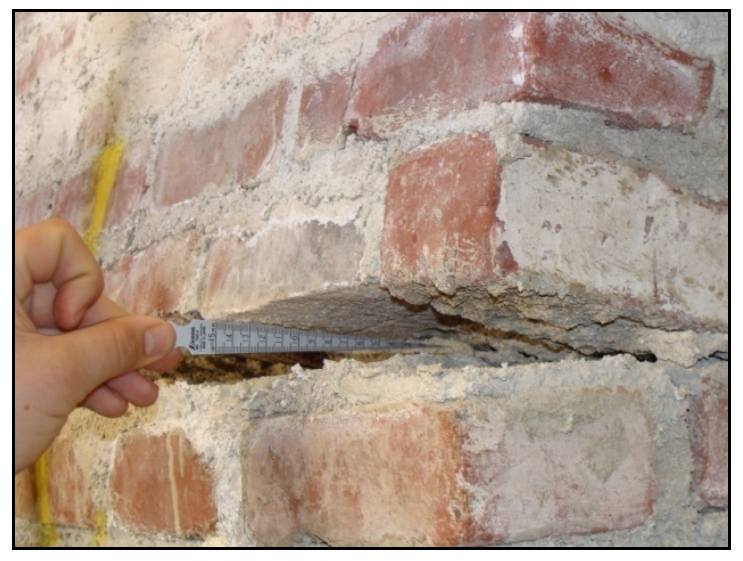

(a)

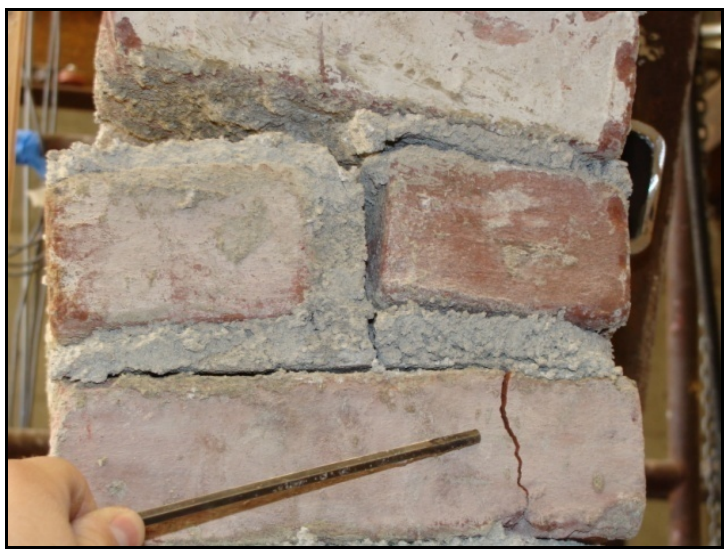

(b)

Figure JJ: Cracking and Masonry Crushing at Ultimate Displacement

It is also important to mention that at this final displacement, additional cracking occurred along a mortar line 3 courses below the location of hinging, in the location where hinging was originally anticipated. This potentially resulted from restoring forces inside the wall from the PT tendon. This additional cracking mirrors that of similar tests discussed in Section 3.3.2. Cracking at this location suggests that the plastic hinge length at the center of the wall may have actually been larger than the assumed 3 courses. The cracking pattern at this final displacement is diagrammed in Figure KK. 


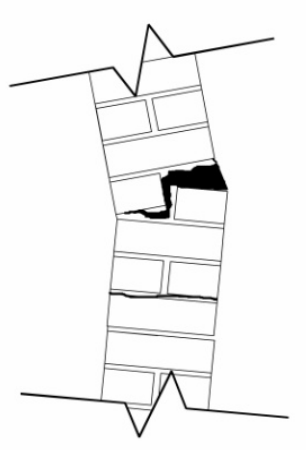

Left

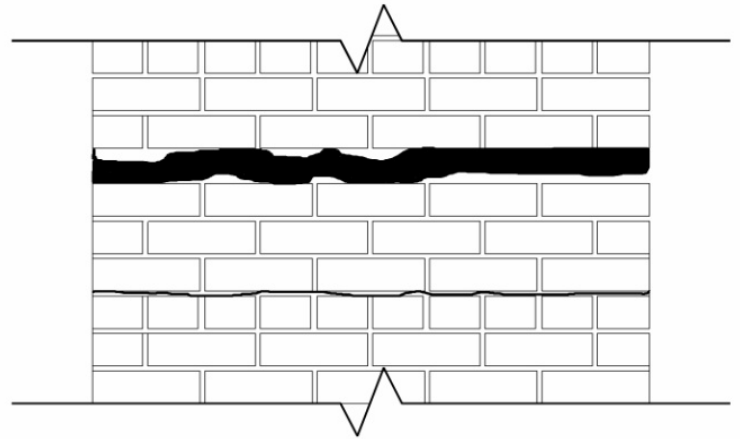

Tension Face

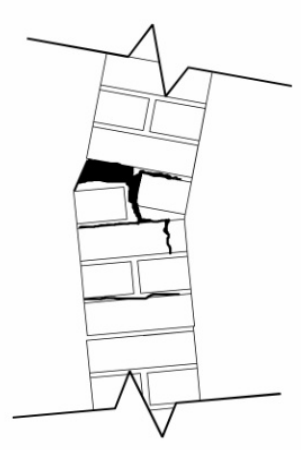

Right

\section{Figure KK: Location of Cracking at 8.0" of Displacement, Maximum Crack Depth $=1.72^{\prime \prime}$}

The final discussion point regarding the test is the change in force within the posttensioning tendon. After the tendon came in direct contact with the wall, the amount of stress increased roughly linearly with more displacement. Eventually, once the masonry had almost entirely crushed, it became evident that the tendon provided nearly all of the remaining stiffness of the wall. Figure LL on the next page shows the percent increase in the PT force with increasing displacement cycles. Figure MM on the next page shows the actual change in the tendon force with increasing displacement over all displacement cycles. 


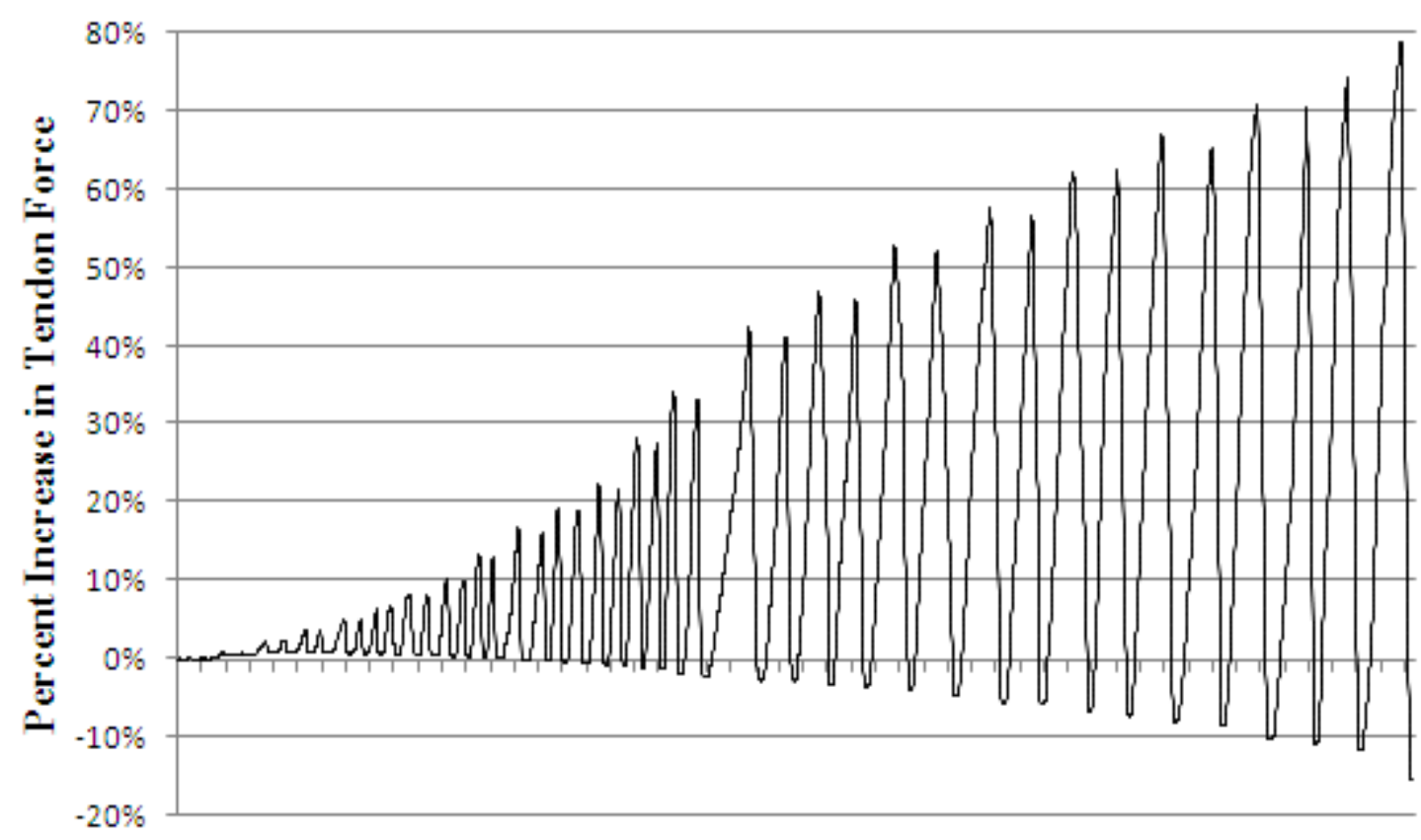

Increasing Displacement Cycles

Figure LL: Percent Increase in Tendon Force over All Loading Cycles

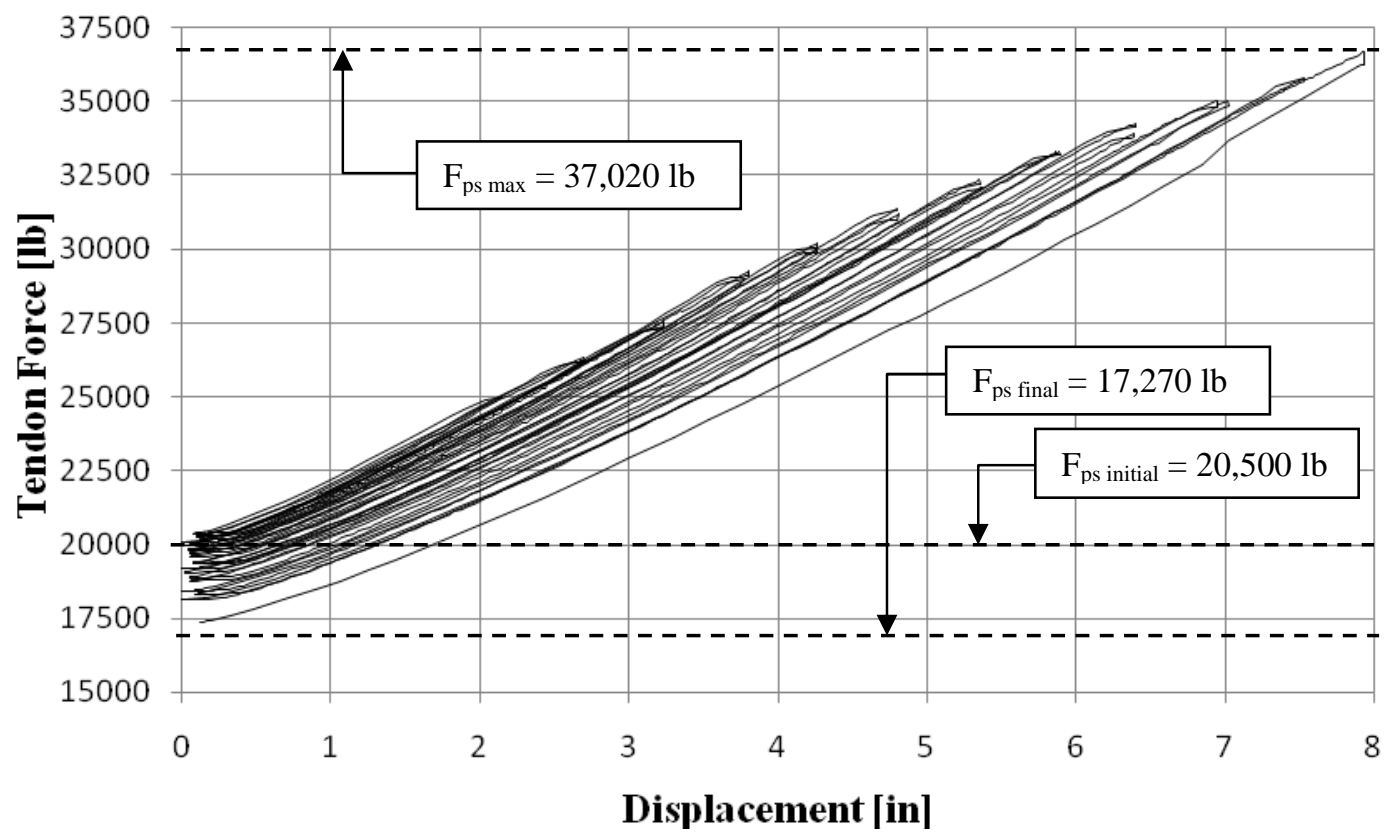

Figure MM: Change in Tendon Force with Increasing Displacement Cycles

Seismic Performance of Unreinforced Masonry Walls Retrofitted with Post-Tensioning Tendons 
The elongation of the tendon at a wall displacement of $8.0^{\prime \prime}$ at the location of hinging can be computed. Because the tendon remains elastic throughout all loading cycles, Equation 21 is again used, where $P$ is the increase in tendon force (79 percent of the initial tendon force), and $l$ is the length of the tendon, equal to $h_{w}$. Thus, the elongation in the tendon at the maximum wall displacement is found to be $\delta=0.495 "$. The increases in the tendon force would compare better to predictions if calculations had considered the hinge mechanism to form at 9" above the wall centerline. Based on Figure LL, it can be seen that the tendon force increased from its initial value by almost 36 percent at a maximum wall displacement (at the location of the plastic hinge) of about 3.6". This increase is similar to the 30 percent increase predicted in Section 6.3.6 for a mid-height displacement of 3.549". The main difference in the two results being that the displacement obtained in testing occurred at the location of the hinge, which was 9" above the mid-height assumed in the predictions of Section 6.

It can also be seen that the tendon lost some of its initial force after testing concluded. This is due to the large amounts of crushing experienced by the masonry at the hinge region of the wall. Enough material had undergone inelastic shortening that the wall itself shortened, causing the tendon to slacken. Since the tendon remained elastic through the entire testing process, Equation 21 can once again be applied using a force equal to 16 percent of the initial tendon force. This computation will result in the amount of shortening experienced by the tendon after returning to equilibrium from a lateral displacement of 8.0". Equation 19 results in a $0.101^{\prime \prime}$ shortening of the PT tendon after testing. While this value does not represent major losses in regards to the post-tensioning 
tendon, it has greater implications for the masonry wall. This amount of shortening in the wall implies significant crushing of the masonry after all of the displacement cycles were completed. Despite material crushing, the presence of the PT tendon was still sufficient to return the wall to its original position upon unloading. Section 8.0 discusses the implications that this testing program has and suggests areas of further study regarding this retrofit technique for out-of-plane forces. 


\subsection{CONCLUSION}

An unreinforced masonry (URM) wall was retrofitted with a single posttensioning tendon and tested in the out-of-plane direction. This test was conducted to better understand the performance of a URM wall retrofitted with post-tensioning tendons in response to out-of-plane loads generated by ground motions. The wall was constructed of salvaged bricks and low-strength mortar to best reflect URM walls built in the early 1900s in San Luis Obispo, California. A retrofitted URM wall having a pin-pin height of $11^{\prime}-1 / 2 "$ was loaded out-of-plane by four equally spaced point loads. The wall had all of the properties presented in Section 6.0, including a slenderness ratio of 18-21 thus requiring out-of-plane retrofit.

Overall, testing proved to be successful and a step forward for the development of an out-of-plane post-tensioning retrofit solution for unreinforced masonry walls. Testing demonstrated that the applied retrofit system allowed the wall to meet and exceed the force demands of the design-level ground motion. The wall ultimately withstood a total out-of-plane base shear of 5,850 lb, which was significantly larger than the ground motion demand base shear of 1,620 lb. Testing not only demonstrated the significant improvement in out-of-plane strength that this system offers URM walls, but also proved that such a system can accommodate large displacements while avoiding major residual deformation and damage. This section discusses the ramifications of test results and design predictions, and also suggests areas for further research and development. 


\subsection{Further Discussion of Results}

Important findings of this experiment are outlined in this section.

\subsubsection{Improved Flexural Strength}

Laboratory testing proved that post-tensioning tendons can be used to effectively retrofit vintage URM walls for out-of-plane forces in seismic regions. The success of the system is well understood in terms of the out-of-plane load carrying capacity of the retrofitted wall. The retrofitted wall was able to withstand the force associated with the design level ground motion while remaining elastic. As an ordinary URM wall it was shown that the candidate wall could not resist this force level. After retrofit with PT tendons, however, the candidate wall resisted the force associated with the design-level ground motion without cracking.

The cracking moment capacity of the tested retrofit wall was well predicted from theory. This was expected because the cracking moment capacity was established based on fundamental mechanics and the actual material properties of the tested wall. Figure DD reveals that the wall underwent a noticeable change in stiffness at the force level associated with the predicted cracking moment of the retrofitted wall. Such a change in stiffness is reflective of the wall surpassing its cracking moment capacity and correlates well with similar tests discussed in the literature review.

At its ultimate capacity, the retrofitted wall withstood almost 3.7 times the force imposed by the design-level ground motion generated per the 2006 IBC. Despite this value being underestimated by almost 18 percent in design predictions, it demonstrates a 
substantial strength increase provided by the addition of PT tendons. In the region of the Force-Displacement plot beyond cracking, the strength of the wall is controlled by increasing axial forces in the tendon and increasing compressive strains in the masonry at the location of plastic hinging.

Results from this test can be compared to those from existing testing on posttensioned masonry walls previously discussed in literature review. The testing in this thesis project compares well to the experimental program of Bean Popehn, Schultz and Drake 2007. The major differences in their testing setup versus that of this project is that new materials were used in the construction of wall test samples and that the PT tendons were not placed in cores within the walls but attached at their outer edges. This project incorporated a tendon placed within an inner core and used materials reflective of URM construction of the early 1900s. For their post-tensioned brick wall with a similar initial level of prestress the nominal moment capacity achieved in testing was 76 percent larger than the cracking moment capacity of the wall. For this thesis project, the retrofitted wall's nominal strength found through testing was 85 percent larger than its cracking moment capacity. This similarity helps qualify the relative strength increase experienced by the wall due to the presence of PT tendons. Comparison of design predictions to testing results reveals that the experimental nominal strength of the wall tested by Bean Popehn, Schultz and Drake was 20 percent larger than predicted by theory. This correlates well with the experimental nominal strength of the wall being 18 percent larger than predicted for the test conducted in this thesis. 


\subsubsection{Ultimate Displacement \& System Ductility}

The displacement at cracking was well predicted from elastic beam theory as expected. The ultimate displacement capacity of the wall, however, was underestimated (see Section 6.3.5). The wall sustained a maximum displacement of approximately 8" (6\% drift) at the hinge location. Contrary to predictions, this maximum displacement was located at the plastic hinge which formed 3 courses (or 9") above the mid-height of the wall. This measured displacement was 2 times larger than the predicted ultimate displacement of $3.549^{\prime \prime}$. This result suggests that strains in the wall at this stage likely exceeded the ranges assumed in Section 6.3.5. The ultimate strain-based analysis used to predict the wall's displacement requires further refinement so that the performance of future retrofits can be accurately quantified.

Because the wall was loaded with four equal point loads, the center region of the wall between the innermost point loads experienced constant moment. This being the case, hinging could have potentially occurred at any point in this $2^{\prime}-2^{1 / 2^{\prime \prime}}$ region. Upon inspection of the test wall, it was determined that the hinge formed at the mortar joint having a relatively small depth and relatively high number of voids. Thus, this mortar joint in particular had the largest bending stresses of the region with constant moment. This being the case, the diagram used to predict the maximum wall displacement and tendon elongation in Figure $\mathrm{S}$ does not exactly correlate to the test wall. Had the plastic rotation been considered at the actual hinge location ( 9 " above the wall centerline) the predictions for the maximum displacement and tendon elongation would have more accurately reflected the test results. 
In testing, damage in the form of brick cracking and mortar crushing occurred over a region consisting of 5 brick courses. Further testing should examine the strains and corresponding curvature of the wall at the hinge location in order to develop a model for a more accurate plastic hinge length assumption. If a measurement of the region experiencing crushing strains could be established from a suite of tests a more realistic plastic hinge dimension could be used in future designs.

A pseudo-yield displacement was computed based on a bi-linear ForceDisplacement approximation discussed in Section 7.5. This displacement was found to be $\Delta_{y}^{\prime}=0.36^{\prime \prime}$. If displacement ductility is considered to be the ratio of ultimate displacement (7.960") to pseudo-yield displacement, the retrofitted wall had an out-ofplane ductility of $\mu=22$. Such a high level of ductility is significant because a ductile system inherently continues to retain stiffness and strength after initial yielding. A ductile system is preferred in response to seismic events because it ensures a gradual, not abrupt and catastrophic failure. Ductile systems, like the out-of-plane retrofit for URM walls presented in this project, have the potential to provide a greater acceptance criteria level of performance when compared to non-ductile systems.

Despite achieving large displacements, the tested wall returned to virtually no residual displacement after unloading. Residual displacements were on the order of $0.1^{\prime \prime}$ compared of 8.0" maximum displacement. These residual displacements, while relatively insignificant, are most likely associated with the cracking displacement of the wall which can never be completely recovered. The self-equilibrating nature of this retrofit system is evident in all of the Force-Displacement curves presented in Figure BB. As expected 
based on literature review, the post-tensioning tendons provided a restoring force that returned the wall to nearly its original position after each displacement cycle. This occurred at all displacement cycles, and would continue to occur as long as the PT tendons remained elastic. A highly ductility performance along with virtually no residual displacement has important implications for URM buildings. No residual displacement is appealing for the immediate occupancy of a structure. The ability of the system to achieve such a high level of ductility without compromising the structural system allows for its potential incorporation into performance-based and lifetime cost-saving designs.

\subsubsection{Variation in Tendon Force}

It is important to consider that after a significant increase in PT force, the tendon would no longer remain elastic. It is apparent that if this were to occur the system would experience residual displacements and thus, greater post-earthquake damage. If the tendon were allowed to yield, it would greatly reduce the stiffness of the system and increase the likelihood of collapse. With a loss of stiffness, the wall would displace further with smaller increments of load until either the tendon were to rupture, or the masonry were to crush and blow out of the hinge region.

Since the restoring force provided by the tendon remaining elastic is strongly desired, design must ensure that the increase in tendon force never reaches the yield strength of the tendon. Tendon spacing and initial prestress levels should be varied in further experimentation to determine the potential benefits of varying these parameters. Ultimately, a set spacing and prestress level could be established to meet specific ductility requirements set forth as part of a performance goal for the structure. 
The results of this experiment pertain to the tested wall with a width of $3^{\prime}-6^{\prime \prime}$ and roughly half the prestress intended for a $6^{\prime}$ tendon spacing in a large wall. The initial amount of prestress in the tested wall was proportioned so that the expected force levels would better reflect those that could be present in a $6^{\prime}$ wide wall panel. The test experiment demonstrated that it is indeed feasible to introduce these force levels into a $3^{\prime}$ $6 "$ wide wall panel. Therefore, it is sufficient to say that the corresponding force levels for the $6^{\prime}$ wide wall panel could provide a successful retrofit to a wall incorporating tendons at this spacing.

The elongation of the tendon at a given wall displacement was predicted using the geometry of the wall hinged about its centerline. While the results from this analysis are comparable to test results (where the wall hinged 9" above its centerline) they do not reflect the hinge mechanism experienced by the test wall. A more accurate calculation for tendon elongation could be found by assuming a model incorporating a hinge 9" above the wall centerline. Losses in post-tensioning were experienced after unloading the wall from large displacement cycles. These losses were found from testing data and were not predicted prior to testing. Losses in the post-tensioning tendons used in an outof-plane retrofit for URM should be further examined as they are directly related to mortar strength, wall composition, and material fatigue.

\subsubsection{Tendon Anchorage}

The anchorage for the tested wall consisted of placing the entire top and bottom of the wall directly in compression from the PT tendon. This configuration varies from the anchorage system proposed in Section 6.3.7 where the prestress force is distributed at the 
top and bottom of the wall using steel plating at each tendon location. This was done in order to idealize the system for structural testing. Design predictions did show, however, that this variation in compressive stress at the top and the bottom of the wall does not skew results as they pertain to the retrofit system. The axial stress provided by the tendon is the same at mid-height of the wall for both the tested wall and the proposed anchorage detail relating to the retrofit design. This being the case, the moment capacity of the tested wall would not differ from a wall constructed according to Figure T.

\subsubsection{Effects of the Out-of-Plane Retrofit on the Overall Structure}

It is important to keep the design and testing of this project in the perspective of an out-of-plane retrofit of URM walls within a URM building. This being the case, some discussion of the effects of this retrofit on the entirety of a URM structure is merited.

The wall type that would benefit most from a PT retrofit for out-of-plane loads is one with a very small aspect ratio (height/length). Ideally these would be the long and stout longitudinal walls of a URM structure consisting of one or two stories. Since these walls are inherently stiff in-plane, the addition of PT tendons for out-of-plane loads will not affect the global stiffness of the structure. This is desired because a global increase in stiffness would result in larger in-plane seismic forces generated within the structure. Long and stout shear walls are inherently controlled in-plane by their shear strength and not their flexural strength because of their minimal aspect ratio. Therefore, potential inplane flexural stiffening added by PT tendons will not likely affect the structure as a whole. 
This out-of-plane retrofit is not at this point intended for URM walls with large aspect ratios because the in-plane effects of adding PT tendons would be much more pronounced in these walls. Walls with large aspect ratios are more controlled by their flexural response to in-plane loads, and would thus be influenced by the presence of PT tendons placed for out-of-plane strengthening.

\subsection{Recommendations for Future Research}

Further research and development is necessary before this out-of-plane retrofit design can be properly implemented in URM structures. As previously mentioned, multiple tests should be conducted to generate more data. This testing should include different wall configurations, material properties, initial prestress levels, tendon spacing, and tendon anchorage configurations. Multiple tests will ultimately demonstrate the system's versatility and instill greater confidence in its applicability to different building configurations. Testing should also incorporate pre-existing URM walls if possible. This would be the most preferred method of testing because it would most closely approximate the final retrofit system. Since testing in this project did not involve coring

of the URM wall as proposed, testing on an existing wall would incorporate coring for the placement of tendons. Coring an existing wall would demonstrate not only the structural advantages of this system, but the feasibility of constructing the retrofit inplace. Through further testing, a better understanding of the ultimate limit state of the wall could be achieved. This understanding would result in a better prediction of the ultimate strength and displacement capacity of the retrofitted wall, enhancing the retrofit design. 
Apart from static testing, dynamic testing would be beneficial to quantify the retrofit's response to actual ground motions. This testing could ultimately be used to calibrate computer modeling. A finite element model could be generated to predict the performance of various retrofit configurations.

Long-term experiments should also be conducted to understand the lifespan of the system. Testing in this fashion would help quantify the ability of the retrofit to withstand subsequent ground motions. The long-term effects of added compression from PT tendons should also be further studied in terms of losses and durability.

Eventually, it would be necessary to consider a retrofitted wall in both the inplane as well as out-of-plane directions. Testing in this fashion would determine if posttensioning tendon cores could be the only technique required to retrofit an entire URM structure for ground motions.

Another important area for future research involves the cost of this retrofit system compared to current retrofit options. For this system to have an advantage over current retrofit options, it would have to be cost-effective in addition to being structurally efficient and aesthetically non-invasive. A thorough cost-analysis considering every aspect of this retrofit would ultimately determine its cost-effectiveness compared to current retrofit techniques. 


\subsection{DEFINITION OF TERMS \& ACRONYMS}

All of the terms and acronyms used throughout this project are presented and defined in this section.

\subsection{Definition of Terms}

The following is a list of definitions used throughout this report. Terms are defined here to ensure correct usage and meaning. Definitions are adopted from ACI 318-05 and ACI 530-05.

Bonded Tendon: Prestressing tendon that is encapsulated in a corrugated duct and bonded to the surrounding material through grouting.

Composite Action: Transfer of stress between components of a member designed so that in resisting loads, the combined components act together as a single member.

Composite Section: A cross-section that acts with composite action.

Compressive Strength of Masonry: Design compressive force resisted per unit of net cross-sectional area of masonry, determined from testing.

Confinement: Prevention of masonry, grout or concrete cracking by means of compressive load or lateral reinforcement.

Design Strength: The nominal strength of an element multiplied by the appropriate strength-reduction factor $\varphi$.

Ductility: The ability to deform inelastically without significant strength degradation.

Laterally Restrained Prestressing Tendon: Prestressing tendon that is not free to move laterally within the cross-section of a member.

Laterally Unrestrained Prestressing Tendon: Prestressing tendon that is free to move laterally within the cross-section of a member. 
Nominal Strength: The strength of an element or cross-section calculated in accordance with the requirements and assumptions of the strength design methods of the governing code provisions.

Post-Tension: The process by which high-strength steel cables are affixed to a structural member and tensioned. The cables then place the member in compression. This compression load counteracts tensile failure in the member.

Post-Tensioned Masonry: Masonry in which internal stresses have been introduced to counteract stresses resulting from applied loads.

Prestressing Grout: A cementations mixture used to encapsulate bonded prestressing tendons.

Shear Wall: A wall, bearing or nonbearing, designed to resist lateral forces acting in the plane of the wall (sometimes referred to as a vertical diaphragm).

Strand: One component of a prestressing tendon (see Tendon below).

Tendon: Assembly consisting of anchorage, prestressing steel, and sheathing with coating for unbonded applications of ducts, or with grout for bonded applications. A tendon consists of multiple post-tensioning strands that have been interwoven.

Tendon Anchorage: In post-tensioning, a device used to anchor the prestressing tendon to the masonry or concrete member; in prestressing, a device used to anchor the prestressing tendon during hardening of masonry mortar, grout, prestressing grout, or concrete.

Transverse Reinforcement: Reinforcement placed perpendicular to the loaded axis of a member.

Unbonded Tendon: Tendon in which the prestressing steel is prevented from bonding to the concrete and is free to move relative to the concrete. The prestressing force is permanently transferred to the concrete at the tendon ends by the anchorages only. 


\subsection{Acronyms}

$\begin{array}{ll}\text { ABK } & \text { Agbabian, Barnes and Kariotis joint venture } \\ \text { ACI } & \text { American Concrete Institute } \\ \text { ASCE } & \text { American Society of Civil Engineers } \\ \text { ASTM } & \text { American Society of Testing Materials } \\ \text { CHBC } & \text { California Historic Building Code } \\ \text { CMU } & \text { concrete masonry unit } \\ \text { EERC } & \text { Earthquake Engineering Research Center } \\ \text { FEMA } & \text { Federal Emergency Management Agency } \\ \text { FRP } & \text { Fiber-Reinforced Polymer } \\ \text { IBC } & \text { International Building Code } \\ \text { ICBO } & \text { International Conference of Building Officials } \\ \text { IEBC } & \text { International Existing Building Code } \\ \text { LRFD } & \text { Load and Resistance Factor Design } \\ \text { MCE } & \text { Maximum Considered Earthquake } \\ \text { MSJC } & \text { Masonry Standards Joint Committee } \\ \text { NEHRP } & \text { National Earthquake Hazards Reduction Program } \\ \text { PT } & \text { post-tensioning } \\ \text { PTI } & \text { Post-Tensioning Institute } \\ \text { SEAOC } & \text { Structural Engineers Association of California } \\ \text { URM } & \text { unreinforced masonry } \\ \text { USGS } & \text { United States Geological Survey } \\ & \end{array}$




\subsection{REFERENCES}

(ABK 1981) Ewing, Robert D. and J C Kariotis. Methodology for Mitigation of Seismic Hazards in Existing Unreinforced Masonry Buildings: Wall Testing, Out-ofPlane, a Joint Venture of Agbabian Associates, S.B. Barnes and Associates, and Kariotis and Associates (ABK), Topical Report 04. El Segundo, CA. 1981.

(Al-Manaseer 1987) Al-Manaseer, A. A. and V. V. Neis. "Load Tests on Post-Tensioned Masonry Wall Panels.” ACI Structural Journal. 84.3 (1987) 467-472.

(Alper, Hacim and Aysoy 1982) Alper, Husamettin, Ergul Hacim and Sefer Aysoy. "Experimental Studies on Post-Tensioned Masonry." Proceedings of the $7^{\text {th }}$ European Conference on Earthquake Engineering. 1982, Athens, Greece. Technical Chamber of Greece, 1982.

(Anand and Bhatia 1996) Anand, Subhash C. and Naresh Bhatia. "Prestress Loss Due to Creep in Post-Tensioned Clay Masonry." Proceedings of the 1996 CCMS of the ASCE Symposium in Conjunction with Structures Congress XIV. 15-18 April, 1996, Chicago, IL, United States. American Society of Civil Engineers, 1996.

(Avvakumovits 1995) Avvakumovits, Otto. "Seismic Evaluation and Retrofitting of Existing Unreinforced Masonry Buildings." Structures Congress- Proceedings Vol 2, Restructuring America and Beyond. 3-5 April, 1995, Boston MA, United States. American Society of Civil Engineers, 1995.

(Bean Popehn, Schultz and Drake 2007). Bean Popehn, Jennifer R., Arturo E. Schultz and Christopher R. Drake. "Behavior of Slender Posttensioned Masonry Walls Under Transverse Loading." Journal of Structural Engineering. 133.11 (2007) 1541-1550.

(Breiholz 1993) Breiholz, David C. "Center-Core Strengthening System for Unreinforced Masonry Bearing Wall Buildings.” Proceedings of the Symposium on Structural Engineering in Hazards Mitigation. 19-21 April, 1993, Irvine, CA, United States. American Society of Civil Engineers. 1993.

(Bruneau 1994) Bruneau, Michael. "Seismic Evaluation of Unreinforced Masonry Buildings- A State-of-the-Art Report." Canadian Journal of Civil Engineering. 21.3 (1994) 512-539.

(Campi 1989) Campi, Dominic E. "Seismic Strengthening of a Historic Unreinforced Masonry Building." Engineering: Research and Practice. 1-5 May, 1989, San Francisco, CA, United States. American Society of Civil Engineers, 1989. 
(CHBC 2001) CHBC: 2001 California Historical Building Code, California Code of Regulations, Title 24, Part 8, California Building Standards Commission, United States, 2001.

(Fattal, and Cattaned) Fattal, S.G. and L.E. Cattaned. "Evaluation of Structural Properties of Masonry in Existing Buildings." NBS Building Science Series 62, Washington, D.C., 1977.

(FEMA-306) FEMA-306: Evaluation of Earthquake Damaged Concrete and Masonry Wall Buildings, Basic Procedures Manual, Federal Emergency Management Agency, United States, 1998.

(FEMA-310) FEMA-310: Handbook for the Seismic Evaluation of Buildings, Federal Emergency Management Agency, United States, 1998.

(FEMA-356) FEMA-356: Prestandard and Commentary for the Seismic Rehabilitation of Buildings, Federal Emergency Management Agency, United States, 2000.

(FEMA-547) FEMA-547: Techniques for the Seismic Rehabilitation of Existing Buildings, Federal Emergency Management Agency, United States, 2006.

(Ganz 1996) Ganz, Hans Rudolf. "VSL's Experience with Post-Tensioned Masonry." Proceedings of the 1996 CCMS of the ASCE Symposium in Conjunction with Structures Congress XIV. 15-18 April, 1996, Chicago, IL, United States. American Society of Civil Engineers, 1996.

(Ganz and Shaw 1997) Ganz, Hanz Rudolf and Gerry Shaw. "Stressing Masonry's Future.” Civil Engineering (New York). 67.1 (1997) 42-45.

(Green 1989) Green, Melvyn. "Retrofitting Existing Seismically Hazardous Buildings." Seismic Engineering: Research and Practice. 1-5 May, 1989, San Francisco, CA, United States. American Society of Civil Engineers, 1989.

(Green 1993) Green, Melvyn. "Code Provisions for Unreinforced Masonry Bearing Wall Buildings in California." Proceedings of the Symposium on Structural Engineering in Hazards Mitigation. 19-21 April, 1993, Irvine, CA, United States. American Society of Civil Engineers. 1993.

(Hamed and Rabinovitch 2008b) Hamed, E. and O. Rabinovitch. "Masonry Walls Strengthened with Composite Materials - Dynamic Out-of-Plane Behavior." European Journal of Mechanics. 27.6 (2008) 1037-1059. 
(IEBC 2006) IEBC: 2006 International Existing Building Code, International Code Council, 2006.

(Kariotis and Nghiem 1993) Kariotis, John and Doc Nghiem. "In-Situ Determination of the Compressive Stress-Strain Relationship of Multi-Wythe Brick Masonry." Structural Engineering in Natural Hazards Mitigation: Proceedings of Papers Presented at the Structures Congress. April 19-21, Irvine, CA, United States. Structural Division of the American Society of Civil Engineers. 1993

(Kaushik et al. 2007) Kaushik, Hemant B., Durgesh C. Rai and Sudhir K. Jain. "StressStrain Characteristics of Clay Brick Masonry under Uniaxial Compression." Journal of Materials in Civil Engineering. Spetember 2007. 728-739.

(Kingsley, Magenes and Calvi 1996) Kingsley, Gregory R., Guido Magenes and G. Michele Calvi. "Measured Seismic Behavior of a Two-Story Masonry Building." Proceedings of the 1996 CCMS of the ASCE Symposium in Conjunction with Structures Congress XIV. 15-18 April, 1996, Chicago, IL, United States. American Society of Civil Engineers, 1996.

(Krause, Devalapura and Tadros 1996) Krause, Gary L., Ravi Devalapura and Maher K. Tadros. "Testing of Prestressed Clay-Brick Walls." Proceedings of the 1996 CCMS of the ASCE Symposium in Conjunction with Structures Congress XIV. 1518 April, 1996, Chicago, IL, United States. American Society of Civil Engineers, 1996.

(Kurama 2002) Kurama, Yahya C., et al. "Seismic Response Evaluation of Unbonded Post-Tensioned Precast Walls.” ACI Structural Journal. 99.5 (2002) 641-651.

(Kurama 2005) Kurama, Yahya C. "Seismic Design of Partially Post-Tensioned Precast Concrete Walls.” PCI Journal. 50.4 (2005) 100-125.

(Laursen 2002) Laursen, Peter T. Seismic Analysis and Design of Post-Tensioned Concrete Masonry Walls. Department of Civil and Environmental Engineering, University of Auckland, New Zealand. 2002.

(Laursen and Ingham 2004) Laursen, Peter T. and Jason M. Ingham. "Structural Testing of Enhanced Post-Tensioned Concrete Masonry Walls." ACI Structural Journal. 101.6 (2004) 852-862.

(Laursen, Wight and Ingham 2006) Laursen, Peter T., Gavin D. Wight and Jason M. Ingham. "Assessing Creep and Shrinkage Losses in Post-Tensioned Concrete Masonry.” ACI Structural Journal. 103.6 (2006) 427-435. 
(Lissel, Shrive and Gilliland 2005) Lissel, Shelley L., Nigel G. Shrive and Jim Gilliland. "Design of Carbon Fibre Reinforced Polymer Post-Tensioned Masonry Diaphragm Retaining walls." Canadian Journal of Civil Engineering. 32.3 (2005) 579-594.

(Manzouri 1996) Manzouri, Teymour, et al. "Repair and Retrofit of Unreinforced Masonry Structures.” Earthquake Spectra. 12.4 (1996) 903-922.

(MSJC 2005) MSJC: Building Code Requirements for Masonry Structures and Specification for Masonry Structures, ACI 530-05/ASCE 5-05/TMS 402-05, The Masonry Standards Joint Committee, United States, 2005.

(Rosenboom and Kowalsky 2003) Rosenboom, Owen A. and Mervyn J. Kowalsky. "Investigation of Alternative Details for Seismic Design of Post-Tensioned Clay Masonry Walls." Proceedings of the 2003 ASCE/SEI Structures Congress and Exposition: Engineering Smarter. 29-31 May, 2003, Seattle WA, United States. American Society of Civil Engineers, 2003.

(Rutherford and Chekene 1990). Rutherford and Chekene. Seismic Retrofittin Alternatives for San Francisco's Unreinforced Masonry Buildings: Estimates of Construction Cost and Seismic Damage for the San Francisco Department of City Planning. Rutherford and Chekene Consulting Engineers: San Francisco CA. 1990.

(Schultz, Bean and Stolarski 2003) Schultz, Arturo E., Jennifer R. Bean and Henryk K. Stolarski. "Out-of-Plane Lateral Load Resistance of Slender Post-Tensioned Masonry Walls with Unbonded Tendons." Proceedings of the 2003 ASCE/SEI Structures Congress and Exposition: Engineering Smarter. 29-31 May, 2003, Seattle WA, United States. American Society of Civil Engineers, 2003.

(Schultz, Bean and Drake 2004) Schultz, A. E., J. R. Bean and C.R. Drake. "Flexural Behavior of Slender Post-Tensioned Masonry Walls." Proceedings of the 2004 Structures Congress - Building on the Past: Securing the Future. 22-26 May, 2004, Nashville TN, United States. American Society of Civil Engineers, 2004.

(Schwein 1990) Schwein, Robert L. "Techniques for Evaluating Unreinforced Masonry Materials." Structural Engineer's Association of Northern California, Fall Seminar. October, 1990. Robert L. Schwein, 1990.

(Scolforo 1996) Scolforo, Matthew J. "Proposed Prestressed Masonry Design Provisions." Proceedings of the 1996 CCMS of the ASCE Symposium in Conjunction with Structures Congress XIV. 15-18 April, 1996, Chicago, IL, United States. American Society of Civil Engineers, 1996. 
(Shaw 1996) Shaw, Gerard. "Innovative Development of Prestressed Masonry."

Proceedings of the 1996 CCMS of the ASCE Symposium in Conjunction with Structures Congress XIV. 15-18 April, 1996, Chicago, IL, United States.

American Society of Civil Engineers, 1996.

(Siviero, Briseghella and Zordan 2005) Siviero, Enzo, Bruno Briseghella and Tobia Zordan. "Advanced Retrofitting Techniques with Hybrid Use of Carbon Fibre and External Post-Tensioning: A Case Study”. Proceedings of the $4^{\text {th }}$ International Conference on Current and Future Trends in Bridge Design, Construction and Maintenance. 10-11 October, 2005, Kuala Lumpur, Malaysia. Thomas Telford Services Ltd, 2005.

(Turer, Korkmaz and Korkmaz 2007) Turer, Ahmet, Serra Zerrin Korkmaz and Hasan Husnu Korkmaz. "Performance Improvement Studies of Masonry Houses Using Elastic Post-Tensioning Straps." Earthquake Engineering and Structural Dynamics. 36.5 (2007) 683-705.

(Wight, Ingham and Kowalsky 2006) Wight, Gavin D., Jason M. Ingham and Mervyn J. Kowalsky. "Shaketable Testing of Rectangular Post-Tensioned Concrete Masonry Walls.” ACI Structural Journal. 103.4 (2006) 587-595. 